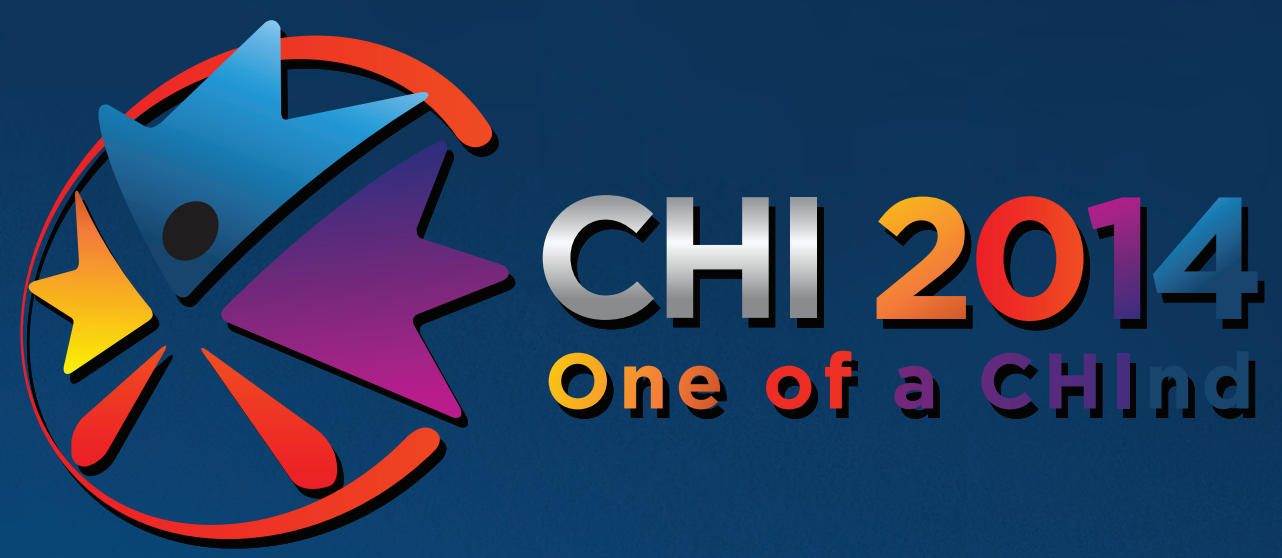

Conference Program

Toronto, Canada | April 26 - May 1, 2014

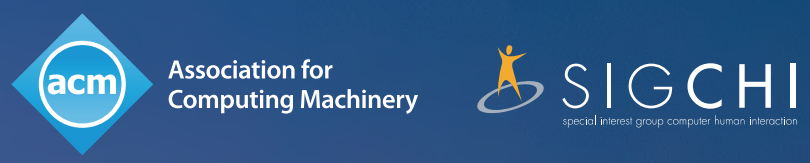

The 32nd Annual ACM Conference on Human Factors in Computing Systems

Human Factors in Computing Systems

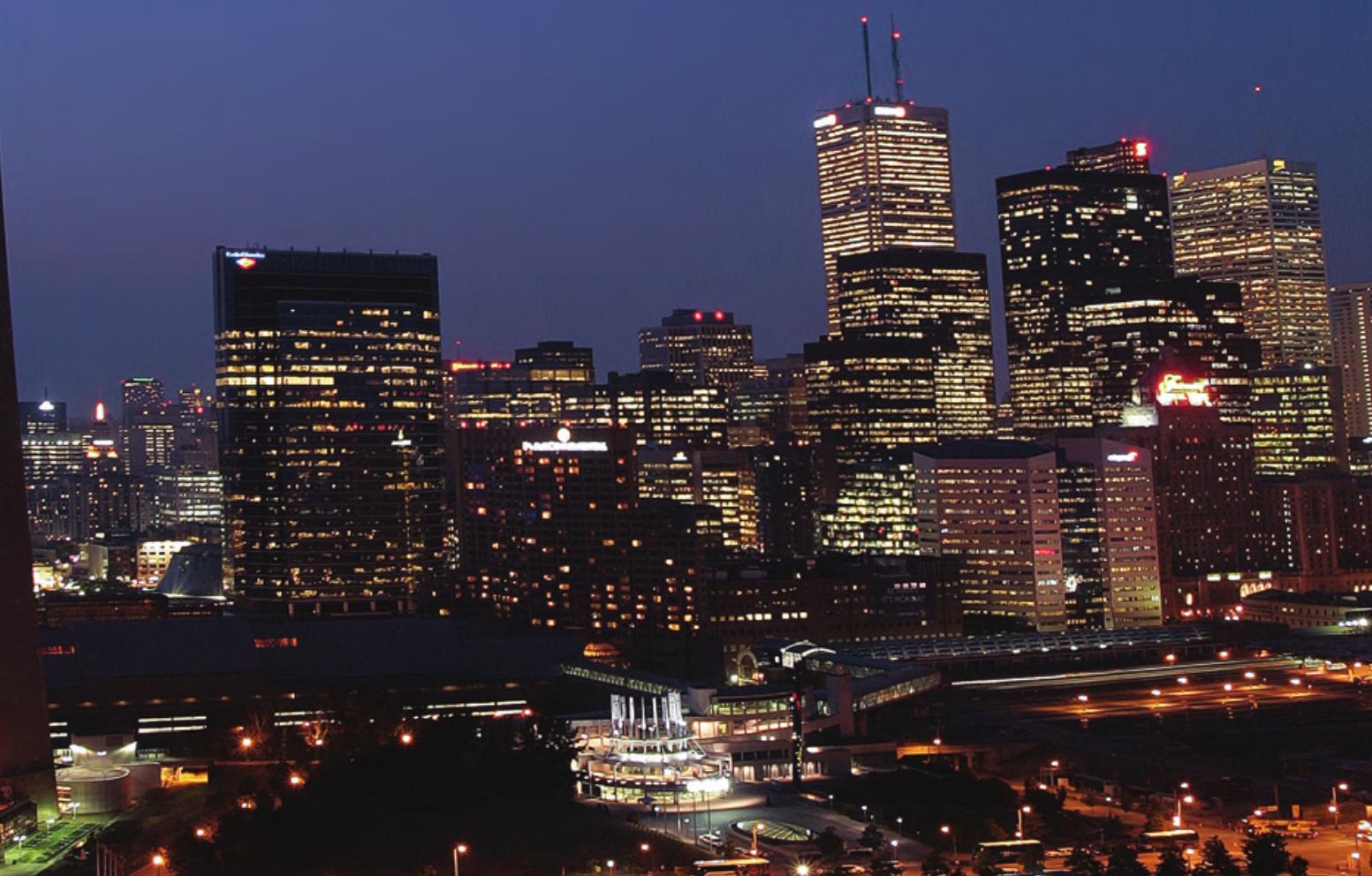




\section{Schedule of Events}

\section{MONDAY}

7:30 - 8:30
9:00 - 10:20
$10: 20-11: 00$
$11: 00-12: 20$
$12: 20-14: 00$
$14: 00-15: 20$
$15: 20-16: 00$
$16: 00-17: 20$
$17: 30-19: 30$

\section{TUESDAY}

$7: 00-8: 20$
$8: 30-8: 50$
$9: 00-10: 20$
$10: 20-11: 00$
$11: 00-12: 20$
$12: 20-14: 00$
$14: 00-15: 20$
$15: 20-16: 00$
$16: 00-17: 20$
$17: 30-19: 30$

\section{WEDNESDAY}

$$
\begin{array}{r}
7: 00-8: 20 \\
8: 30-8: 50 \\
9: 00-10: 20 \\
10: 20-11: 00 \\
11: 00-12: 20 \\
12: 20-14: 00 \\
14: 00-15: 20 \\
15: 20-16: 00 \\
16: 00-17: 20 \\
18: 00-20: 00
\end{array}
$$

\section{THURSDAY}

$$
\begin{array}{r}
7: 00-8: 20 \\
8: 30-8: 50 \\
9: 00-10: 20 \\
10: 20-11: 00 \\
11: 00-12: 20 \\
12: 20-14: 00 \\
14: 00-15: 20 \\
15: 20-16: 00 \\
16: 00-17: 20
\end{array}
$$

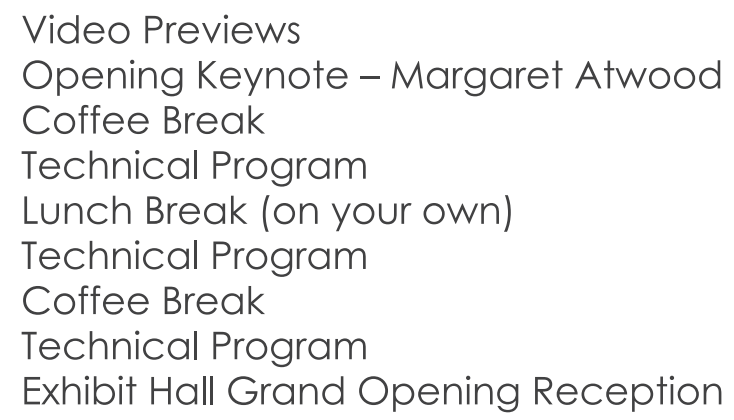

\section{Video Previews \\ Provoke! Wisdom! Impact! - Nathan Eagle \\ Technical Program \\ Coffee Break \\ Technical Program \\ Lunch Break (on your own) \\ Technical Program \\ Coffee Break \\ Technical Program \\ Job Fair | A Taste of CHI Public Night}
Video Previews
Provoke! Wisdom! Impact! - Scooter Morris
Technical Program
Coffee Break
Technical Program
Lunch Break (on your own)
Technical Program
Coffee Break
Technical Program
Hospitality Event 


\section{Welcome to $\mathrm{CHI} 2014$}
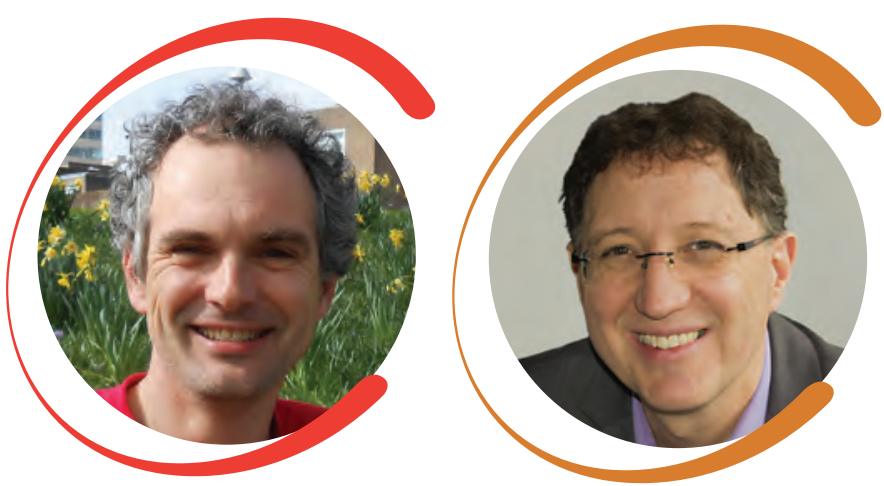

$\mathrm{CHI}$ is more than a conference, it is an international community of researchers and practitioners who want to make a difference. Everything we do is focused on uncovering, critiquing and celebrating radically new ways for people and technology to evolve together. People in their everyday contexts, in diverse regions of the world, from very different backgrounds, with alternative outlooks on life drive this innovation. As you take part in the conference sessions we really hope you will experience how powerful this people-centred approach to technological transformation can be.

$\mathrm{CHI}$ as a conference is now in its 32 nd year and has grown to become the premier international forum on human-computer interaction, gathering us all to share innovative interactive insights that shape people's lives. $\mathrm{CHI}$ draws together a multidisciplinary community from around the globe. Our great strength is our ability to bring together students and experts, researchers and practitioners, scientists, designers and engineers, drawing from their rich perspectives to create new visions of human-computer interaction.

This year's conference theme is One of a CHInd. We chose this nearly two years ago as we began planning for this event. It has helped us focus our efforts and we hope you will use it to keep your eyes open to the bigger picture amongst all the excitement, range of presentations and activities at the conference. $\mathrm{CHI} 2014$ is One of $\mathrm{CH}$ Ind because it is a celebration of the conference's one of a kind diversity; from the broad range of backgrounds of its attendees, to the diverse spectrum of communities and fields that the conference and its research have an impact on. $\mathrm{CHI} 2014$ will take place at the Metro Toronto Convention Centre in Toronto, Canada, a city itself known for its one of a kind cultural diversity. But, $\mathrm{CHI} 2014$ is more than a celebration of the diversity of our community and conference setting. We hope that this year's event, more than anything, reminds you that the "people", "participants", "users" or "humans" that you hear described throughout this week are actually uniquely wonderful individuals full of hopes, concerns, joys and frustrations. $\mathrm{CHI}$ is here to serve all of these one of a kinds.

CHI 2014 features two outstanding keynote speakers: Booker prize winning author, Margaret Atwood; and, leading UX designer, Scott Jenson. New for $\mathrm{CHI}$ 20l4, we have Provoke! Wisdom! Impact! plenary talks first thing each morning on Tuesday, Wednesday and Thursday. Come

Matt Jones, Swansea University, UK Philippe Palanque, Université Paul Sabatier, France CHI 2014 General Conference Chairs

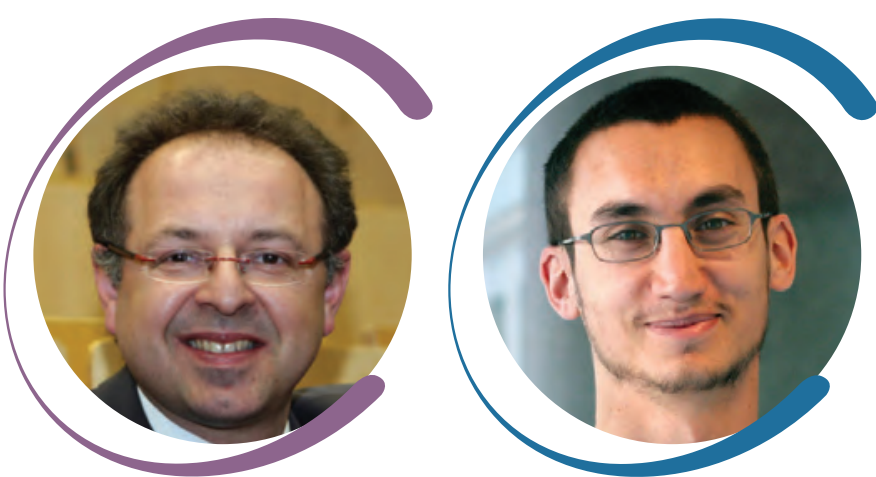

along, join the crowd and be energised by our speakers who will each bring in their experience of the Big Picture to inspire us. The talks will be short - twenty minutes - and then the rest of the day's programme will begin. We are also delighted to host a timely retrospective exhibition on wearable technology curated by Thad Starner and Clint Zeagler.

$\mathrm{CHI} 2014$ also includes two days of focused workshops and four days of technical content, including CHI's prestigious technical program, with I5 parallel sessions of rigorously reviewed research Papers, engaging Panels, Case Studies and Special Interest Groups (SIGs), an extensive Course program and invited talks from SIGCHI's award winners: Steve Whittaker, Gillian Grampton Smith and Richard Ladner. We also host student research, design, and game competitions, provocative alt.chi presentations and last-minute SIGs for discussing current topicsInteractivity hands-on demonstrations showcase the best of interactive technology. We also highlight over 24I Work-In-Progress posters: this year we have added some features to these sessions to better help you get the most out of the exciting, early stage work on show; do go along and engage with the authors about their work. Evening events include the $\mathrm{CHI} 2014$ conference reception, Sponsors and University events, local performances and the Job Fair.

We received over 3200 submissions and accepted nearly 1000 that will appear in the ACM Digital Library.To help you navigate through this immense program, there are a number of online and digital resources from the conference website to our mobile apps. You can also browse the videos, papers and extended abstracts on the CHI 2014 USB Key But, $\mathrm{CHI} 2014$ is about being in Toronto so perhaps the best way to select from and experience the event is by asking for pointers and chatting with your fellow attendees, our wonderful student volunteers, the information desk helpers or any of this year's committee. We are all here to make your experience as useful and enjoyable as possible.

We are deeply indebted to our vast number of volunteers, without whom $\mathrm{CHI} 2014$ would not be possible, including over 3800 reviewers, over 180 senior members of the program committee, nearly 100 members of the $\mathrm{CHI} 2014$ conference committee and, of course, the more than 180 student volunteers. We thank you all!

We are honored and excited by the opportunity to host $\mathrm{CHI} 20 \mathrm{I} 4$ and wish you a productive and enjoyable stay in Toronto!

Albrecht Schmidt, University of Stuttgart, Germany

Tovi Grossman, Autodesk Research, Canada

CHI 20I4Technical Program Chairs 
Conference Chairs

Matt Jones

Philippe Palanque

Swansea University, Wales, UK Université Paul Sabatier, France

Technical Program

Technical Program Chairs

Tovi Grossman

Autodesk Research, Canada

Albrecht Schmidt

University of Stuttgart, Germany

Technical Program Chair Assistant

Michael Glueck

Autodesk Research, Canada

Papers and Notes

Stephen Brewster

University of Glasgow, UK

Andy Cockburn University of Canterbrury, New Zealand

Panels

Gillian Hayes

Khai Truong

University of California, Irvine, USA

University of Toronto, Canada

Case Studies

Jonathan Arnowitz

Google, USA

Michael Arent

Austin Henderson

Rivendel Consulting, USA

Flipside, The Netherlands

Dirk-Jan Hoets

SAP, USA

Courses

Regina Bernhaupt

Elizabeth Churchill

RUWIDO, France

eBay Research Labs, USA

Interactivity

Steve Benford

Julie Rico Williamson

University of Nottingham, UK

University of Glasgow, Scotland, UK

Video Showcase

Nicolas Roussel

Inria, France

jinwook Seo

Seoul National University, South Korea

SIGs

Henry Duh

Enrico Rukzio

University OfTasmania, Australia

Ulm University, Germany

Doctoral Consortium

Katherine Isbister

Manfred Tscheligi

Workshops

Juergen Steimle

Nadir Weibel

Works in Progress

Shelly Farnham

New York University, USA

University of Salzburg, Austria

Shamsi lqbal

Shaun Lawson

Max Planck Institute, Germany

University of California, San Diego, USA

Student Research Competition

Celine Latulipe

Floyd Muller

Microsoft, USA

Microsoft, USA

University of Lincoln, USA

UNC Charlotte, USA

University in Melbourne, Australia

Student Design Competition

Youn-Kyung Lim

KAIST, Korea, Korea

Thecla Schiphorst
Student Game Competition

Alessandro Canossa

Northeastern University, USA

Seth Cooper

University of Washington, USA

alt.chi

Lilly Irani

Daniela Rosner

$\mathrm{TOCH}$ papers

Jeffrey Nichols

UC San Diego, USA

University of Washington, USA

IBM Research, USA

Best of $\mathrm{CH}$ Awards

Karyn Moffatt

Daniel Wigdor

McGill School of Information, Canada

University of Toronto, Canada

Spotlights

Spotlights Chairs

Ed Chi

Google Research, USA

Kristina Höök

Royal Institute of Technology, Swedeen

Games \& Entertainment

Magy Seif El-Nasr

Northeastern University, USA

Behavioristics, Inc, USA

Lennart Nacke University of Ontario, Canada

$\mathrm{HCl}$ For Development (HCl4D)

Ban Al-Ani

University of California - Irvine, USA

Melissa Densmore

Microsoft Research, USA

Matthew Kam

Carnegie Mellon University, USA

Interaction Science

Paul Cairns

University of York, UK

Benjamin R. Cowan

Anna L Cox

University of Birmingham, UK

University College London, UK

Anthony J. Hornof

University of Oregon, USA

Andrew Howes

Christian P. Janssen

University of Birmingham, UK

The Smith-Kettlewell Eye Research Institute USA

Stephen J. Payne

University of Oxford, UK

Peter Pirolli

Palo Alto Research Center (PARC), USA

Making Cultures

Jeffrey Bardzell

Indiana University, USA

Shaowen Bardzell

Carl DiSalvo

Ann Light

Daniela Rosner

Indiana University, USA

Georgia Institute of Technology, USA

Northumbria University, UK

University of Washington, USA

Art and Interaction

David England

Joceyn Spence

John Moores University, UK

University of Surrey, UK

Operations

Student Volunteer Coordinator Lindsay Reynolds

Cornell University, USA

Jon Haber

University of Calgary, Canada

Technology Liaison

Sara Drenner University of Minnesota-Twin Cities, USA

Scooter Morris University of California, San Francisco, USA

Webmaster

Liam Betsworth

Swansea University, Wales, UK 
Social Media

Katie Panciera

Max Wilson

University of Minnesota, USA

Nottingham University, UK

Proceedings Chairs

Stéphane Conversy

ENAC, France

Yann Riche

Marco Winckler

Microsoft, USA

Université Paul Sabatier, France

Infrastructure Accessibility Chair Jennifer Rode

Drexel University, USA

Digital Accessibility Chair Jonathan Lazar

Towson University, USA

Community Sourcing \& Scheduling

Paul André

Anant Bhardwaj

Lydia Chilton

Steven Dow

Juho Kim

Rob Miller

Haoqi Zhang

Facebook, USA

MIT, USA

University of Washington, USA Carnegie Mellon University, USA

MIT, USA

MIT, USA

Northwestern University, USA

Mobile Apps

Stephen Oney

Eiji Hayashi

Jason Wiese

Célia Martinie

Carnegie Mellon University, USA

Carnegie Mellon University, USA

Carnegie Mellon University, USA

Université Paul Sabatier, France

Video Previews

Gene Golovchinsky

Gonzalo Ramos

Fanny Chevalier

[in memory]

University of Toronto, Canada

INRIA, France

Conference Management

Janeé Pelletier Conference \& Logistics Consultants, USA

Allison Perrelli Conference \& Logistics Consultants, USA

Sponsors, Exhibits \& Recruitment

Carol Klyver

Foundations of Excellence, USA

Registration

Yvonne Lopez

Executive Events Inc., USA

Brooke Daley

Executive Events Inc., USA

PCS Liaison

Max van Kleek University of Southampton, UK

Carol Klyver

Foundations of Excellence, USA

Scooter Morris University of California, San Francisco, USA

Women's Breakfast Event

Allison Druin

University of Maryland, USA
TABLE OF CONTENTS

\section{Welcome from the Chairs}

\section{Conference Committee}

CHI 2014 Conference-at-a-Glance ................... 4

Monday-Tuesday..

Wednesday-Thursday

Notes

\section{General Information.}

About ACM/SIGCHI

$\mathrm{CHI} 2014$ Overview

CHI 2014 Proceedings and

Extended Abstracts.

Industry Day

Special Daytime and Evening Events

Opening Hours

$\mathrm{CHII}$ Information and Policies............................. 15

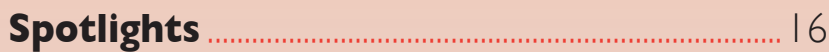

Awards

SIGCHI Awards

$\mathrm{CHI}$ Academy

Past Honorees

ACM/SIGCHI 2014 Best of CHI Awards......2I

People's Choice Best Talk Award...................... 2 I

Keynotes and Plenaries .......................................22

Sessions-at-a-Glance ................................................24

Monday .........................................................24

Tuesday ...................................................................... 30

Wednesday ...........................................................38

Thursday................................................................ 46

Workshops …………………………………………....5

Student Events ……......................................................5

Doctoral Consortium.............................................54

Research Competition ...........................................5

Design Competition .................................................55

Games Competition...............................................55

Courses ......................................................................... 56

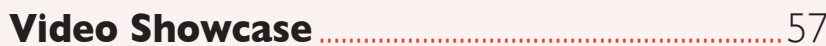

Works In Progress .......................................................58

First Rotation - Tuesday all day ..........................58

Second Rotation - Wednesday all day ...........61

Interactivity .....................................................64

Exhibits .................................................................. 67

Exhibits and Interactivity Map .......................69

Toronto Metro Centre Maps ..............................70 
7:30 - 8:30 • Video Previews (80|AB)

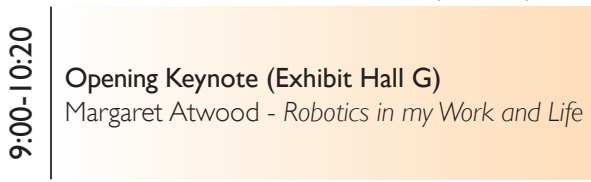

10:20 - 11:00 - Coffee Break (Level 700 Foyer)

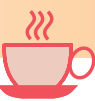

\begin{tabular}{|c|c|c|c|c|c|c|c|}
\hline $701 \mathrm{~A}$ & $701 \mathrm{~B}$ & 709 & 711 & $7 \mid 3 A B$ & $7 / 4 A B$ & $715 A$ & $716 \mathrm{~A}$ \\
\hline $\begin{array}{l}\text { Papers } \\
\text { Visualization and } \\
\text { Aesthetics }\end{array}$ & $\begin{array}{l}\text { Papers } \\
\text { Stress }\end{array}$ & & $\begin{array}{l}\text { Course } \\
\text { Designing Unbi- } \\
\text { ased Surveys for } \\
\mathrm{HCl} \text { Research }\end{array}$ & $\begin{array}{l}\text { Course } \\
\text { Sampling \& Syn- } \\
\text { thesis:The Two } \\
\text { Sides of Experi- } \\
\text { ence Sketching }\end{array}$ & $\begin{array}{l}\text { Papers } \\
\text { Social Local } \\
\text { Mobile }\end{array}$ & $\begin{array}{l}\text { SIG } \\
\mathrm{HCl} \text { in Food } \\
\text { Product Inno- } \\
\text { vation }\end{array}$ & $\begin{array}{l}\text { Panel } \\
\text { Design Methods } \\
\text { for the Future } \\
\text { that is NOW }\end{array}$ \\
\hline
\end{tabular}

12:20 - 14:00 - Lunch Break

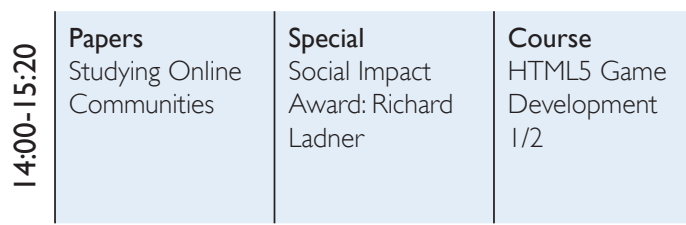

15:20 - 16:00 - Coffee Break (Level 700 Foyer)

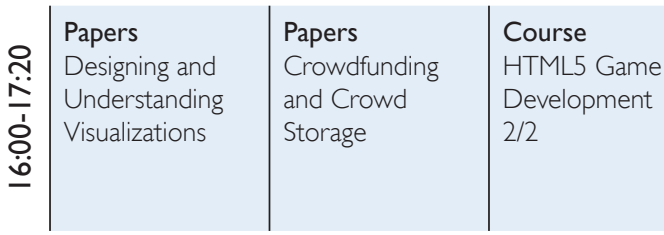

Papers

Image and Ani-

mation Authoring ethods

for $\mathrm{HCl} \mid / 2$

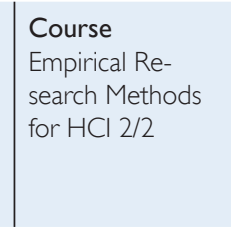

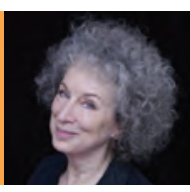

The Digital Arts

Panel

Designing for the

Experiential Body

17:30 - 19:30 • Conference Reception \& Exhibit Grand Opening • Interactivity (Exhibit Hall E)

7:00 - 8:20 • Video Previews (Exhibit Hall G) • Women's Breakfast (Exhibit Hall F)

융 Provoke! Wisdom! Impact! Plenary (Exhibit Hall G)

ᄋे Nathan Eagle - Big Data for Social Good

œ 8:50 - 9:00-Break

\begin{tabular}{|c|c|c|}
\hline $701 \mathrm{~A}$ & $70 / B$ & 709 \\
\hline $\begin{array}{l}\text { Papers } \\
\text { Interactive Visual- } \\
\text { ization and Visual } \\
\text { Elements }\end{array}$ & $\begin{array}{l}\text { Papers } \\
\text { Understanding } \\
\text { and Designing } \\
\text { Games }\end{array}$ & $\begin{array}{l}\text { Course } \\
\text { Improving the } \\
\text { User Interface } \\
\text { for People with } \\
\text { Disabilities } 1 / 2\end{array}$ \\
\hline
\end{tabular}

\begin{tabular}{|l|l|} 
7II & 7I3AB \\
Course & Course \\
Multimodal & Citizen Science: \\
Detection of Af- & An Introduction \\
fective States I/2 &
\end{tabular}

\begin{tabular}{|l|} 
7| $4 \mathrm{AB}$ \\
Papers \\
Personal Values \\
and Preferences
\end{tabular}

7I5A

SIG

Current Issues

in Assessing and

Improving Infor-

mation Usability

10:20 - I I:00 - Coffee Break • WIP Posters Rotation I - Doctoral Consortium Poster Focus (Exhibit Hall E)

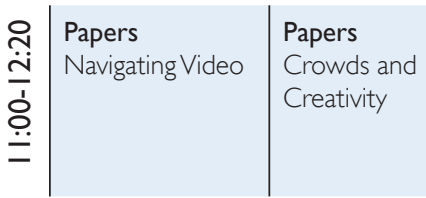

\begin{tabular}{|l|} 
Course \\
Improving the \\
User Interface \\
for People with \\
Disabilities $2 / 2$
\end{tabular}

\begin{tabular}{|l|} 
Course \\
Multimodal \\
Detection of Af- \\
fective States $2 / 2$
\end{tabular}

Course
Reflections on
Design

Papers
Interacting with
the Web

SIG

Games and

Entertainment:

Reaching beyond $\mathrm{CHI}$

\section{2:20 - 14:00 - Lunch Break}

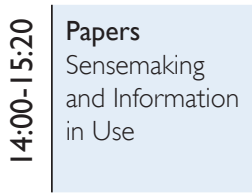

\begin{tabular}{|l} 
Special \\
Lifetime Research \\
Award: Steve \\
Whittaker
\end{tabular}
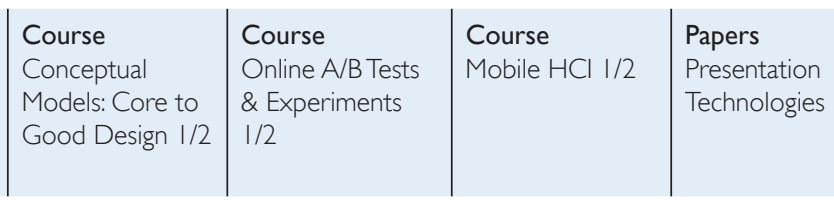

15:20 - 16:00 - Coffee Break •WIP Posters Rotation I • SDC and SRC Poster Focus (Exhibit Hall E)
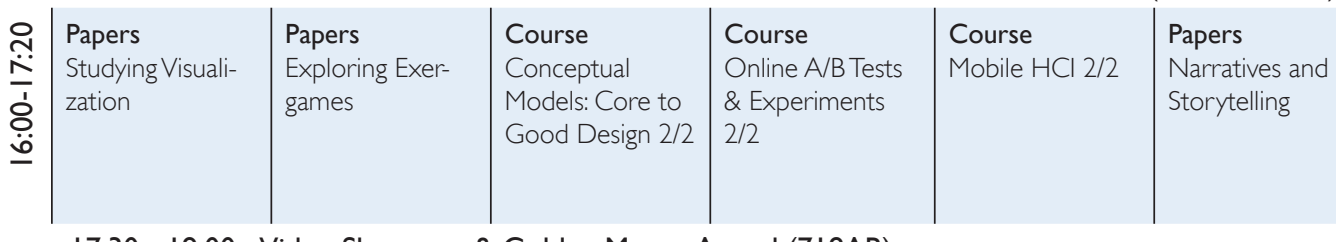

SIG

Interaction Science: Overcoming Challenges

SIG

Jogging with

Technology: In-

teraction Design

Supporting Sport

Activities

17:30 - 19:00 • Video Showcase \& Golden Mouse Award (718AB)

17:30 - 19:30 - Job Fair \& Recruiting Boards (Exhibit Hall E) 
7:30 - 8:30 • Video Previews (80IAB)

Opening Keynote (Exhibit Hall G)

Margaret Atwood - Robotics in my Work and Life

10:20 - I।:00 - Coffee Break (Level 700 Foyer)

\begin{tabular}{|c|c|c|c|c|c|c|}
\hline $716 \mathrm{~B}$ & $717 \mathrm{AB}$ & Exhibit Hall G & $718 \mathrm{AB}$ & $801 \mathrm{~A}$ & $80 I B$ & $802 A B$ \\
\hline $\begin{array}{l}\text { Papers } \\
\text { Coordination } \\
\text { and Collabora- } \\
\text { tion }\end{array}$ & $\begin{array}{l}\text { alt.chi } \\
\text { Ways of Knowing } \\
\text { in } \mathrm{HCl}\end{array}$ & $\begin{array}{l}\text { Papers } \\
\text { Watches and } \\
\text { Small Devices }\end{array}$ & $\begin{array}{l}\text { Papers } \\
\text { The Third Di- } \\
\text { mension }\end{array}$ & $\begin{array}{l}\text { Papers } \\
\text { Audio Interaction }\end{array}$ & $\begin{array}{l}\text { Papers } \\
\text { Sustainability } \\
\text { and Everyday } \\
\text { Practices }\end{array}$ & \\
\hline
\end{tabular}

I2:20 - 14:00 - Lunch Break

\begin{tabular}{|c|c|c|c|c|c|c|}
\hline $\begin{array}{l}\text { Papers } \\
\text { Studying and De- } \\
\text { signing Gameplay }\end{array}$ & $\begin{array}{l}\text { alt.chi } \\
\text { Understanding } \\
\text { Interactions }\end{array}$ & $\begin{array}{l}\text { Papers } \\
\text { Force Input and } \\
\text { Haptic Feedback }\end{array}$ & $\begin{array}{l}\text { Papers } \\
\text { Hackerspaces, } \\
\text { Making and } \\
\text { Breaking }\end{array}$ & $\begin{array}{l}\text { Papers } \\
\text { Activity Recog- } \\
\text { nition }\end{array}$ & $\begin{array}{l}\text { Papers } \\
\text { Managing Income }\end{array}$ & $\begin{array}{l}\text { Course } \\
\text { Methods of } \\
\text { Design Synthesis } \\
\text { - Moving from } \\
\text { Data to Innova- } \\
\text { tion } 1 / 2\end{array}$ \\
\hline \multicolumn{7}{|c|}{ I5:20 - 16:00 - Coffee Break (Level 700 Foyer) } \\
\hline $\begin{array}{l}\text { Papers } \\
\text { Interfaces for } \\
\text { Care and Sup- } \\
\text { port }\end{array}$ & $\begin{array}{l}\text { Papers } \\
\text { Research through } \\
\text { Design }\end{array}$ & $\begin{array}{l}\text { Papers } \\
\text { Pointing and } \\
\text { Cursors }\end{array}$ & $\begin{array}{l}\text { Papers } \\
\text { Always Connect- } \\
\text { ed: Email and } \\
\text { Social Media }\end{array}$ & $\begin{array}{l}\text { Papers } \\
\text { Smart Homes } \\
\text { and Sustainability }\end{array}$ & $\begin{array}{l}\text { Papers } \\
\text { Multilingual } \\
\text { Communication }\end{array}$ & $\begin{array}{l}\text { Course } \\
\text { Methods of } \\
\text { Design Synthesis } \\
\text { - Moving from } \\
\text { Data to Innova- } \\
\text { tion } 2 / 2\end{array}$ \\
\hline
\end{tabular}

17:30 - 19:30 • Conference Reception \& Exhibit Grand Opening • Interactivity (Exhibit Hall E)

7:00 - 8:20 • Video Previews (Exhibit Hall G) • Women's Breakfast (Exhibit Hall F)

Provoke! Wisdom! Impact! Plenary (Exhibit Hall G)

Nathan Eagle - Big Data for Social Good

\begin{tabular}{|c|c|c|c|c|c|c|}
\hline \multicolumn{7}{|c|}{ 8:50 - 9:00 - Break } \\
\hline $716 \mathrm{~B}$ & $717 A B$ & Exhibit Hall G & $718 \mathrm{AB}$ & $801 \mathrm{~A}$ & $801 \mathrm{~B}$ & $802 A B$ \\
\hline $\begin{array}{l}\text { Papers } \\
\text { Battery Life and } \\
\text { Energy Har- } \\
\text { vesting }\end{array}$ & $\begin{array}{l}\text { alt.chi } \\
\text { Ways of Creating } \\
\text { in } \mathrm{HCl}\end{array}$ & $\begin{array}{l}\text { Papers } \\
\text { Mid-Air Gestures }\end{array}$ & $\begin{array}{l}\text { Papers } \\
\text { Touch and Stylus } \\
\text { Interaction }\end{array}$ & $\begin{array}{l}\text { Papers } \\
\text { Quantified Self }\end{array}$ & $\begin{array}{l}\text { Papers } \\
\text { Sustainability } \\
\text { Perspectives }\end{array}$ & $\begin{array}{l}\text { Course } \\
\text { Card Sorting } \\
\text { for Navigation } \\
\text { Design I/2 }\end{array}$ \\
\hline
\end{tabular}

10:20 - I I:00 - Coffee Break •WIP Posters Rotation I - Doctoral Consortium Poster Focus (Exhibit Hall E)

\begin{tabular}{|c|c|c|c|c|c|c|}
\hline $\begin{array}{l}\text { Papers } \\
\text { Social Media and } \\
\text { Health }\end{array}$ & $\begin{array}{l}\text { alt.chi } \\
\text { Limits and Futures }\end{array}$ & $\begin{array}{l}\text { Papers } \\
\text { On and Above } \\
\text { the Surface }\end{array}$ & $\begin{array}{l}\text { Papers } \\
\text { Interactive White- } \\
\text { boards and Public } \\
\text { Displays }\end{array}$ & $\begin{array}{l}\text { Papers } \\
\text { Human-Robot } \\
\text { Interaction }\end{array}$ & $\begin{array}{l}\text { Papers } \\
\text { Emergency } \\
\text { Response }\end{array}$ & $\begin{array}{l}\text { Course } \\
\text { Card Sorting } \\
\text { for Navigation } \\
\text { Design } 2 / 2\end{array}$ \\
\hline
\end{tabular}

12:20 - 14:00 - Lunch Break

\begin{tabular}{|c|c|c|c|c|c|c|}
\hline $\begin{array}{l}\text { Papers } \\
\text { Personal Health } \\
\text { and Wellbeing }\end{array}$ & \begin{tabular}{|l} 
Papers \\
Design Theory
\end{tabular} & $\begin{array}{l}\text { Papers } \\
\text { Novel Keyboards }\end{array}$ & $\begin{array}{l}\text { Papers } \\
\text { DIY and Hacking }\end{array}$ & $\begin{array}{l}\text { Papers } \\
\text { User Models and } \\
\text { Prediction }\end{array}$ & $\begin{array}{l}\text { Papers } \\
\text { Engage and Edu- } \\
\text { cate Children }\end{array}$ & $\begin{array}{l}\text { Course } \\
\text { ComputerVision } \\
\text { in interaction } \\
\text { and UX I/2 }\end{array}$ \\
\hline
\end{tabular}

15:20 - 16:00 - Coffee Break •WIP Posters Rotation I • SDC and SRC Poster Focus (Exhibit Hall E)

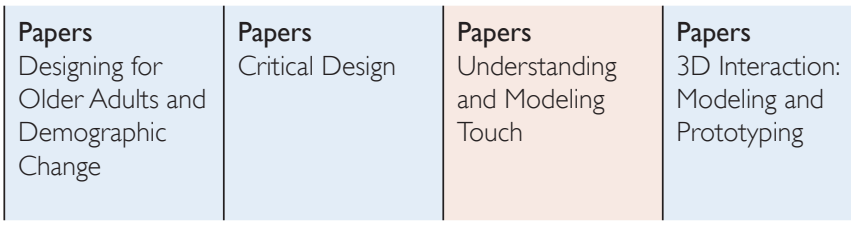

17:30 - 19:00 • Video Showcase \& Golden Mouse Award (7I8AB)

17:30 - 19:30 • Job Fair \& Recruiting Boards (Exhibit Hall E) 
ㅇํㅇ Provoke! Wisdom! Impact! Plenary (Exhibit Hall G)

Oे Scooter Morris - A CHI Story - Past, Present, and the Next Chapters

$\infty \quad 8: 50$ - 9:00 - Break

\begin{tabular}{|c|c|c|c|c|c|c|c|}
\hline $701 \mathrm{~A}$ & $701 \mathrm{~B}$ & 709 & 711 & $7 \mid 3 A B$ & $7 \mid 4 A B$ & $715 A$ & $716 \mathrm{~A}$ \\
\hline $\begin{array}{l}\text { Papers } \\
\text { Telepresence and } \\
\text { Connecting over } \\
\text { Video }\end{array}$ & $\begin{array}{l}\text { Papers } \\
\text { Exergame Design }\end{array}$ & $\begin{array}{l}\text { Course } \\
\text { Rapid Design } \\
\text { Labs-A Tool } \\
\text { to Turbocharge } \\
\text { Design-Led } \\
\text { Innovation I/2 }\end{array}$ & $\begin{array}{l}\text { Course } \\
\text { Agile User } \\
\text { Experience and } \\
\text { UCD I/2 }\end{array}$ & $\begin{array}{l}\text { Course } \\
\text { How social media } \\
\text { design reshapes } \\
\text { society }\end{array}$ & $\begin{array}{l}\text { Papers } \\
\text { Designing } \\
\text { and Modeling } \\
\text { GUls }\end{array}$ & & $\begin{array}{l}\text { SIG } \\
\text { Child Computer } \\
\text { Interaction:To- } \\
\text { wards Sustainable } \\
\text { Thinking \& Being }\end{array}$ \\
\hline
\end{tabular}

10:20 - I I:00 - Coffee Break •WIP Posters Rotation 2 - SGC (Exhibit Hall E)

\begin{tabular}{|c|c|c|c|c|}
\hline $\begin{array}{l}\text { Papers } \\
\text { Understanding } \\
\text { and Using Social } \\
\text { Media }\end{array}$ & $\begin{array}{l}\text { Papers } \\
\text { Working Together }\end{array}$ & $\begin{array}{l}\text { Course } \\
\text { Rapid Design } \\
\text { Labs-A Tool } \\
\text { to Turbocharge } \\
\text { Design-Led } \\
\text { Innovation 2/2 }\end{array}$ & $\begin{array}{l}\text { Course } \\
\text { Agile User } \\
\text { Experience and } \\
\text { UCD } 2 / 2\end{array}$ & \begin{tabular}{|l} 
Course \\
Designing for \\
Seniors
\end{tabular} \\
\hline
\end{tabular}

\begin{tabular}{l|l} 
Papers & \\
Programming and & \\
Development & \\
Tools & th
\end{tabular}

SIG

The Usability of Text Entry Systems Now and in the Future

Panel

Making Cultures: Empowerment,

Participation, and Democracy - or Not?

12:20 - 14:00 - Lunch Break • SIGCHI Town Hall Lunch (7I8AB) • SGC (Exhibit Hall E)

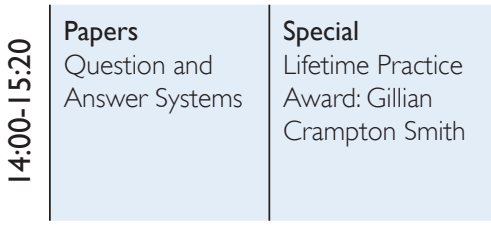

\begin{tabular}{l|l} 
Course & Course \\
Introduction to & Including Children \\
Designing and & in Technology \\
Building Musical & Design Processes \\
Interfaces $1 / 2$ & $1 / 2$
\end{tabular}

\begin{tabular}{l|} 
Course \\
Interaction \\
Design for Online \\
Video and Televi- \\
sion $1 / 2$
\end{tabular}

\begin{tabular}{|l} 
Papers \\
Cross-Device \\
Interaction
\end{tabular}

SIG

Community Centered Collaborative $\mathrm{HCl}$ in Developing Countries

15:20 - 16:00 - Coffee Break • WIP Posters Rotation 2 (Exhibit Hall E)

Course
Interaction
Design for Online
Video and Televi-
sion $2 / 2$

Papers

Decisions, Recommendations, and Machine Learning
SIG

Interactions Magazine
Panel

CROWDFUND-

ING: An Emerging

Field of Research

18:00 - 20:00 - Joint Hospitality Reception (Mattamy Athletic Centre)
Panel

The Meaning

of Design in Healthcare

\begin{tabular}{|c|c|c|c|}
\hline $\begin{array}{l}\text { Papers } \\
\text { Journalism and } \\
\text { Social News }\end{array}$ & \begin{tabular}{|l} 
Papers \\
Interruptions and \\
Distractions
\end{tabular} & \begin{tabular}{|l} 
Course \\
Introduction to \\
Designing and \\
Building Musical \\
Interfaces $2 / 2$
\end{tabular} & $\begin{array}{l}\text { Course } \\
\text { Including Children } \\
\text { in Technology } \\
\text { Design Processes } \\
2 / 2\end{array}$ \\
\hline
\end{tabular}

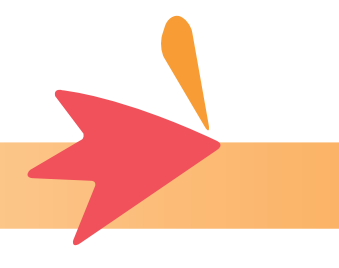

7:00 - 8:20 • Video Previews (Exhibit Hall G)

Provoke! Wisdom! Impact! Plenary (Exhibit Hall G)

Elizabeth F. Churchill - Reasons to be Cheerful, Part 4

œ 8:50 - 9:00 - Break

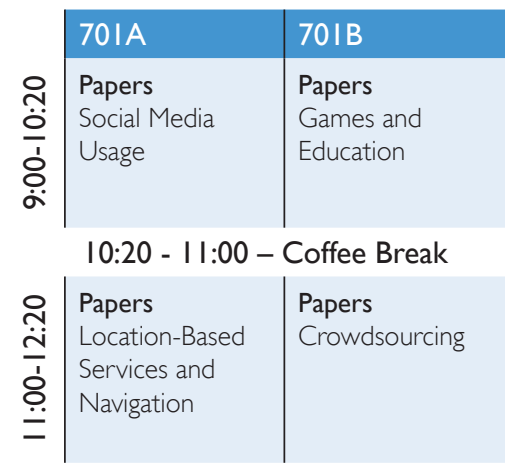

709

711
Course
Speech-based
Interaction I/2

\begin{tabular}{|l|} 
7I $3 \mathrm{AB}$ \\
Course \\
The Glass Class: \\
Designing Weara- \\
ble Interfaces I/2
\end{tabular}

\begin{tabular}{|l} 
7I $4 \mathrm{AB}$ \\
Papers \\
Learning and \\
Games
\end{tabular}

\begin{tabular}{|l} 
7I 5 A \\
SIG \\
Managing UX \\
Teams
\end{tabular}

\section{$716 \mathrm{~A}$}

Case studies

Realities of

Fieldwork

Designing Weara-
Course

Speech-based Interaction $2 / 2$

Course

The Glass Class:

ble Interfaces $2 / 2$

Papers

Desktop Search and History

12:20 - 14:00 - Lunch Break

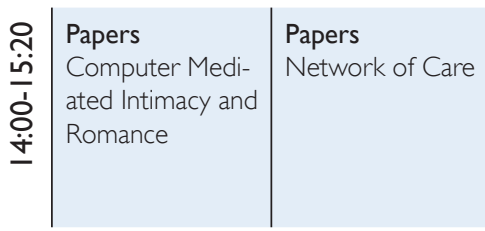

15:20 - 16:00 - Coffe Break

옳
Course

How You Could Benefit from Using ISO Standards

\section{Course}

Evaluating Children's Interactive Products

\section{Closing Keynote (Exhibit Hall G)}

Scott Jenson - The Physical Web with Susan Dray

Papers
SIG

Communicating User Research to Drive Design and Product Decisions
Panel

Can You Do

Good and Do

Well? Exploring

Development
$\mathrm{HCl}$ Careers in
Case studies Cross-Perspective Collaboration
Case studies Creating Methods . 
7:00 - 8:20 • Video Previews (Exhibit Hall G)

Provoke! Wisdom! Impact! Plenary (Exhibit Hall G)

Scooter Morris - A CHI Story - Past, Present, and the Next Chapters

8:50 - 9:00 - Break

\begin{tabular}{|c|c|c|c|c|c|c|}
\hline $716 \mathrm{~B}$ & $717 A B$ & Exhibit Hall G & $718 A B$ & $801 \mathrm{~A}$ & $80 I B$ & $802 A B$ \\
\hline $\begin{array}{l}\text { Papers } \\
\text { Health and } \\
\text { Everyday Life }\end{array}$ & $\begin{array}{l}\text { alt.chi } \\
\text { Navel Gazing }\end{array}$ & $\begin{array}{l}\text { Papers } \\
\text { Text Entry and } \\
\text { Evaluation }\end{array}$ & $\begin{array}{l}\text { Papers } \\
\text { Emotions and } \\
\text { Mobiles }\end{array}$ & $\begin{array}{l}\text { Papers } \\
\text { Privacy }\end{array}$ & $\begin{array}{l}\text { Papers } \\
\text { Issues That Matter }\end{array}$ & $\begin{array}{l}\text { Course } \\
\text { HCI Meets Data } \\
\text { Mining: Principles } \\
\text { and Tools for Big } \\
\text { Data Analytics } \\
\text { I/2 }\end{array}$ \\
\hline
\end{tabular}

I0:20 - I I:00 - Coffee Break •WIP Posters Rotation 2 • SGC (Exhibit Hall E)

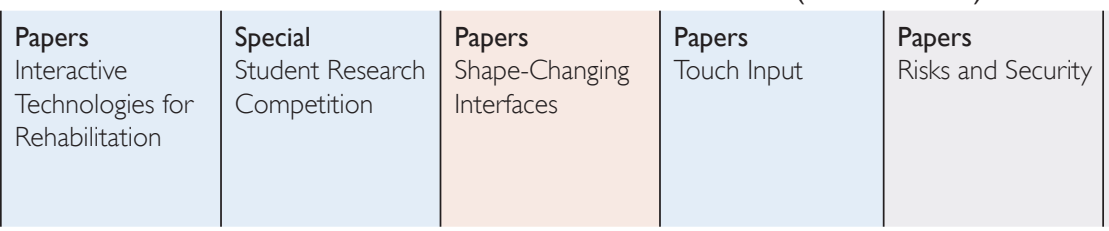

\begin{tabular}{l|l|} 
Papers & Course \\
CHI for Social & HCl Meets Data \\
Development & Mining: Principles \\
& and Tools for Big \\
& Data Analytics \\
& $2 / 2$
\end{tabular}

I2:20 - |4:00 - Lunch Break • SIGCHI Town Hall Lunch (7I8AB) • SGC (Exhibit Hall E)
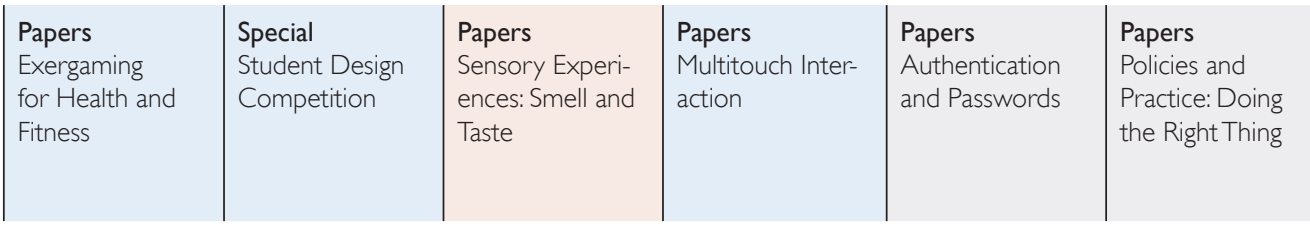

Course

Make This!

Introduction

to Electronics

Prototyping Using

Arduino I/2

15:20 - 16:00 - Coffee Break •WIP Posters Rotation 2 (Exhibit Hall E)

\begin{tabular}{|l|l|l|l|} 
Papers & Special & Papers & Papers \\
Accessibility & Student Game & Tangible & Head-Worn \\
& Competition & Interactions and & Displays \\
& Technologies & \\
& &
\end{tabular}

\begin{tabular}{l|l} 
Papers & \\
Applications of & \\
Body Sensing &
\end{tabular}

Papers
Urban Commu-
nities and Social
Media

\section{Course}

Make This!

Introduction

to Electronics

Prototyping Using

Arduino 2/2

18:00 - 20:00 - Joint Hospitality Reception (Mattamy Athletic Centre)

7:00 - 8:20 • Video Previews (Exhibit Hall G)

Provoke! Wisdom! Impact! Plenary (Exhibit Hall G)

Elizabeth F. Churchill - Reasons to be Cheerful, Part 4

8:50 - 9:00 - Break

\begin{tabular}{|c|c|c|c|c|c|c|}
\hline $716 \mathrm{~B}$ & $717 \mathrm{AB}$ & Exhibit Hall G & $718 \mathrm{AB}$ & $801 \mathrm{~A}$ & $801 \mathrm{~B}$ & $802 A B$ \\
\hline $\begin{array}{l}\text { Papers } \\
\text { Persuasive } \\
\text { Technologies and } \\
\text { Applications }\end{array}$ & $\begin{array}{l}\text { alt.chi } \\
\text { Intimate Inter- } \\
\text { faces }\end{array}$ & $\begin{array}{l}\text { Papers } \\
\text { Whole Body } \\
\text { Sensing and } \\
\text { Interaction }\end{array}$ & $\begin{array}{l}\text { Papers } \\
\text { Novel Mobile Dis- } \\
\text { plays and Devices }\end{array}$ & $\begin{array}{l}\text { Papers } \\
\mathrm{HCl} \text { Paradigms: } \\
\text { Past, Present and } \\
\text { Future }\end{array}$ & $\begin{array}{l}\text { Papers } \\
\text { PolitiCHI }\end{array}$ & $\begin{array}{l}\text { Course } \\
\text { Hands-on Sketch- } \\
\text { ing Course I/2 }\end{array}$ \\
\hline
\end{tabular}

10:20 - I 1:00 - Coffee Break

\begin{tabular}{|l|l|} 
Papers & Papers \\
Lost and Found in & Participatory \\
Translation & Design \\
&
\end{tabular}

\begin{tabular}{|l|l|} 
Papers & Papers \\
Brain Computer & 3D Printing and \\
Interfaces & Fabrication \\
&
\end{tabular}

Papers

Modeling Users and Interaction

12:20 - 14:00 - Lunch Break

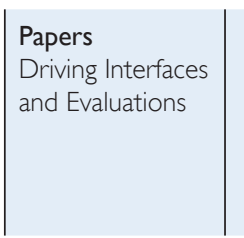

I5:20 - 16:00 - Coffee Break

Closing Keynote (Exhibit Hall G)

Scott Jenson - The Physical Web
Course

Hands-on Sketching Course 2/2
Technology

\section{Papers}

Social Media for

Relationships

\section{Course}

Modern Geog-

raphy for $\mathrm{HCl}$

Researchers and

Practitioners .

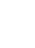




\section{As a proud}

Champion Sponsor,

Autodesk welcomes

CHI 2014

to Toronto

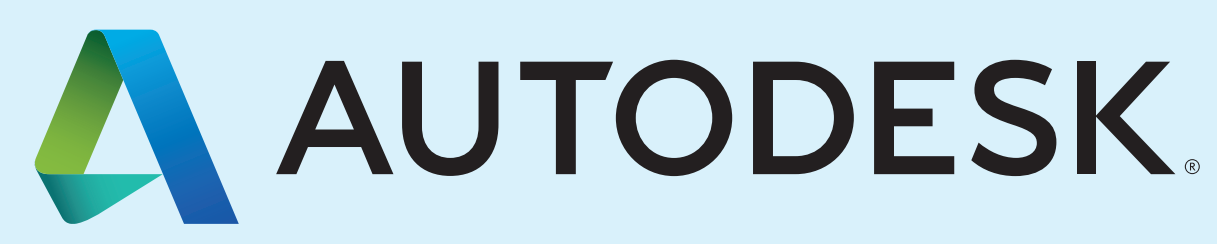




\section{Microsoft}

\section{Computers alone can't change the world. But people and computers? Yes.}

Come pay us a visit. Chat with employees and recruiters about careers at Microsoft. Talk with $\mathrm{CHI}$ presenters and authors.

Great swag, the latest UX/HCl Microsoft research demos, and $\mathrm{Xbox}$ and large-screen games. Enter a raffle to win an Xbox One.

Visit us at booths $3,4 \& 5$

Joint Hospitality Reception

Mattamy Athletic Centre, 50 Carlton Street, Toronto

Wednesday, April 30th 6pm-8pm

Microsoft is a CHI Champion Sponsor Host 


\section{ACM SIGCHI}

$\mathrm{CHI} 2014$ is sponsored by ACM's Special Interest Group on ComputerHuman Interaction (ACM SIGCHI). ACM, the Association for Computing Machinery, is an educational and scientific society uniting the world's computing educators, researchers, and professionals to inspire dialogue, share resources, and address the field's challenges. ACM strengthens the profession's collective voice through strong leadership, promotion of the highest standards, and recognition of technical excellence. ACM supports the professional growth of its members by providing opportunities for life-long learning, career development, and professional networking. ACM offers its more than 100,000 worldwide members cutting edge technical information through world class journals and magazines, dynamic special interest groups, and globally recognized conferences. Visit www.acm.org for more information about ACM.

$\mathrm{SIGCHI}$ is the premier international society for professionals, academics, and students who are interested in human-computer interaction $(\mathrm{HCl})$. We provide a forum for the discussion of all aspects of $\mathrm{HCl}$ through our conferences, including our flagship $\mathrm{CHI}$ conference, publications, web sites, email discussion groups, and other services. We advance education in $\mathrm{HCl}$ through courses, workshops, and outreach, and we promote informal access to a wide range of individuals and organizations involved in $\mathrm{HCl}$. Members can be involved in $\mathrm{HCl}$-related activities with others in their region through local SIGCHI chapters. Come to the SIGCHITown Hall meeting on Wednesday at 12:20 in Room 7I 8AB or visit www.sigchi.org to learn more about $\mathrm{SIGCHI}$.

\section{Membership Information}

Please contact ACM's Member Services Department

$\begin{array}{ll}\text { Online: } & \text { www.acm.org } \\ \text { Tel: } & +\mid-800-342-6626 \quad \text { (USA/Canada) } \\ & +\mid-212-626-0500 \text { (International) } \\ \text { Fax: } & +|-2| 2-944-1318 \\ \text { Email: } & \text { acmhelp@acm.org } \\ \text { Write: } & \text { Association for Computing Machinery, Inc. } \\ & \text { General Post Office } \\ & \text { P.O. Box 30777 New York, NY } \\ & \text { I0087-0777, USA }\end{array}$

\section{CHI 2014 OVERVIEW}

The $\mathrm{CHI} 2 \mathrm{O} / 4$ technical program showcases presentations of outstanding research in human-computer interaction $(\mathrm{HCl})$, demonstrations of new and innovative technology, discussions of timely and controversial issues, and presentations of the latest developments in $\mathrm{HCl}$ design and practice. The $\mathrm{CHI}$ technical program includes presentations in multiple formats, recorded in the $\mathrm{CHI} 2014$ Proceedings and Extended Abstracts available from the ACM Digital Library and on the CHI 2014 USB key.

INVITATION-ONLY | SATURDAY-SUNDAY
Doctoral Consortium Room 7/ I
Selected doctoral students present and explore their research topics
with senior researchers and other students in a two-day interdisciplinary
workshop. Doctoral Consortium posters are displayed in the Commons
and brief descriptions appear in the CHI 20 I 4 Extended Abstracts.

Doctoral Consortium Faculty:

Bill Buxton, Adrian Cheok, Kristina Höök, Katherine Isbister (Co-Chair), Yvonne Rogers, Manfred Tscheligi (Co-Chair)
Workshops

Level 700 and Level 800

Workshops provide a valuable opportunity for small communities of people with diverse perspectives to engage in rich one- and two-day discussions about a topic of common interest. Workshop participants are pre-selected based on submitted position papers and a brief description of each workshop appears in the CHI 2014 Extended Abstracts. Some workshops choose to display a poster in the Exhibit Hall E Poster Area.

\section{TECHNICAL PROGRAM | MONDAY — THURSDAY}

$\mathrm{CHI} 2014$ received over 3200 submissions and accepted over 1000 presentations and events distributed across 15 parallel sessions over four days. With so many presentations happening at once, how do you choose? $\mathrm{CHI} 20 \mathrm{I} 4$ offers the following resources to help you make the most of your conference experience:

\section{Choosing sessions to attend}

I. This $\mathrm{CHI} \mathrm{2014}$ Conference Program describes the venues and offers at-a-glance summaries of all events in the main technical program, as well as times and locations.

2. The CHI 2014 USB key provided when you register includes the $\mathrm{CHI} 2014$ Conference Proceedings and Extended Abstracts, also available in the ACM Digital Library, and the CHI 2014 Video Previews (see below). Extra USB keys are available for purchase at the Registration Desk.

3. The free $\mathrm{CHI} 2014$ Mobile App contains the full $\mathrm{CHI} 2014$ program as well as a personal interactive schedule to help you keep track of events you would like to see. The $\mathrm{CHI} 2014$ Proceedings and Extended Abstracts as well as Video Previews (below) can be loaded into the Mobile App for easy access. That app can be downloaded from Apple's App Store and Google Play. A web version can be accessed at: http://chi20 I4.acm.org/mobileapp.

4. The CHI 20I4 Video Previews are 30-second video overviews of most presentations in the main technical program. Daily preview sessions will be held Monday in room 80IAB from 7:30am to 8:30am, Tue - Thu from 7:00am to 8:20am in Exhibit Hall G. You can also browse Video Previews on the CHI 2014 USB, the $\mathrm{CHI} 2014$ web site and the CHI2OI4 Mobile App. You can also watch them on the $\mathrm{CHI} 2014$ Interactive Display (below).

5. The large-screen, high resolution, $\mathrm{CHI} 2014$ Interactive Display will use the Paper Forager system to allow attendees to browse through and view all 4276 papers and notes ever published at $\mathrm{CHI}$ conference. You can search and filter the collection by keywords or authors, and view any individual paper full-screen to read the content. For $\mathrm{CHI} 20 \mathrm{I} 4$ papers, you can watch the video preview for each submission, and trace it's citation network back to the past $\mathrm{CHI}$ papers which it cites.

6. $\mathrm{CHI} 2014$ Student Volunteers (SVs) are available to point you in the right direction or answer questions about the program. 


\section{CHI 2014 CONFERENCE PROCEEDINGS}

The CHI 2014 Conference Proceedings contain Papers and Notes, the most rigorously reviewed and prestigious material in the main technical program. The $\mathrm{CHI} 2014$ Program Committee received over 2000 submissions for Papers and Notes. Each was reviewed by one or more Associate Chairs, as well as three or more external reviewers. After a rebuttal phase, the $200+$ senior Associate Chairs met in person within specialized subcommittees to discuss and select the accepted papers. The $\mathrm{CHI} 2014$ acceptance rate was 23\%.

The $\mathrm{CHI} 2014$ Papers and Notes document research that makes a lasting and significant contribution to our knowledge and understanding of human-computer interaction. $\mathrm{CHI}$ Conference Proceedings are read and cited worldwide, with a broad impact on the development of $\mathrm{HCl}$ principles, theories, techniques, and their practical application.

\section{$\mathrm{CHI}$ Papers}

20-minute presentations

Papers present significant contributions to research, development, and practice in all areas of human-computer interaction.

\section{$\mathrm{CHI}$ Notes}

10-minute presentations

Notes are briefer and more focused than $\mathrm{CHI}$ Papers but follow the same rigorous review process.

\section{TOCHI Papers}

20-minute presentations

TOCHI papers were published within the past year in SIGCHI's flagship journal, ACM Transactions on Computer-Human Interaction.

\section{CHI 2014 EXTENDED ABSTRACTS}

The $\mathrm{CHI} 2014$ Extended Abstracts record interactive events designed to provoke, intrigue, teach and inspire the $\mathrm{CHI}$ audience and capture a history of $\mathrm{HCl}$ practice.

\section{Courses}

Rooms 709, 7II, 7I3AB, 802AB

One or two 80-minute units

List on page 56

Courses provide professional development opportunities for existing and prospective $\mathrm{HCl}$ community members. This year, $\mathrm{CHI}$ is pleased to also offer six "One of a CHInd Courses". These are special invited courses that will be given by distinguished members of the $\mathrm{HCl}$ community. Pre-register to receive the course notes and an identifier on your badge that permits entry to the course. You may register for any unfilled courses at the Registration Desk

\section{Case Studies}

Room 7I6A

20-minute presentations

Case Studies describe examples of best practices in human-computer interaction. The goal is to explain methods that deliver reliable, highquality results based on real-world experience and to present the lessons learned.

Panels

Room 7I6A

80-minute sessions

Panels take various formats but always involve significant interaction among panelists and audience members around a specified topic. The goal is to stimulate thought and discussion on current issues in humancomputer interaction. alt.chi

Room 7I7AB

20-minute presentations

alt.chi offers an outlet for unusual, controversial, alternative or thoughtprovoking work that does not fit within the standard $\mathrm{CHI}$ submission process. The format encourages lively audience participation.

Special Interest Groups (SIGs)

Rooms 7I5A and 7I6A 80-minute sessions

SIGs offer a forum for conference attendees who share similar interests to discuss a specified topic. Previous SIGs have launched new conferences and publications or generated new $\mathrm{CHI}$ activities.

\section{Video Showcase}

Room $7 / 8 A B$

80-minute session

List on page 57

The Video Showcase features engaging videos that offer a variety of perspectives on human-computer interaction, including novel interfaces, reflective pieces and future envisionments. Come and enjoy the videos on Tuesday (17:30) followed by the Golden Mouse award ceremony.

\section{Interactivity}

Exhibit Hall E

Hands-on demonstrations

List on page 64

Interactivity offers hands-on demonstrations that let you see, hear and touch interactive visions of the future. They take the form of prototypes, demonstrations, artworks, design experiences and inspirational technologies. Interactivity offers an alternative to CHI's traditional text format to disseminate advances in the field. Interactivity promotes and provokes discussion about the role of technology by actively engaging attendees one-on-one. Come see Interactivity at the CHI 20I4 Conference Reception and Exhibits Grand Opening (Monday 17:30 - 19:30 Exhibit Hall E) and during coffee breaks.

Works in Progress (WIP)

Exhibit Hall E Posters List on page 58

Works in Progress present work at an early stage that can benefit from one-on-one discussions with colleagues. WIP Posters will be displayed in two rotations; the first rotation on Tuesday (29th April) and the second on Wednesday (30th April). Each rotation contains a number of themed clusters. Morning and afternoon coffee breaks on Tuesday and Wednesday are designated sessions during which WIP authors will be available at their posters to informally discuss their research with colleagues. These sessions will also feature some structured interactive activities where authors will pitch their work; do please come along and support them in doing this! Finally, watch out for WIP mini-presentations on the $\mathrm{CHI}$ YouTube channel!

\section{Doctoral Consortium}

Exhibit Hall E Posters List on page 54

Doctoral Consortium students are available to discuss their research in the DC Spotlight session Tuesday during morning coffee break $(10: 20-11: 00)$

\section{Student Research Competition}

Posters and 80-minute session

List on page 54

The Student Research Competition (SRC) is a branch of the ACM Student Research Competition. Monday 16:00 - 17:20 (Room 7I5B) is the Judging session (jury \& competitors only). Students' posters are on display in Exhibit Hall E with author presentations during Tuesday's afternoon break (15:20-16:00). Final presentations are held on Wednesday 1 1:00 - 12:20 in 717AB. Winners are announced at the Closing Plenary. 


\section{Student Design Competition}

Posters and 80-minute session

List on page 55

The Student Design Competition (SDC) challenges students to design an object, interface, system, or service related to bodydata: the qualities of the quantified self. Monday 1 1:00 - 12:20 (Room 7I5B) is the Judging session (jury \& competitors only). Semi-finalist posters are displayed in Exhibit Hall E poster area and authors will be presenting their work to all attendees during Tuesday's afternoon break (15:20 - 16:00). The SDC jury selects four finalists to present on Wednesday 14:00 - 15:20 in 7I7AB. The winner is announced at the Closing Plenary.

\section{Student Game Competition}

Demonstrations and 80-minute session

List on page 55

The Student Game Competition (SGC) challenges students to design games in three categories: Games for a Purpose, Innovative Interface, and Innovative Game Design. Students demonstrate their games on Wednesday (10:00 - 14:00, Exhibit Hall E). The final presentations and ceremony is held on Wednesday (16:00 - 17:20, Room 7I7AB). Winners are also announced at the Closing Plenary.

\section{INDUSTRY DAY}

Thursday, 8:30 - 17:20

$\mathrm{CHI}$ has always been a dynamic, vibrant community that mixes up academic researchers with those in industry and others who at the cutting edge of practice. This year, as well as the leading research papers, we have highlights especially attractive to those who do $\mathrm{CHI}$ out there, 'in the wild'!

We have designated Thursday as our Industry Focused Day. Come along and hear and see:

- $\quad$ Plenary talk to open the day by Elizabeth Churchill, e-Bay

- Conference closing Keynote from Scott Jenson, Google

- A conversation with Susan Dray, leading practitioner who has worked with many large clients, worldwide

- Hands-on courses covering topics as diverse as speech systems, prototyping in arduino and sketching for design

- A Special Interest Group session on managing UX teams

- Case studies from companies including SAP, Naver, Sandvik and Leadin, Google and NASA

\section{Suggested Sessions}

\begin{tabular}{|c|c|c|}
\hline $8: 30-8: 50$ & Plenary: Reasons to be Cheerful, Part 4 & (Exhibit Hall G) \\
\hline $9: 00-10: 20$ & Papers: HCl Paradigms: Past, Present and Future & $(80 \mid A)$ \\
\hline $0-10: 20$ & SIG: Managing UXTeams & $(7 \mid 5 \mathrm{~A})$ \\
\hline $0-10: 20$ & Case Studies: Realities of Fieldwork & $(7 \mid 6 \mathrm{~A})$ \\
\hline $0-12: 20$ & $\begin{array}{l}\text { SIG: Communicating User Research to } \\
\text { Drive Design and Product Decisions }\end{array}$ & $(7 \mid 5 A)$ \\
\hline$: 00-12: 20$ & Case Studies: Cross-Perspective Collaboration & $(7 \mid 6 A)$ \\
\hline$: 00-12: 20$ & Papers: Participatory Design & $(7 \mid 7 A B)$ \\
\hline $00-15: 20$ & $\begin{array}{l}\text { Panel: Can You Do Good and Do Well? } \\
\text { Exploring } \mathrm{HCl} \text { Careers in Development }\end{array}$ & $(7 \mid 5 A)$ \\
\hline $0-15: 20$ & Case Studies: Creating Methods & $(7 \mid 6 \mathrm{~A})$ \\
\hline $0-15: 20$ & Course: A Conversation with Susan Dray & $(7 \mid 3 A B)$ \\
\hline $0-15$ & Papers: Research and Deployment in the Wild & $(80 \mid A)$ \\
\hline $0-1$ & Closing Keynote: The Physical Web & (Exhibit Hall \\
\hline
\end{tabular}

\section{SPECIAL DAYTIME EVENTS}

ACM SIGCHI Town Hall Lunch

Wednesday, 12:20 - 14:00

Room 7/8AB

SIGCHI officers present ongoing programs and activities, followed by an audience Q\&A session. Participants interested in shaping SIGCHI's future are encouraged to attend. An informal lunch is available on a first-come, first-served basis.

\section{Video Previews}

Monday: 7:30 - 8:30 Room 80IAB

Tue-Thu: 7:00 - 8:20 in Exhibit Hall G

For the early risers! Plan your daily schedule by viewing the 30 second Video Previews for the current day. The video previews for the current day's Papers and Notes will be played through, in a single, back-to-back, playlist.

\section{Wearable Computing Exhibit \\ Monday 14:00-19:00 \\ Tuesday 10:00-19:30 \\ Wednesday 10:00-17:20 \\ Thursday 10:00-13:00}

In the July 200I issue of IEEE Micro Thad Starner laid out the major challenges of wearable computing. The challenges included Power, Networking, and Interface. In the past 13 years we have come a long way in meeting some of these challenges. Using Thad Starner's extensive collection of on-body and wearable devices we are forming an educational and interactive exhibition to showcase the strides made in wearable computing. We will use this exhibition to present the evolution of electronic textiles, advances in battery life, on-body interfaces, and head mounted displays.

\section{Women's Breakfast}

Exhibit Hall F

Tuesday, 7:00 - 8:30

This breakfast offers participants the opportunity to broaden personal professional networks in the field of $\mathrm{HCl}$ and to engage in discussions on such topics as mentoring networks, work-life balance, diverse success paths, and personal-branding. During this program participants share their stories of success and challenge which can inspire $\mathrm{CHI}$ women who may be longtime leaders or new to the field. 


\section{GENERAL INFORMATION}

\section{SPECIAL EVENING EVENTS}

Conference Reception

\& Exhibits Grand Opening
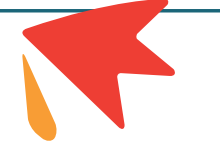

\section{Exhibit Hall E}

Monday, 17:30 - 19:30

Catch up with old friends and meet new ones at the $\mathrm{CHI} 2014$ Conference Reception! Explore almost 70 hands-on demonstrations and performances at the Grand Opening of Exhibits and Interactivity. The reception features Canadian themed food choices, local beer and live performances! Admission and drinks tickets are included with your conference registration; additional tickets may be purchased at Registration Desk. Tickets are not available at the door.

Job Fair \& Recruiting Boards

Exhibit Hall E Tuesday, 17:30 - 19:30

Recruiters and job candidates are invited to take advantage of the $\mathrm{CHI} 2014$ Job Fair on Tuesday evening. Visit the Recruiting Boards and designated exhibit booths throughout the conference to find out more about available positions.

\section{CHI 2014 Champion Sponsor Recruiters:}

$\begin{array}{lll}\text { Bloomberg } & \text { Booths } 6-7 & \text { Recruiting Board } \\ \text { Google } & \text { Booths } 14-15 & \text { Recruiting Board } \\ \text { Microsoft } & \text { Booths } 3-5 & \text { Recruiting Board }\end{array}$

\section{CHI 2014 Contributing Sponsor Recruiters:}

$\begin{array}{lll}\text { Facebook } & \text { Booth } 36 & \text { Recruiting Board } \\ \text { Yahoo Labs! } & \text { Booth } 10 & \text { Recruiting Board }\end{array}$

\section{CHI 2014 Other Recruiters:}

\begin{tabular}{|c|c|c|}
\hline $\begin{array}{l}\text { Samsung } \\
\text { Research America }\end{array}$ & Booth 23 & Recruiting Board \\
\hline Tandem Launch & & Recruiting \\
\hline
\end{tabular}

\section{Video Showcase}

Tuesday, 17:30 - 19:00

Room 7/8AB

Join us on Tuesday to watch the $\mathrm{CHI} 2014$ Video Showcase. At the end, join us for the Golden Mouse ceremony to award the best videos.
Joint Hospitality Reception

Wednesday, 18:00 - 20:00

Please join us at the Joint Hospitality Reception on Wednesday evening at Toronto's historic Maple Leaf Gardens, now known as the Mattamy Athletic Centre. Referred to as Canada's "Cathedral of Hockey," this site is not only a historical symbol for Canada's on-ice claim to fame, but has also been home to twelve Canadian sports teams since first opening its doors on November 12th, 1931. Recognized as a National Historic Site of Canada in 2007, "the Gardens" is the perfect place to celebrate Toronto and congratulate Canadian colleagues on those recent Olympic gold medals. There will be an exhibition from the Hockey Hall of Fame available, and you can enjoy watching adult men's hockey league teams playing while you meet our hosts and network with colleagues.

This reception is a great prelude to an evening out on the town. Light appetizers and a bar will be available - pick up drink tickets at the door. Your badge is your ticket to enter the reception, so please be sure to wear it. Prominently set in the heart of Toronto and in the heart of Canadians, the former Maple Leaf Gardens is not to be missed. We hope to see you there!

\section{CHI Champion Sponsor Hosts:}

Autodesk

Bloomberg

Google

Microsoft

\section{Friends of $\mathrm{CHI}$ Hosts:}

Universities Group (Virginia Tech, University of California Irvine, University of Maryland, UMBC)

Subway transportation to Mattamy Athletic Centre - It is 10 minutes to 50 Carlton Street (at Church Street)

- College station is the closest stop to Mattamy Athletic Centre (Maple Leaf Gardens)

- From southbound \& northbound platform, head North on Yonge St. towards College St.

- Turn right onto Carlton St.

- Mattamy Athletic Centre (Maple Leaf Gardens) will be on the left on the corner of Church St. and Carlton St. 


\section{OPENING HOURS}

Registration and Merchandise Desk

Register for the $\mathrm{CHI} 2014$ Conference and Courses (subject to availability) at the Registration Desk located on Level 600 of the Metro Toronto Convention Centre. CHI 2014 Merchandise, including mugs, snow globes and additional USB keys, will be available for purchase, subject to availability.

$\begin{array}{ll}\text { Saturday } & 07: 30-12: 00 \\ \text { Sunday } & 07: 30-17: 30 \\ \text { Monday } & 07: 30-19: 30 \\ \text { Tuesday } & 07: 30-19: 30 \\ \text { Wednesday } & 07: 30-17: 30 \\ \text { Thursday } & 07: 30-16: 30\end{array}$

The Commons

Exhibit Hall E

Exhibit Hall $\mathrm{E}$ is on Level 800 of the Metro Toronto Convention Centre and is where you can enjoy a beverage and light snack during coffee breaks, talk with colleagues or explore Exhibits, Posters and Interactivity demonstrations and performances. Opens on Monday evening.

$\begin{array}{lll}\text { Monday } & 17: 30-19: 30 & \text { Opening Reception } \\ \text { Tuesday } & 10: 00-18: 00 & (17: 30-19: 30 \text { Job Fair }) \\ \text { Wednesday } & 10: 00-18: 00 & \\ \text { Thursday } & 10: 00-13: 00 & \end{array}$

Roundtable Meeting Room

Room 7/5B

Tue-Thu, 9:00 - 12:20, 14:00 - 17:20

A roundtable room is available this year for participants who need a place to sit and have conversations with other attendees of the conference. The room can accommodate multiple groups at once. The room is for drop-in use and cannot be reserved.

\section{Coffee Breaks}

Regularly scheduled morning and afternoon coffee breaks are complimentary for all registered $\mathrm{CHI} 2014$ attendees every day 10:20 - 11:00 and 15:20 - 16:00:

$$
\begin{array}{ll}
\text { Mon } & \text { Level 700 Foyer } \\
\text { Tue-Thu } & \text { Exhibit Hall E }
\end{array}
$$

Speaker Ready Room

Room 704

Speakers and session chairs may use this room as a central checkin point and speakers may reserve a projector to prepare materials and rehearse their presentations. Sign up early with the staff person, since appointments are on a first-come, first-served basis and only one projector is available.

$$
\begin{array}{ll}
\text { Sat-Wed } & 07: 00-17: 00 \\
\text { Thu } & 07: 00-14: 00
\end{array}
$$

\section{Media/Press Office}

Room 810

$\mathrm{CHI} 2014$ welcomes members of the media. Please stop by the Media Office to get information on scheduled Media Events this week, and to learn more about $\mathrm{CHI} 2014, \mathrm{SIGCHI}$, and future $\mathrm{CHI}$ conferences. $\mathrm{CHI} 2014$ media coordinators will be happy to schedule interviews with select authors at the conference. The Media Office hours are the same as the Registration Desk.

\section{CHI INFORMATION AND POLICIES}

CHI 2014 Information Desk

Exhibit Hall E

Student Volunteers staff the Information desk during Commons hours They are happy to help answer your questions or find someone who can. At other times, stop by the Registration Desk for information.

Student Volunteers

Room 703 and 705

CHI 2014 has over 175 Student Volunteers, easily identified by their bright colored SV t-shirts. Most are graduate students in humancomputer interaction and some are seeking jobs or internships.

\section{Name Badges}

Your $\mathrm{CHI} 20 \mathrm{I} 4$ name badge serves as your admission pass to conference sessions and events. Please wear your name badge at all times while inside the Metro Toronto Conference Center. Conference management reserves the right to deny admission to anyone not wearing a $\mathrm{CHI} 2014$ name badge.

Internet Café

Exhibit Hall E

Enjoy chatting with colleagues during the breaks at the Internet Café, located next to the Posters area in the. $\mathrm{CHI} 2014$ provides access to power for your mobile devices in addition to wireless access.

\section{Wireless Access}

$\mathrm{CHI} 2014$ offers wireless high-speed internet access throughout the Metro Toronto Conference Center including in all meeting rooms. Also, please be considerate of your colleagues and limit your time spent online.

\section{Blogging \& Photosharing}

$\mathrm{CHI}$ encourages conference attendees to blog $\mathrm{CH}$. Please add the category or keyword " $\mathrm{CHI} 2014$ " to your blog entries so that others may find them easily. We encourage photosharing by services such as Flickr, but please add a "CHI 20 I4" tag to your photos and "\#chi20 I4" to your tweets.

\section{Photography and Recording}

Photographing crowd scenes and people interacting with technology is common at $\mathrm{CHI}$ and attendees should be aware that their image might be captured. Please use common courtesy when taking photos or video of individuals that are later uploaded to YouTube, Flickr or similar sites and ask permission before posting pictures of identifiable people. The use of any type of audio or video recording device is not permitted during any part of the conference.

\section{Smoking Policy}

The Metro Toronto Conference Center is a non-smoking facility and smoking is permitted outside only in designated areas. 


\section{SPOTLIGHTS}

Spotlights replaces what used to be known as Communities at $\mathrm{CHI}$. Spotlights are a chance for SIGCHI members with a common area of interest to gather and advance their area through the $\mathrm{CHI}$ conference. Spotlights emerging through the $\mathrm{CHI}$ conference may even spawn new, more specialized conferences in the future. This year we have five exiting research areas that have been selected to appear as Spotlights at $\mathrm{CHI}$ 20 4: Games \& Entertainment, $\mathrm{HCl}$ for Development, Interaction Science, Making Cultures, and Art and Interaction. Below you will find a short description of each Spotlight, as well as a list of suggested sessions relevant to these topics. We also welcome you to visit the Works-inProgress and Student Competitions in Exhibit Hall E for other content related to these Spotlights.

$(P)=$ Paper Session, $(C)=$ Course

Games and Entertainment

The games and entertainment community has been growing rapidly during the past two years with an increasing number of games and entertainment related submissions in all venues and successful student game competition. In 2014 we are planning to make it the best year yet for the Games and Entertainment Community at $\mathrm{CHI}$ as a Spotlight. We are planning to continue the Student Games Competition, increase the quality and quantity of submissions from games researchers and practitioners, and increase the involvement and engagement of practitioners within the community. We also invite you to the Special Interest Group (SIG) on Games and Entertainment session scheduled at $\mathrm{CHI} 2014$

\section{Suggested Sessions}

$$
\begin{aligned}
& \text { Monday } \\
& \text { 1 1:00 - 12:20 (P) The Third Dimension } \\
& \text { 14:00 - 15:20 (P) Studying and Designing Gameplay } \\
& \text { 14:00 - 15:20 (C) HTML5 Game Development (1/2) } \\
& \text { 16:00 - 17:20 (C) Novel Approaches to Navigation } \\
& \text { 16:00 - 17:20 (P) Interfaces for Care and Support } \\
& \text { 16:00 - 17:20 (C) HTML5 Game Development (2/2) }
\end{aligned}
$$

\section{Tuesday}

9:00 - 10:20 (P) Understanding and Designing Games

9:00 - 10:20 (P) Mid-Air Gestures

1 1:00 - 12:20 SIG: Games and Entertainment Community SIG: Reaching beyond $\mathrm{CHI}$

(Exhibit Hall G)

$$
\begin{aligned}
& \text { I 1:00 - 12:20 (P) Navigating Video } \\
& \text { I 1:00 - 12:20 (P) Music, Dance, and Television } \\
& \text { I 1:00 - 12:20(P) Interactive Whiteboards and Public Display }
\end{aligned}
$$

I 1:00 - 12:20 (P) Human-Robot Interaction

14:00 - 15:20(P) Engage and Educate Children

16:00 - 17:20(P) Exploring Exergames

\section{Wednesday}

9:00 - 10:20 (P) Telepresence and Connecting overVideo

9:00 - 10:20 (P) Exergame Design

9:00 - 10:20 (P) Health and Everyday Life

14:00 - 15:20(P) Exergaming for Health and Fitness

16:00 - 17:20(P) Tangible Interactions and Technologies (Exhibit Hall G)
Thursday

9:00 - 10:20 (P) Games and Education

9:00 - 10:20 (P) Learning and Games

9:00 - 10:20 (P) Persuasive Technologies and Applications

9:00 - 10:20 (P) Whole Body Sensing and Interaction

(Exhibit Hall G)

$\mathrm{HCl}$ for Development (HCl4D)

Information and communication technologies (ICTs) are increasingly used and appropriated by communities and other stakeholders in low-resource contexts around the world to improve education, healthcare, and lives. Yet, we lack a sufficiently rigorous evidence base that policymakers, practitioners and researchers can draw on to design and apply ICTs for maximum positive social impact. Most importantly, over the decades, human-computer interaction $(\mathrm{HCl})$ has successfully contributed to our methodological toolkit for user-centered, datadriven design; and how decisions in technology design influence technology usage, adoption and the resulting social consequences. With a $\mathrm{HCl}$ orientation that recognizes the power of "design thinking", we advance the discourse about "ICTs in development" by recognizing that technology is neither culturally-neutral, static nor deterministic.

The HCl4D community welcomes everyone who is interested in the role of technology in diverse domains such as, but not limited to: conflict zones; literacy; infant mortality; rural and urban community development; and marginalized populations in both developing countries and industrialized nations. We expect members to come from various geographic regions and backgrounds such as anthropology, computer science, economics, education, international development, psychology, and sociology, among others. By being inclusive, we look forward to members engaging with one another in a dialogue that builds on our collective diverse experiences, and in turn strengthening the evidence base for ICTs to impact development in more positive ways.

\section{Suggested Sessions}

\section{Monday}

I 1:00 - 12:20 (P) Sustainability and Everyday Practices

14:00 - 15:20(P) Managing Income

Tuesday

8:30 - 8:50 Plenary: Big Data for Social Good (Exhibit Hall G)

9:00 - 10:20 (P) Realities of Fieldwork

14:00 - 15:20 (P) Personal Health and Wellbeing

Wednesday

1 1:00 - 12:20(P) CHI for Social Development

14:00 - 15:20 SIG: Community Centered Collaborative HCl Design / Research in Developing Countries

14:00 - 16:20 (P) Policies and Practice: Doing the Right Thing

Thursday

9:00 - 10:20 (P) HCl Paradigms: Past, Present and Future

1 1:00 - 12:20(P) Lost and Found in Translation

I 1:00 - 12:20(P) Cross-Perspective Collaboration

14:00 - 15:20 (C) A Conversation with Susan Dray: Uncovering the Ordinary, Inspiring the Extraordinary

| 4:00 - 15:20 Panel: Can You Do Good and Do Well? Exploring $\mathrm{HCl}$ Careers in Development 
Interaction Science

We want to highlight Interaction Science work and establish a stronger presence of this community within the $\mathrm{CHI}$ conference and outside of it. Over the past 30 years science has played a key role in shaping and advancing research in Human-Computer Interaction. Informed in part by methods, theories and findings from the behavioral sciences and from computer science, scientific contributions to $\mathrm{HCl}$ have provided explanations of how and why people interact through and with technology. We argue that the contribution of science to $\mathrm{HCl}$ could be enhanced if key challenges are met. These challenges are different from those of other disciplines (e.g., engineering, design) that make valuable contributions to $\mathrm{HCl}$.

\section{Suggested Sessions}

\section{Tuesday}

I 1:00 - 12:20 Interaction Science SIG: Overcoming Challenges (7I5A) We will be maintaining a blog during the conference that will support the discussion of Interaction Science issues. For further information follow us on twitter@l×_Sci.

\section{Making Cultures}

In recent years, $\mathrm{HCl}$ researchers have increasingly turned to processes of making, from knitting to digital fabrication, to rethink the digitization of our everyday worlds. Some have studied the rise of communityoperated workspaces and blogs that celebrate hands-on practices of hacking, crafting, and tinkering. Others have used reflective modes of making to provoke alternative forms of qualitative inquiry. Through making, such research has probed social responses in participatory design workshops, extended and interrogated existing theory in "critical making" projects, and enacted social change in citizen science initiatives. In all cases, researchers have posed making as a research activity that asks how tactile engagements become tactical within specific sociotechnical environments.

The Making Cultures Spotlight includes researchers and practitioners focusing on:

- Empirical study of existing cultures of making, including physical computing, hackerspaces, amateur multimedia production, craft, etc.

- Theory on issues closely related to making, including digital materiality, sustainability, research through design, creativity, and communities of practice and interest

- All aspects of design, development, and deployment of makingfocused systems, technologies, technology components, and interfaces

- Use of making as a research method

- Computer science education

- Participatory and democratic design

\section{Suggested Sessions}

\section{Monday}

14:00 - 15:20 (P) Hackerspaces, Making, and Breaking

Tuesday

9:00 - 10:20 alt.chi: Ways of Creating in $\mathrm{HCl}$

14:00 - I5:20 (C) Make This! Introduction to Electronics Prototyping using Arduino

14:00 - 15:00(P) DIY \& Hacking

16:00 - 17:20 (C) Make This! Introduction to Electronics Prototyping using Arduino

Wednesday

1 1:00 - 12:20 Panel: Making Cultures: Empowerment, Participation, and Democracy - or Not

Thursday

1 1:00 - 12:20(P) 3D Printing and Fabrication
Art and Interaction

The Arts and Interaction Spotllight brings together researchers, practitioners, and artists whose work is informed by the digital arts. We recognize that many of these individuals are hybrids between $\mathrm{HCl}$ and other disciplines, which include digital arts, design, computer science, performance, music, education, arts administration, and science museum exhibition development. The digital arts intersect with traditional $\mathrm{CHI}$ topics such as screen-based interaction, embodied interaction, virtual and augmented environments, games, and data visualization.

The digital arts have been consistently represented in the $\mathrm{CHI}$ program for the past decade. Many of these activities are integrated within a larger international and interdisciplinary digital arts movement. The goals of the Art and Interaction Spotlight include supporting this work within $\mathrm{CHI}$, building connections between this work and work in other subdomains of $\mathrm{CHI}$, and networking to communities and resources currently outside of the $\mathrm{CHI}$ community. The hope is that through this exposure, $\mathrm{CHI}$ researchers will gain alternative insights into the interactive process. By participating in academic conferences such as $\mathrm{CHI}$, digital artists gain access to an audience familiar with their technologies. Through $\mathrm{CHI}$, artists can learn of technological advances and engage in discourse about these technologies. By providing a platform for digital arts at $\mathrm{CHI}$, we can facilitate interdisciplinary collaboration between artists and technologists, and additional insights can be gained in turn. A new goal for $\mathrm{CHI} 2014$ will be the development of an Arts Gallery and associated arts catalogue from $\mathrm{CHI} 2015$ onwards.

\section{Suggested Sessions}

\section{Monday}

I 1:00 - 12:20(P) Visualization and Aesthetics

। 1:00 - 12:20(P) Audio Interaction

14:00 - 15:20 SIG: Art and Interaction: Cataloging The Digital Arts (7I5A)

16:00 - 17:20(P) Research through Design

\section{Tuesday}

9:00 - 10:20 (P) Enabling Interactive Performances

9:00 - 10:20 alt.chi: Ways of Creating in $\mathrm{HCl}$

1 1:00 - 12:20(P) Crowds and Creativity

1 1:00 - 12:20(P) Music, Dance, and Television

14:00 - 15:20(P) DIY and Hacking

16:00 - 17:20(P) Critical Design

16:00 - 17:20(P) Narratives and Storytelling

\section{Wednesday}

9:00 - 10:20 (P) Issues That Matter

1 1:00 - 12:20 Panel: Making Cultures: Empowerment, Participation, and Democracy or Not?

14:00 - 15:20 (P) Sensory Experiences: Smell and Taste

(Exhibit Hall G)

16:00 - 17:20(P) Urban Communities and Social Media

Thursday

9:00 - 10:20 (P) Whole Body Sensing and Interaction (Exhibit Hall G)

9:00 - 10:20 alt.chi: Intimate Interfaces

1 1:00 - 12:20 Panel: Lost and Found in Translation

14:00 - 15:20 (P) Computer Mediated Intimacy and Romance

14:00 - 15:20(P) Research and Deployment in the Wild 


\section{LIFETIME RESEARCH AWARD}

The SIGCHI Lifetime Research Award is presented to individuals for outstanding contributions to the study of human-computer interaction. This award recognizes the very best, most fundamental and influential research contributions. It is awarded for a lifetime of innovation and leadership

Steve Whittaker is Professor in Psychology at University of California at Santa Cruz. His research examines the design and evaluation of technologies to support human memory, productivity, socialising and well-being. His work uses insights from the social sciences to evaluate existing technologies and generate new designs that address important human problems. He has previously worked at Hewlett Packard, Bell Labs, AT\&T, and IBM. In 2008 he was elected the Association of Computational Machinery (ACM) Computer Human Interaction Academy for sustained research contributions. He is Editor of Human Computer Interaction. Right now he is working on online communities and digital tools to support human memory that have mental and physical health benefits.

\section{LIFETIME PRACTICEAWARD}

The SIGCHI Lifetime Practice Award is presented to individuals for outstanding contributions to the practice and understanding of humancomputer interaction. This award recognizes the very best and most influential applications of human-computer interaction. It is awarded for a lifetime of innovation and leadership.

Gillian Crampton Smith studied Philosophy and Art History, then followed her long-standing interest in typography. In 1981 an issue of the typographic magazine Upper \& Lower Case, on computers in graphic design, inspired her to buy a computer and write a program to do magazine layouts on screen - very early desktop publishing. Convinced of the potential contribution of artist-designers to the design of human-computer interaction, in 1984 she started a graduate program for practicing graphic designers at St Martin's School of Art in London. In 1990 she moved to the Royal College of Art, Britain's graduate school of art and design, where she became professor and, with a generous grant from the Palo Alto company, Interval Research, founded the Computer Related Design Research Studio. This studio collaborated with many high-tech companies, developing the role of the art and design disciplines in shaping how people interact with electronic tools, products and media. She spent several summers in Silicon Valley collaborating with Apple, IDEO and Interval. In 2000 she became the first Director of Interaction Design Institute Ivrea, a teaching and research institute funded by Telecom Italia and Olivetti. Despite its short life, Interaction-lvrea remains, though its alumni, a worldwide influence. In 2005 she moved to luav University of Venice where, with Philip Tabor, she developed the Interaction Design program within its Masters in Design. A Senior Fellow of the Royal College of Art, she has served on England's Arts and Humanities Research Council, the start-up program of the UK National Endowment for Science Technology and the Arts, and the advisory boards of Copenhagen Institute of Interaction Design, Fabrica, and MIT's SENSEable City Laboratory.

\section{LIFETIME SERVICE AWARD}

The SIGCHI Lifetime Service Award goes to individuals who have contributed to the growth of SIGCHI in a variety of capacities. This award is for extended services to the community at large over a number of years.

Wendy Mackay is currently Research Director, Classe Exceptionnelle, at Inria in France where she heads the In|Situ| research group in HumanComputer Interaction, which includes 7 faculty and 20 students and research staff from Inria, CNRS and Université Paris-Sud. She is a member of the $\mathrm{CHI}$ Academy and a recipient of a prestigious European
Research Council Advanced grant. She recently served as Vice President of Research for the Computer Science Department at Universite Paris-Sud, France and spent two years as Visiting Professor at Stanford University. She received her Ph.D. from M.I.T. and has managed software development groups at Digital Equipment Corporation and research groups at Digital, MIT, Xerox, CENA and Aarhus University. She has been actively involved in SIGCHI since 1983 and has participated in every $\mathrm{CHI}$ conference since then. She was elected Chair of ACM/SIGCHI, has served on most other SIGCHI executive positions, co-founded the first SIGCHI local SIG, Greater Boston SIGCHI, and has also served on the ACM Publications Board, ACM SIGBoard and CACM Web Editorial Board. She has published over 150 peer-reviewed research articles in the area of human-computer interaction and has served as program chair or on the program committees of ACM CHI, ACM UIST, ACM CSCW, ACM DIS and ACM Multimedia, among others. She was co-editor in chief of $\mathrm{IJHCS}$ and served on the editorial boards of $\mathrm{ACM} / \mathrm{TOCH}$ and $\mathrm{RIHM}$. Most recently, she served as general chair of $\mathrm{CHI} 2013$ in Paris, with almost 3500 attendees. Her current research interests include participatory design, creativity, co-adaptive instruments, mixed reality and interactive paper, and multidisciplinary research methods.

Tom Hewett is Professor Emeritus of Psychology and Computer Science at Drexel University. Tom's SIGCHI service activities began with a proposal to the SIGCHI Executive Committee that they fund the creation and work of a Curriculum Development Group to develop the first SIGCHI recommended sample Curriculum for Human Computer Interaction. The final report, with its infamous "lime green" cover, became an official ACM document. After twice serving as SIGCHI Executive Committee Vice Chair for Operations (1989-93), Tom was CHI '94 General Co-Chair. As part of four CHI Conference Committees from $\mathrm{CHI}$ '9I to $\mathrm{CHI}$ 2006, Tom was Tutorials Chair or Co-Chair. In addition, he has been on the organizing committee of four SIGCHI sponsored Creativity and Cognition conferences, serving as papers program Chair or Co-Chair for three of those conferences. Most recently Tom was papers program chair for the 9th Creativity and Cognition Conference, Sydney, June, 2013.

\section{SOCIAL IMPACT AWARD}

This award is given to individuals who promote the application of human-computer interaction research to pressing social needs.

Richard E. Ladner is a Professor in the Department of Computer Science and Engineering at the University of Washington with adjunct appointments in the Departments of Electrical Engineering and Linguistics. His current research is in the area of accessible computing which is an important subarea of human-computer interaction $(\mathrm{HCl})$. He entered this research area relatively late in his career after working in theoretical computer science for more than 30 years. His MobileAccessibility project is exploring mobile applications to improve the lives of blind, low-vision, and deaf-blind people. He is the creator of the ASL-STEM Forum which is an on-line community for uploading and discussing sign language for terms in science, technology, engineering, and mathematics. He is the Principal Investigator for the NSF-funded AccessComputing Alliance that has the goal of increasing participation of students with disabilities in computing fields. From 2007 - 2013, he directed the Summer Academy for Advancing Deaf and Hard of Hearing in Computing, a nine week program for students transitioning from high school to college. He served on the NSF Committee on Equal Opportunities in Science and Engineering (CEOSE) from 2006 to 2012. He is a recipient of the 2004 Presidential Award for Excellence in Science, Mathematics and Engineering Mentoring (PAESMEM) and the 2008 Computing Research Association's A. Nico Habermann Award. He is a winner of a 2008 Purpose Prize. He was the Outstanding Service Award winner at the University of Washington in 2009. He is a member of the Board of Trustees of Gallaudet University, a liberal arts university that primarily serves deaf students. 


\section{CHI ACADEMY}

The $\mathrm{CHI}$ Academy is an honorary group of individuals who have made substantial contributions to the field of human-computer interaction. These are the principal leaders of the field, whose efforts have shaped the disciplines and/or industry, and led the research and/or innovation in human-computer interaction.

John C. Tang is a Senior Researcher at Microsoft Research where he designs and studies new tools to support connecting people over distance. His research has focused on supporting remote collaboration, using a range of technologies (video, instant messaging, rhythmic patterns) in diverse contexts (distributed work teams, long-distance social connections). He not only researches distributed collaboration, but also lives it through working with teams at other sites in the U.S. and around the world. John's research approach combines understanding users' needs through social science methods with designing and prototyping new technologies and learning from how they are used. John's career in industry has included previous positions at IBM Research Almaden, Sun Microsystems, and Xerox PARC. He has been active in the $\mathrm{CHI}$ and $\mathrm{CSCW}$ research communities through research papers, patents, and service on conference committees, including cochairing CSCW 201 I in Hangzhou, China. John received his Ph.D. from the Design Division at Stanford University.

Jeff A. Johnson is Principal Consultant at UI Wizards, Inc., a product usability consultancy. He also is a principal at Wiser Usability, Inc., a consultancy focused on usability and accessibility for adults 50+. After earning B.A. and Ph.D. degrees from Yale and Stanford Universities, he worked at Cromemco, Xerox, USWest, Hewlett-Packard Labs, and Sun Microsystems. In 1990, he co-chaired the first Participatory Design conference, PDC'90. Since 2004 he has served on the SIGCHI U.S. Public Policy Committee. He has taught at Stanford and Mills College, and in 2006 and 2013 taught $\mathrm{HCl}$ as an Erskine Fellow at the University of Canterbury in New Zealand. He has authored many articles and chapters on $\mathrm{HCl}$, as well as the books GUI Bloopers, Web Bloopers, GUI Bloopers 2.0, Designing with the Mind in Mind, and (with Austin Henderson) Conceptual Models: Core to Good Design. A second edition of Designing with the Mind in Mind was published in early 2014.

Susan Dray has worked to advance human-centered design since 1979, initially in a human factors research group at Honeywell, and later championing usability of corporate systems at American Express. Since founding her consulting firm in 1993, she has provided user experience research for a long list of clients to help them create innovative products and services that are useful, usable, and desirable. Through her publications, teaching, mentoring, and many speaking engagements, Susan has contributed significantly to the evolution of UX research practice, especially in field research, naturalistic usability evaluation, and international usability and user research. Extensive experience doing research in developing countries led to her involvement in forming a professional community focused on user-centered design for development (UCD4D), applying UCD to technological aspects of economic development. She is currently pursuing this interest as a Fulbright Scholar on the faculty at the Technological University of Panama. Susan is a Fellow of the Human Factors and Ergonomics Society, recipient of the SIGCHI Lifetime Service Award and an ACM Distinguished Engineer. She is a long-time Column/Forum editor for Interactions and served as Director of Publications on the Board of the User Experience Professionals Association. Susan holds a doctorate in Psychology from UCLA.

Jodi L. Forlizzi is an Associate Professor in the Human-Computer Interaction Institute and the School of Design at Carnegie Mellon University. She was the first design professor hired into the $\mathrm{HCll}$ and the School of Computer Science at CMU. Jodi has advanced design research in $\mathrm{HCl}$, illustrating to the $\mathrm{CHI}$ community that design research, while different than scientific research or research on human behavior, is a critical part of our community. Jodi's early work explored experience design, and understanding how to best design all aspects of product behavior - functional, aesthetic, emotional, and social. Jodi has also conducted research in human-robot interaction, big data and what it means for design, how technology services can better adapt and be personalized to people's needs, and how design research can help to address societal problems, such as our aging population and today's healthcare needs. Jodi has authored or co-authored over I 30 papers and book chapters.

Keith Edwards is a Professor of Interactive Computing in the College of Computing at Georgia Tech. His research focuses largely on bringing human concerns to bear on the creation of core computing infrastructure, for example, by exploring human-centered approaches to networking and computer security. Lately his research has expanded into a number of explorations of the social impacts of computing technology, such as understanding how technology can support the work of non-profits and NGOs, or help build stronger communities. Prior to joining Georgia Tech, he was a Principal Scientist at Xerox PARC and managed PARC's Ubiquitous Computing group. He is an ACM Distinguished Scientist, a member of Microsoft's Trustworthy Computing Academic Advisory Board, and has served as the Technical Program Chair for CHI 20I0, the Program Chair for UIST 2002, and the General Chair for UIST 2000. While he is a technologist at heart, he enjoys working with designers, social scientists, and others from diverse backgrounds.

Ken Hinckley is a Principal Researcher at Microsoft Research, where he has spent the last 17 years investigating novel input devices, device form-factors, and modalities of interaction. He feels fortunate to have had the opportunity to collaborate with many $\mathrm{CHI}$ Academy members while working there, including noted trouble-makers such as Bill Buxton, Patrick Baudisch, and Eric Horvitz-as well as George Robertson, whom he owes a debt of gratitude for hiring him fresh out of grad school. Ken is perhaps best know for his work on sensing techniques, cross-device interaction, and pen computing. He has published over 75 academic papers and is a named inventor on upwards of 150 patents. Ken holds a Ph.D. in Computer Science from the University of Virginia, where he studied with Randy Pausch. He has also published fiction in professional markets including Nature and Fiction River, and prides himself on still being able to hit 30 -foot jump shots at age 44 . Not too shabby.

Richard H. R. Harper is Principal Researcher at Microsoft Research in Cambridge and co-manages the Socio-Digital Systems group. Richard is a sociologist concerned with how to design for 'being human' in an age when human nature is often caricatured or rendered in oversimplifying ways. His book, Texture: Human expression in the age of communications overload (MIT Press) was awarded the Society of Internet Researcher's 'Book of the Year (20I I)'. Amongst his prior books was the IEEE award winning The Myth of the Paperless Office (MIT Press,2002, with Abi Sellen), and Inside the IMF: an ethnography of documents, technology and organisational action (Academic Press, 1997). His latest collection, Trust, Computing and Society ', will be published by CUP in April this year. He is currently working on a monograph (with Dave Randall and Wes Sharrock) called Choice:The science of reason in the 2 Ist Century, (Polity Press).

Gary Marsden was professor of computer science at the University of Cape Town, pioneer and passionate advocate of $\mathrm{HCl}$ for development and community builder. He became internationally known for his work in mobile interface design, design, and ICT for development (ICT4D) for which he was a recipient of the ACM SIGCHI's Social Impact Award in 2007. He went to great lengths to show how mobile technologies were revolutionizing how developing countries were advancing apace. In doing so, he raised the profile of what developing world actually meant. In just a few years, he had managed to put $\mathrm{HCl}$ in South Africa and South Africa in $\mathrm{HCl}$. As well as a being a renowned researcher, he received many teaching awards, the last one a prestigious award from his university that only a few ever receive. Gary died suddenly of a heart attack on December 27,20 I3, at the age of 42 and is survived by his wife Gil and his two children, Holly and Jake. 


\section{PAST HONOREES}

\section{SIGCHI Lifetime Research Award}

2013 George G. Robertson

2012 Dan Olsen

2011 Terry Winograd

2010 Lucy Suchman

\section{SIGCHI Lifetime Practice Award}

2013 Jakob Nielsen

2012 Joy Mountford

2011 Larry Tesler

2010 Karen Holtzblatt

\section{SIGCHI Lifetime Achievement Award}

\section{Sara Kiesler}

2008 Bill Buxton

2007 James D. Foley

2006 Gary M. Olson, Judith S. Olson

2005 Tom Landauer

2004 Thomas P. Moran

2003 John M. Carroll

2002 Donald A. Norman

2001 Ben Shneiderman

2000 Stuart K. Card

1998 Douglas Engelbart

\section{SIGCHI Lifetime Service Award}

2013 Joseph A. Konstan

2012 Mike Atwood, Kevin Schofield

2011 Arnie Lund, Jim Miller

2010 Mary Czerwinski

2009 Clare-Marie Karat, Steven Pemberton

2008 John Karat, Marian Williams

2007 Richard I. Anderson

2006 Susan M. Dray

2005 Sara Bly, John 'Scooter' Morris, Don Patterson, Gary Perlman, Marilyn Mantei Tremaine

2004 Robin Jeffries, Gene Lynch

2003 Lorraine Borman

2002 Dan R. Olsen Jr.

2001 Austin Henderson

\section{SIGCHI Social Impact Award}
2013 Sara J. Czaja
2012 Batya Friedman
201 I Alan Newell, Clayton Lewis
2010 Allison Druin, Ben Bederson
2009 Helen Petrie
2008 Vicki Hanson
2007 Gregory Abowd, Gary Marsden
2006 Ted Henter
2005 Gregg Vanderheiden

\section{$\mathrm{CHI}$ Academy Members}

Class of 2013 Patrick Baudisch,Victoria Bellotti, Clarisse Sieckenius de Souza, Alan Dix, Rebecca E. Grinter, Eric Horvitz, Bonnie Nardi, Thomas S.Tullis

Class of 2012 Ben Bederson, Steve Benford, Hugh Dubberly, Carl Gutwin, Joy Mountford, Alan Newell, Yvonne Rogers
Class of 201 I Ravin Balakrishnan, Steven Feiner, Joseph Konstan, James Landay, Jenny Preece, Abigail (Abi) Sellen, Dennis Wixon

Class of 2010 Susanne Bødker, Mary Czerwinski, Austin Henderson, David Kieras, Arnie Lund, Larry Tesler, Shumin Zhai

Class of 2009 Mark Ackerman, Bill Gaver, Clayton Lewis, Wendy E. Mackay, Aaron Marcus, Elizabeth Mynatt, Tom Rodden

Class of 2008 Gregory Abowd, Paul Dourish, Wendy Kellogg, Randy Pausch, Mary Beth Rosson, Steve Whittaker

Class of 2007 Joëlle Coutaz, Karen Holtzblatt, Gerhard Fischer, Robert J. K. Jacob, Jun Rekimoto, Chris Schmandt

Class of 2006 Scott Hudson, Hiroshi Ishii, Michel Beaudouin-Lafon, Jakob Nielsen, Peter Pirolli, George Robertson

Class of 2005 Ron Baecker, Susan Dumais, John Gould, Saul Greenberg, Bonnie E. John, Andrew Monk

Class of 2004 George Furnas, Jonathan Grudin, Brad Myers, William Newman, Dan R. Olsen Jr., Brian Shackel, Terry Winograd

Class of 2003 Thomas Green, James D. Hollan, Robert E. Kraut, Gary M. Olson, Peter G. Polson

Class of 2002 William A. S. Buxton, John M. Carroll, Douglas C. Engelbart, Sara Kiesler, Thomas K. Landauer, Lucy A. Suchman

Class of 200 I Stuart K. Card, James D. Foley, Morten Kyng, Thomas P. Moran, Judith S. Olson, Ben Shneiderman

ACM/SIGCHI BEST OF CHI AWARDS

The SIGCHI "Best of CHI" awards honor exceptional papers published at the $\mathrm{CHI}$ conference. The top 5\% of submissions are chosen by the associate chairs to receive an award. Among these, the associate chairs and a separate Best Papers Committee select the very best $1 \%$ of submissions to receive a Best Paper award.

X The $\mathrm{CHI}$ Associate Chairs nominated 5\% of the Paper and

0 Notes submissions. 84 papers and notes received Honorable Mention, designated by a medallion logo.

SIf The separate Best Papers committee selected the top $1 \%$ of total submissions. 2 I Papers and Notes received a Best Paper award, designated by a trophy logo.

Daniel Wigdor (Chair), Karyn Moffat (Chair), Duncan Brumby, John Canny, Tiago Guerreiro, Steve Harrison, Otmar Hilliges, Lilly Irani, Michal Jacovi, Judy Kay, Kris Luyten, David McGookin, Antti Oulasvirta and Lana Yarosh.

\section{PEOPLE'S CHOICE BEST TALK AWARD}

The People's Choice Best Talk Awards are meant to celebrate the very best of in-conference presentations. Did a presenter go the extra mile to make their talk genuinely interesting and informative? Did a speaker make you stop and think about something new? Did a presentation make an otherwise dull topic come alive? Nominate the speaker for a People's Choice Best Talk Award! It takes only a moment, and helps to reward those who spend the extra time to make help make the conference truly memorable and extraordinary.

You may cast as many votes as you wish, provided they don't occupy the same time slot (overlapping sessions are ok). Please, do not wait until the end of the conference to choose a single 'best'. Think of your votes as nominations for awards made to the best that the conference has to offer. Votes are cast using the $\mathrm{CHI} 2014$ mobile application or through the voting site: http://chi20l4.acm.org/vote. Your Voter ID is on the back of your name badge. It only takes a few seconds - vote now! The winners of the People's Choice Best Talk Awards will be announced at the $\mathrm{CHI} 2014$ closing plenary! 


\section{KEYNOTES}

$\mathrm{CHI} 2014$ will open and close with plenaries that will each feature keynotes from distinguished speakers.

The Opening Plenary introduces ACM/SIGCHI and the $\mathrm{CHI} 2014$ Conference, announces the $2014 \mathrm{SIGCHI}$ award winners and offers suggestions for navigating through the $\mathrm{CHI} 2014$ technical program. Awards for Best Papers and Notes and Honorable Mentions are indicated in the Session-at-a-Glance pages.

The Opening Keynote speaker is Booker Prize winning author Margaret Atwood. Write your questions for the keynote speakers on cards distributed by the Student Volunteers.

The Closing Plenary is the last event of $\mathrm{CHI} 2014$. We announce the award winners for the Student Design Competition, the Student Game Competition and the Student Research Competition. The Golden Mouse award is announced on Tuesday evening at the Video Showcase and the Closing Plenary. We will also announce the winners of the inaugural People's Choice Best Talk Awards.

The Closing Keynote is by leading UX designer, Scott Jenson. $\mathrm{CHI} 2014$ ends with the hand-off to the $\mathrm{CHI} 2015$ committee, who will introduce next year's conference taking place in Seoul, Korea.

\section{Opening Keynote: Robotics in My Work and Life Margaret Atwood}

Monday 28 April, 9:00

Exhibit Hall G

Biography

Margaret Atwood is a giant of modern literature who refuses to rest on her laurels. She has anticipated, satirized, and even changed the popular

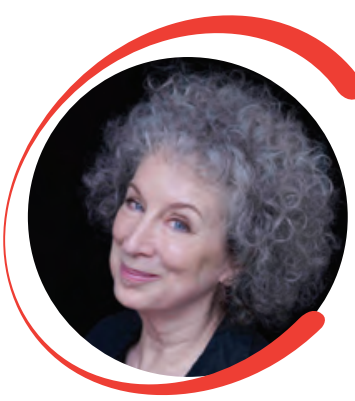
pre-conceptions of our time, and is the rare writer whose work is adored by the public, acclaimed by the critics, and read on university campuses. On stage, Atwood is both serious minded and wickedly funny.

A winner of many international literary awards, including the prestigious Booker Prize, Margaret Atwood is the author of more than thirty volumes of poetry, children's literature, fiction, and nonfiction. She is perhaps best known for her novels, which include The Edible Woman, The Handmaid's Tale, The Robber Bride, Alias Grace, The Blind Assassin, Oryx and Crake, and The Year of the Flood. Her non-fiction book Payback: Debt and the Shadow Side of Wealth, part of the Massey Lecture series, was recently made into a documentary. Her new book, Madaddam (the third novel in the Oryx and Crake trilogy), has received rave reviews: "An extraordinary achievement" (The Independent); "A fitting and joyous conclusion" (The New York Times).

Atwood's work has been published in more than forty languages, including Farsi, Japanese, Turkish, Finnish, Korean, Icelandic and Estonian. In 2004, she co-invented the LongPen, a remote signing device that allows someone to write in ink anywhere in the world via tablet PC and the internet. She is also a popular personality on Twitter, with over 300,000 followers.

Atwood was born in 1939 in Ottawa and grew up in northern Ontario, Quebec, and Toronto. She received her undergraduate degree from Victoria College at the University of Toronto and her master's degree from Radcliffe College.

\section{Closing Keynote: The Physical Web}

Scott Jenson, Google, Inc.

Thursday I May, I 6:00

Exhibit Hall G

Abstract

Too often when we discuss "interaction" we think of it as a desktop vs tablet vs mobile issue. However, with the plummeting cost of both processing and connectivity, our understanding of a 'smart device' is rapidly changing. The challenge is that this new, amazing category of devices will blind side us, requiring entirely new ways of interacting. This talk will discuss the exploding new area of smart devices, how the Internet of things is a UX disaster, and how we are on the verge of an entirely new way of interacting with devices.

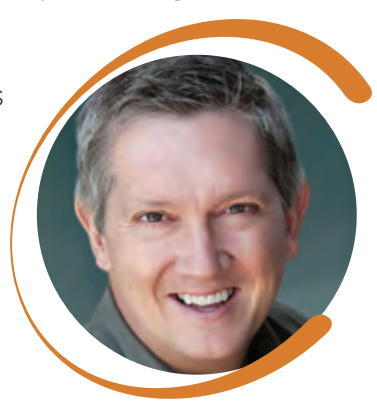

\section{Biography}

Scott Jenson has been at the forefront of user interface design for over 25 years. He was the first member of the User Interface group at Apple in the late 80s, working on System 7, the Apple Human Interface Guidelines and was on the original Newton team. Following that he was Director of Product Design for Symbian, managed the mobile UX group at Google and was Creative Director at frog design. As a battle scarred veteran of the software industry, Scott has shipped a consumer spreadsheet, been a part of over 10 different OS releases, 4 commercial web site revisions, designed 3 different mobile phone Uls, did the UX for the Google Mobile Maps, and has over 20 patents.

\section{PLENARIES: PROVOKE! WISDOM! IMPACT!}

New for $\mathrm{CHI} 20$ I4, plenary talks first thing each morning on Tuesday, Wednesday and Thursday. Come along, join the crowd and be energised by our speakers who will each bringing their experience of the Big Picture to inspire us. The talks will be short - twenty minutes and then the rest of the day's program will begin.

\section{Plenary: Big Data for Social Good}

Nathan Eagle, Jana Mobile, Inc.

Tuesday 29 April, 8:30 - 8:50

Exhibit Hall G

Abstract

Petabytes of data about human movements, transactions, and communication patterns are continuously being generated by everyday technologies such as mobile phones and credit cards. This unprecedented volume of information facilitates a novel set of research questions applicable to a wide range of development issues. In a collaboration involving 237 mobile operators across 102 countries, Jana's mobile technology platform can instantly poll and compensate 3.48 billion active mobile subscriptions. This talk will discuss how insights gained from living in Kenya became the genesis of a technology

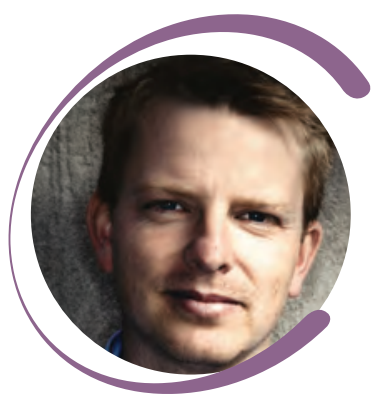
company currently working with global clients in over 50 countries, including P\&G, Google, Unilever, Danone, General Mills, Nestle, Johnson \& Johnson, Microsoft, the World Bank, and the United Nations. After providing an overview of the mobile and social media landscapes in emerging markets, it will conclude by emphasizing the value of consumer data in underserved and understudied regions of the world. 
Biography

Nathan Eagle is the co-founder and CEO of Jana, a company that provides consumers in emerging markets with free mobile phone airtime to incentivize surveys and purchasing. In addition to being CEO of Jana, Eagle holds an Adjunct Assistant Professor appointment at Harvard University.

His MIT PhD was declared one of the "I O Technologies Most Likely to Change the Way We Live," and he's been named one of the world's top mobile application developers and been elected to the TR35, a group of Top Innovators Under 35. Often sought after for his expert commentary, Nathan is regularly featured in such publications as the BBC, New York Times, Wall Street Journal, BusinessWeek and CNN.

\section{Plenary: A CHI Story - Past, Present, and the Next Chapters}

Scooter Morris, University of California, San Francisco

Wednesday 30 April, 8:30 - 8:50

Exhibit Hall G

Abstract

I became part of the $\mathrm{CHI}$ community in 1985, when I signed up to be the

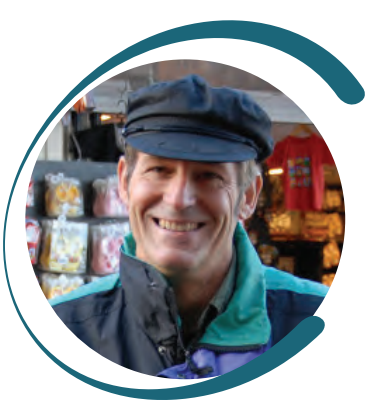
first AV Chair for the $\mathrm{CHI}$ conference. For the $\mathrm{CHI} 2014$ conference....'m still the AV Chair (we call it "technology liaison" now). Along the way, l've cochaired a $\mathrm{CHI}$ conference, served on the SIGCHI Conference Management Committee for many years, and I'm now the Vice President for Conferences for SIGCHI. What is it about $\mathrm{CHI}$ that would induce a bioinformatician and hard-core hacker to become passionate about $\mathrm{HCl}$ and devote a significant amount of time and energy to support the field of $\mathrm{HCl}$ through service to the $\mathrm{CHI}$ conference? In this brief talk, we'll look at the $\mathrm{CHI}$ conference through the eyes of a volunteer who has spent time in the lowest levels of conference operations, chaired the conference, and now is responsible for overseeing all of the SIGCHI conferences. I'll try to address some or all of the following questions:

Where did we come from? What is $\mathrm{CHI}$ trying to achieve and have we been successful? If we have been successful, what are the key ingredients to that success? Where are going and how are we going to get there without losing what we currently have? And finally, why should you care? Oh, and along the way, it will probably become clear why I care...

\section{Biography}

John "Scooter" Morris is the Executive Director of the Resource for Biocomputing, Visualization, and Informatics at the University of California, San Francisco. Before finding his home in academia, he was a Distinguished Systems Architect at Genentech, Inc., where for 19 years, he participated in the joys and trials of life in industry. He received his Ph.D. in Medical Information Science from UCSF in 1990, and has bachelor's degrees in Physics, Biology, and Computer Science from UC Irvine. Scooter is a member of the Cytoscape core development team (an open source system for the visualization and analysis of biological networks), and author of several Cytoscape plugins and core features. In his "spare time" he is the Vice President for Conferences of the ACM Special Interest Group for Computers and Human Interaction (SIGCHI), a long-time $\mathrm{CH}$ conference volunteer, past $\mathrm{CHI}$ conference co-chair, and recipient of the SIGCHI Lifetime Service Award. He is also known to voluntarily jump off perfectly good boats near Alcatraz Island for a brisk swim to San Francisco, swim across Lake Tahoe, and generally do silly things in cold water, but that's a different story.
Plenary: Reasons to be Cheerful, Part 4

Elizabeth F. Churchill, eBay Research Labs

Thursday I May, 8:30 - 8:50

Exhibit Hall G

Abstract

Reasons to be Cheerful, Part 3 was a song released by the UK's lan Dury and the Blockheads in 1979. The song simply enumerates a series of reasons for being cheerful: Summer, Buddy Holly..... I8-wheeler Scammels, Domenecker camels....The list includes sex, generosity and politeness, yellow socks, breakfast cereal, John Coltrane..... and more. In 1979 when the song was released $\mathrm{HCl}$ was still in its infancy, starting its 'first wave'. Much focus was on efficiency and on communication

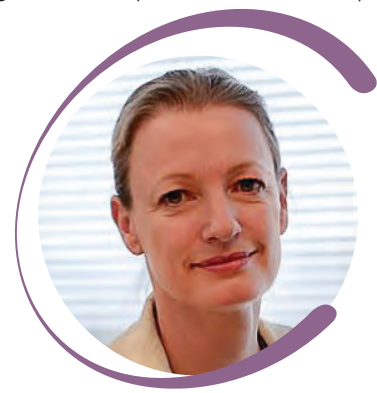
as command. Satisfaction was noted, but not central. Frustration was acknowledged but not deeply theorized. Now, in 2014, in the third or perhaps even fourth wave of $\mathrm{HCl}$, we talk about engagement, connection, emotion, enjoyment, delight and joy..... Efficiency is still on the table but not dominant. In this talk, I reflect on cheer, on joy and the human capacity for optimism. I will update the Blockheads' list, to include some reasons I believe we should be cheerful about the emerging landscape of mediated interaction and social connection. My list will offer examples from my own collaborative work in the design and development of engaging Internet experiences.

\section{Biography}

Dr. Elizabeth F. Churchill is director of human computer interaction at eBay Research Labs, where she is focusing on human centered commerce. Originally a psychologist by training, she has focused on understanding people's social and collaborative interactions in their everyday digital and physical contexts. Dr. Churchill has over 100 peerreviewed research publications, over 40 patents filed or in process, five edited books, and has been a regular columnist for ACM Interactions. Her most recent book, co-authored with Frank Ritter and Gordon Baxter, is entitled Foundations for Designing User-Centered Systems. She is the current Executive Vice President of ACM SIGCHI, a Distinguished Scientist of the ACM, a Distinguished Visiting Scholar at Stanford University's Media X, and serves on the advisory board for the Mobile Life Research Center in Kista, Sweden. Dr. Churchill has recently been advising on the creation of a new initiative in Human Data Interaction with scholars in the United Kingdom. Before joining eBay, Dr. Churchill was a principal research scientist at Yahoo! Research, where she founded the Internet Experiences Group. She has also worked at PARC's Computing Science Lab. Prior to that, she formed and led the Social Computing Group at Fuji Xerox's FX Palo Alto Laboratory. Dr. Churchill has a $\mathrm{PhD}$ in Cognitive Science from the University of Cambridge in Cambridge, United Kingdom. 


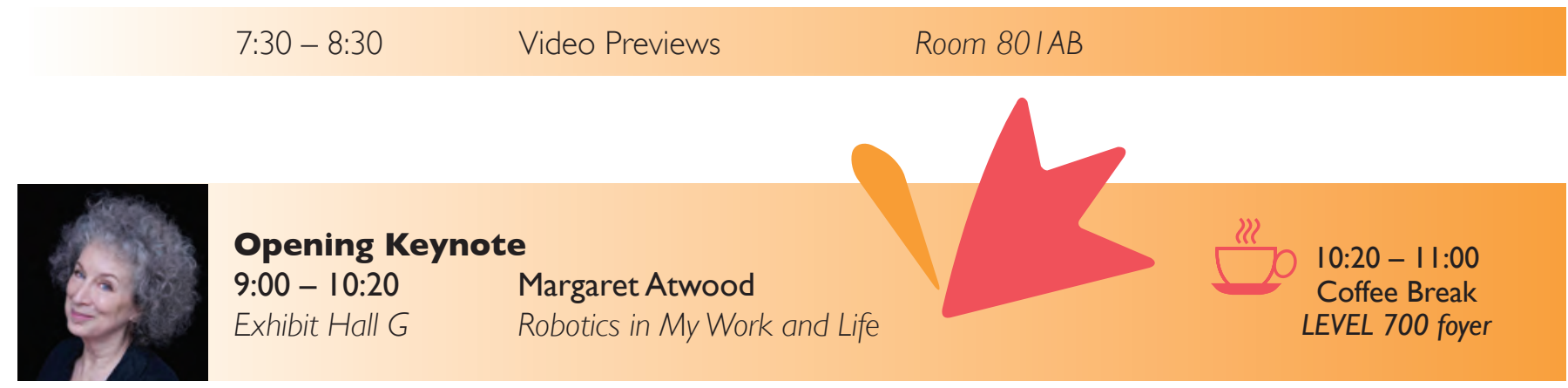

70IA Papers: Visualization and Aesthetics

CHAIR: ANTONELLA DE ANGELI

Metaphone: Machine Aesthetics Meets Interaction Design Vygandas Simbelis, Anders Lundstrom, Kristina Hook, Jordi Solsona Belenguer, Vincent J. Lewandowski

Quantifying Visual Preferences Around the World Katharina Reinecke, Krzysztof Z. Gajos

The Influence of Aesthetics in Usability Testing: The Case of Dual-Domain Products

Andreas Sonderegger, Andreas Uebelbacher, Manuela Pugliese, Juergen Sauer

Extracting References Between Text and Charts via Crowdsourcing

Nicholas Kong, Marti A. Hearst, Maneesh Agrawala

\section{IB Papers: Stress}

CHAIR: YUNAN CHEN

$\rightleftarrows \Longleftarrow$

Stress and Multitasking in Everyday College Life:

An Empirical Study of Online Activity

Gloria Mark, Yiran Wang, Melissa Niiya

Under Pressure: Sensing Stress of Computer Users Javier Hernandez, Pablo E. Paredes, Asta Roseway, Mary P. Czerwinski

MouStress: Detecting Stress from Mouse Motion

David Sun, Pablo E. Paredes, John F. Canny

Investigating the Effects of Using Biofeedback as Visual Stress Indicator during Video-mediated Collaboration Chiew Seng Sean Tan, Kris Luyten, Johannes Schöning, Karin Coninx

\section{II Course: COI}

Designing Unbiased Surveys for $\mathrm{HCl}$ Research Hendrik Müller, Aaron Sedley, Elizabeth Ferrall-Nunge

\section{I3AB Course: CHInd-A}

Sampling \& Synthesis: The Two Sides of

Experience Sketching

William Buxton

7I4AB Papers: Social Local Mobile

CHAIR: DAVID K. MCGOOKIN

Let's Do It at My Place Instead? Attitudinal and Behavioral

Study of Privacy in Client-Side Personalization

Alfred Kobsa, Bart P. Knijnenburg, Benjamin Livshits

The Effect of Developer-Specified Explanations for Permission Requests on Smartphone User Behavior Joshua S. Tan, Khanh Nguyen, Michael Theodorides, Heidi Negron-Arroyo, ChristopherThompson, Serge Egelman, David Wagner

Reflection or Action?: How Feedback and Control Affect Location Sharing Decisions

Sameer Patil, Roman Schlegel, Apu Kapadia,Adam J. Lee

Effects of Security Warnings and Instant Gratification Cues on Attitudes toward Mobile Websites

Bo Zhang, Mu Wu, Hyunjin Kang, Eun Go, S. Shyam Sundar

W Social Media Participation and Performance at Work: A Longitudinal Study

N. Sadat Shami, Jeffrey Nichols, Jilin Chen

\section{I5A Special Interest Group}

$\mathrm{HCl}$ in Food Product Innovation

Winyu Chinthammit, Henry Been-Lirn Duh, Jun Rekimoto

\section{B Student Design Competition (Closed Judging)}

Students will present their posters in this closed judging session, for the jury and competitors only.

\section{I6A Panel}

Design Methods for the Future that is NOW: Have Disruptive Technologies Disrupted Our Design Methodologies?

Karen Holtzblatt, Ilpo Koskinen, Janaki Kumar, David Rondeau, John Zimmerman 
7/6B Papers: Coordination and Collaboration

CHAIR: MARK ROUNCEFIELD

The Doing of Doing Stuff: Understanding the Coordination of Social Group-Activities

Richard P. Schuler, Sukeshini A. Grandhi, Julia M. Mayer, Stephen T. Ricken, Quentin Jones

Effects of Implicit Sharing in Collaborative Analysis

Nitesh Goyal, Gilly Leshed, Dan Cosley, Susan R. Fussell

Effects of Simultaneous and Sequential Work Structures on

Distributed Collaborative Interdependent Tasks

Paul André, Robert E. Kraut, Aniket Kittur

Necessary, Unpleasant, and Disempowering: Reputation Management in the Internet Age Allison Woodruff

\section{I7AB alt.chi: Ways of Knowing in $\mathrm{HCl}$}

CHAIR: BARRY BROWN

Running an $\mathrm{HCl}$ Experiment in Multiple Parallel Universes Pierre Dragicevic, Fanny Chevalier, Stephane Huot

Reliability of NIRS-Based BCls: A Placebo-Controlled

Replication and Reanalysis of Brainput

Megan Strait, Cody Canning, Matthias Scheutz

A Path to Understanding the Effects of Algorithm Awareness Kevin Hamilton, Karrie Karahalios, Christian Sandvig, Motahhare Eslami

Building Castles in Quicksand: Blueprint for a

Crowdsourced Study

Arne Renkema-Padmos, Melanie Volkamer, Karen Renaud

\section{HALL G Papers: Watches and Small Devices}

\section{CHAIR: YANG LI}

$\rightleftarrows \rightleftarrows$

Duet: Exploring Joint Interactions on a Smart Phone and a Smart Watch

Xiang 'Anthony' Chen, Tovi Grossman, Daniel J.Wigdor,

George Fitzmaurice

Interaction on the Edge: Offset Sensing for Small Devices lan Oakley, DoYoung Lee

More Than Touch: Understanding How People Use Skin as an Input Surface for Mobile Computing

Martin Weigel, Vikram Mehta, Jürgen Steimle

TouchSense: Expanding Touchscreen Input Vocabulary Using Different Areas of Users' Finger Pads

Da-Yuan Huang, Ming-Chang Tsai,Ying-Chao Tung, Min-Lun Tsai, Yen-Ting Yeh, Liwei Chan, Yi-Ping Hung, Mike Y. Chen

Expanding the Input Expressivity of Smartwatches with Mechanical Pan, Twist, Tilt and Click

Robert Xiao, Gierad Laput, Chris Harrison
7I8AB Papers: The Third Dimension

CHAIR: MARK HANCOCK

The Use of Surrounding Visual Context in Handheld AR:

Device vs. User Perspective Rendering

Klen Copic Pucihar, Paul Coulton, Jason Alexander

Altering Gameplay Behavior Using Stereoscopic 3D

Vision-Based Video Game Design

Jonas Schild, Joseph J. LaViola Jr., Maic Masuch

$\mathbf{W}$ Depth Perception with Gaze-contingent Depth of Field

Michael Mauderer, Simone I. Conte, Miguel A. Nacenta,

Dhanraj Vishwanath

Imperceptible Depth Shifts for Touch Interaction with

Stereoscopic Objects

Dimitar Valkov, Alexander Giesler, Klaus H. Hinrichs

\section{IA Papers: Audio Interaction}

CHAIR: SRIRAM SUBRAMANIAN

SonicExplorer: Fluid Exploration of Audio Parameters

AlexanderT.Adams, Berto Gonzalez, Celine E. Latulipe

The BoomRoom: Mid-air Direct Interaction with Virtual Sound Sources

Jörg Müller, Matthias Geier, Christina Dicke, Sascha Spors

ISSE: An Interactive Source Separation Editor

Nicholas J. Bryan, Gautham J. Mysore, Ge Wang

Evaluation of Hear-Through Sound Localization

Georgios N. Marentakis, Rudolfs Liepins

80 IB Papers: Sustainability and Everyday Practices

CHAIR: MIKE HAZAS

Performativity in Sustainable Interaction: The Case of Seasonal Grocery Shopping in EcoFriends Maria Normark, Jakob Tholander

Negotiating Food Waste: Using a Practice Lens to Inform Design

Eva Ganglbauer, Geraldine Fitzpatrick, Rob Comber

Walking and the Social Life of Solar Charging in Rural Africa Nicola J. Bidwell, Masbulele Siya, Gary Marsden, William D. Tucker, M. Tshemese, N. Gaven, S. Ntlangano, Simon Robinson, Kristen A. Eglinton

Practices as a Unit of Design: An Exploration of Theoretical Guidelines in a Study on Bathing Lenneke Kuijer, Annelise M. de Jong, Daan Van Eijk

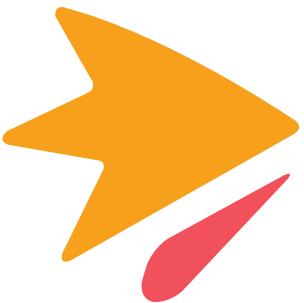

12:20 - 14:00

Lunch Break

Restaurants, bars

\& cafés available nearby 
70IA Papers: Studying Online Communities CHAIR: ROGERIO DE PAULA

The Impact of Membership Overlap on the Survival of Online Communities

Haiyi Zhu, Robert E. Kraut, Aniket Kittur

Goals and Perceived Success of Online Enterprise Communities: What Is Important to Leaders \& Members? Tara L. Matthews, jilin Chen, Steve Whittaker, Aditya Pal, Haiyi Zhu, Hernan Badenes, Barton Smith

Selecting an Effective Niche: An Ecological View of the Success of Online Communities

Haiyi Zhu, jilin Chen, Tara L. Matthews, Aditya Pal, Hernan Badenes, Robert E. Kraut

Snuggle: Designing for Efficient Socialization and Ideological Critique

Aaron Halfaker, R.Stuart Geiger, Loren G. Terveen

70 IB Special: Social Impact Award: Richard Ladner CHAIR: JEFFREY P.BIGHAM

Design for User Empowerment

\section{Course: C04-I}

HTML5 Game Development Jim Parker

\section{7| Course: C05-I}

Empirical Research Methods for

Human-Computer Interaction

I. Scott MacKenzie, Steven Castellucci

\section{7|3AB Course: C02-I}

Introduction to Human-Computer Interaction

Jonathan Lazar, Simone Barbosa

\section{7| $4 A B$ Papers: Image and Animation Authoring}

CHAIR: TOMER MOSCOVICH

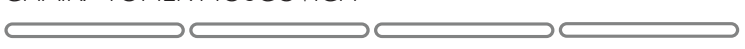

Offline Painted Media for Digital Animation Authoring Makoto Nakajima, Daisuke Sakamoto, Takeo Igarashi

Supporting Informal Design with Interactive Whiteboards Nicolas Mangano, Thomas D. LaToza, Marian Petre, André van der Hoek Juxtapoze: Supporting Serendipity and Creative Expression in Clipart Compositions

William Benjamin, Senthil Chandrasegaran, Devarajan Ramanujan, Niklas L. Elmqvist, S. V. N. Vishwanathan, Karthik Ramani

Draco: Bringing Life to Illustrations with Kinetic Textures

U Rubaiat Habib Kazi, Fanny Chevalier, Tovi Grossman, Shengdong Zhao,

$\$$ George Fitzmaurice
7I5A Special Interest Group

Art and Interaction SIG: Cataloging The

Digital Arts

David England, Jocelyn Spence, Celine Latulipe, ernest edmonds, Linda Candy, Thecla Schiphorst, Nick Bryan-Kinns, Kirk Woolford

\section{I6A Panel}

Designing for the Experiential Body

Helena Mentis, Kristina Höök, Florian Mueller, Katherine Isbister, George Poonkhin Khut, Toni Robertson

7 I6B Papers: Studying and Designing Gameplay CHAIR: CARL GUTWIN

A User Study of Different Gameplay Visualizations Simone Kriglstein, Günter Wallner, Margit Pohl

The Influence of Controllers on Immersion in Mobile Games Paul Cairns, ling Li, Wendy Wang, A. Imran Nordin

Combining Think-aloud and Physiological Data to Understand Video Game Experiences Chek Tien Tan, Tuck W. Leong, Songjia Shen

The MOY Framework for Collaborative Play Design in Integrated Shared and Private Interactive Spaces Wooi Boon Goh, Ming Chen, Cuong H. Trinh, Jacquelyn Tan, Wei Shou

\section{7/7AB alt.chi: Understanding Interactions}

CHAIR: DANIELA ROSNER

Mining Online Software Tutorials: Challenges and Open Problems

Adam Fourney, Michael Terry

$\mathrm{HCl}$ Over Multiple Screens

Andy Brown, Michael Evans, Caroline Jay, Maxine Glancy, Rhianne Jones, Simon Harper

A Funny Thing Happened OnThe WayTo The Website: Telling About Browsing John P. Fass

Translation from Text to Touch -Touching a "Japanese OldTale" yasuhiro suzuki, Rleko Suzuki, Junji Watanabe 
HALL G Papers: Force Input and Haptic Feedback

CHAIR: IAN OAKLEY

Transient and Transitional States: Pressure as an Auxiliary Input Modality for Bimanual Interaction

Ross McLachlan, Daniel Boland, Stephen A. Brewster

VacuumTouch: Attractive Force Feedback Interface for Haptic Interactive Surface using Air Suction

Taku Hachisu, masaaki fukumoto

Expressive Touch: Studying Tapping Force on Tabletops

Esben W. Pedersen, Kasper Hornbæk

Presstures: Exploring Pressure-Sensitive Multi-Touch Gestures on Trackpads

Christian Rendl, Patrick Greindl, Kathrin Probst, Martin Behrens, Michael Haller

Gaze Gestures and Haptic Feedback in Mobile Devices Jari Kangas, Deepak Akkil, Jussi Rantala, Poika M. Isokoski, Päivi H. Majaranta, Roope Raisamo

\section{7/8AB Papers: Hackerspaces, Making and Breaking}

CHAIR: MANFREDTSCHELIG

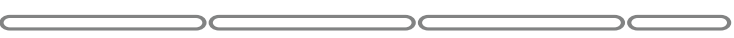

STP Emerging Sites of $\mathrm{HCl}$ Innovation: Hackerspaces, Hardware Startups \& Incubators

Silvia Lindtner, Garnet D. Hertz, Paul Dourish

Breakdown, Obsolescence and Reuse:

$\mathrm{HCl}$ and The Art of Repair

Steven J. Jackson, Laewoo Kang

Q Printing Teddy Bears: A Technique for 3D Printing of Soft Interactive Objects

Scott E. Hudson

Taking Things Apart: Reaching Common Ground and Shared Material Understanding

Martin Murer, Mattias Jacobsson, Siri Skillgate, Petra Sundström

"Now That's Definitely a Proper Hack": Self-Made Tools in Hackerspaces

Jeffrey Bardzell, Shaowen Bardzell, Austin L. Toombs

\section{A Papers: Activity Recognition}

CHAIR: DANIELA BUSSE

Toss 'N'Turn: Smartphone as Sleep and Sleep Quality Detector

Jun-Ki Min, Afsaneh Doryab, Jason Wiese, Shahriyar Amini, John Zimmerman, Jason I. Hong

Persuasive Technology in the Real World: A Study of Long-Term Use of Activity Sensing Devices for Fitness Thomas Fritz, Elaine M. Huang, Gail C. Murphy, Thomas Zimmermann

Complex Activity Recognition Using Context Driven Activity Theory and Activity Signatures

Saguna Saguna,Arkady Zaslavsky, Dipanjan Chakraborty

Predictors of Life Satisfaction Based on Daily Activities from Mobile Sensor Data

OnurYürüten, liyong Zhang, Pearl H. Pu

80 I B Papers: Managing Income

CHAIR: SARITAY.SCHOENEBECK

Q Pay or Delay: The Role of Technology When Managing a Low Income

John Vines, Paul Dunphy, Andrew F. Monk

Poverty on the Cheap: Estimating Poverty Maps Using Aggregated Mobile Communication Networks Christopher Smith-Clarke, Afra Mashhadi, Licia Capra

Money Talks: Tracking Personal Finances

Joseph 'Jofish' Kaye, Mary McCuistion, Rebecca Gulotta David A. Shamma

Fostering Social Capital in Economically Distressed Communities

Tawanna R. Dillahunt

\section{AB Course: C03-I}

Methods of Design Synthesis - Moving from Data to Innovation

Jon Kolko
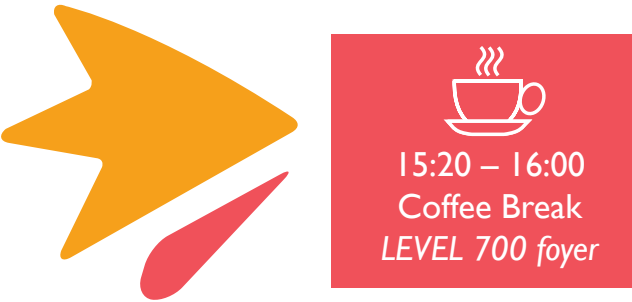
70IA Papers: Designing and Understanding Visualizations CHAIR: PETRA ISENBERG

Automatic Generation of Semantic Icon Encodings forVisualizations

Vidya Setlur, Jock D. Mackinlay

Task-Driven Evaluation of Aggregation in Time

Series Visualization

Danielle Albers, Michael A. Correll, Michael Gleicher

Dive In! Enabling Progressive Loading for Real-Time

Navigation of Data Visualizations

Michael Glueck, Azam Khan, Daniel J. Wigdor

Sample-Oriented Task-Driven Visualizations: Allowing Users to Make Better, More Confident Decisions

Nivan R. Ferreira, Danyel Fisher, Arnd Christian Konig

\section{I B Papers: Crowdfunding and Crowd Storage}

CHAIR: MICHAEL MULLER

Learning to Fail: Experiencing Public Failure Online

Through Crowdfunding

Michael D. Greenberg, Elizabeth M. Gerber

Crowdfunding: Motivations and Deterrents for Participation Elizabeth M. Gerber, Julie S. Hui

Show Me the Money! An Analysis of Project Updates during Crowdfunding Campaigns

Anbang Xu, Xiao Yang, Huaming Rao, Wai-Tat Fu, Shih-Wen Huang Brian P. Bailey

Crowd Storage: Storing Information on Existing Memories Jeffrey P. Bigham, Walter S. Lasecki

709 Course: C04-2

HTML5 Game Development

Jim Parker

7| Course: C05-2

Empirical Research Methods for

Human-Computer Interaction

I. Scott MacKenzie, Steven Castellucci
7I3AB Course: C02-2

Introduction to Human-Computer Interaction

Jonathan Lazar, Simone Barbosa

7I 4AB Papers: Novel Approaches to Navigation

CHAIR: YUICHIROTAKEUCHI

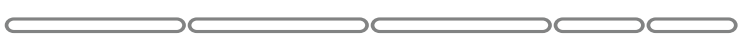

Walk this Way: Musically Guided Walking Experiences Adrian Hazzard, Steve Benford, Gary E. Burnett

Simplifying Orientation Measurement for Mobile Audio Augmented Reality Applications

Florian Heller, Aaron Krämer, Jan O. Borchers

Gifting Personal Interpretations in Galleries

Lesley Fosh, Steve Benford, Stuart Reeves, Boriana Koleva

W Visual Recognition in Museum Guide Apps:

Do Visitors Want It?

Leonard Wein

A Billion Signposts: Repurposing Barcodes for Indoor Navigation

Simon Robinson, Jennifer S. Pearson, Matt Jones

\section{I6A Panel}

Electronic Privacy and Surveillance

Juan Pablo Hourcade, Ann Cavoukian, Ronald Deibert, Lorrie Cranor, lan Goldberg

\section{7/6B Papers: Interfaces for Care and Support} CHAIR: JESPER KJELDSKOV

W Taking Part: Role-play in the Design of Therapeutic Systems Mark Matthews, Geri Gay, Gavin Doherty

Staccato Social Support in Mobile Health Applications Phil Adams, Eric P. Baumer, Geri Gay

W My Journey Compass: A Preliminary Investigation of a Mobile Tool for Cancer Patients

Maia L. Jacobs, James Clawson, Elizabeth D. Mynatt

An Assistive Robotic Table for Older and Post-Stroke Adults: Results from Participatory Design and Evaluation Activities with Clinical Staff

Anthony L. Threatt, Jessica Merino, Keith E. Green, Johnell O. Brooks, lan Walker, Stan Healy 
7/7AB Papers: Research through Design

CHAIR: CHRISTINA SATCHELL

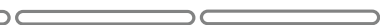

Experience Design Theatre: Exploring the Role of Live Theatre in Scaffolding Design Dialogues

John Vines, Tess Denman-Cleaver, Paul Dunphy, Peter C. Wright, Patrick Olivier

Non-Finito Products: A New Design Space of User Creativity for Personal User Experience

Jin-min Seok, Jong-bum Woo, Youn-kyung Lim

Q Research Through Design Fiction: Narrative in Real and Imaginary Abstracts

Mark A. Blythe

Q Research on Research: Design Research at the Margins: Academia, Industry and End-Users

Juri Dachtera, Dave Randall, Volker Wulf

HALL G Papers: Pointing and Cursors

CHAIR: POURANG P.IRANI

Impact of Form Factors and Input Conditions on Absolute Indirect-Touch Pointing Tasks

Jérémie Gilliot, Géry Casiez, Nicolas Rousse

Beating the Bubble: Using Kinematic Triggering in the Bubble Lens for Acquiring Small, Dense Targets

Martez E. Mott, Jacob O. Wobbrock

Mouse Pointing Endpoint Prediction Using Kinematic

Template Matching

Phillip T. Pasqual, Jacob O. Wobbrock

The Implicit Fan Cursor: A Velocity Dependent Area Cursor Xiaojun Su, Oscar Kin-Chung Au, Rynson W. Lau

7I8AB Papers: Always Connected: Email and Social Media

CHAIR: SVETLANAYAROSH

The Product of Availability: Understanding the Economic Underpinnings of Constant Connectivity

Melissa Mazmanian, Ingrid Erickson

Giving up Twitter for Lent: How and Why We Take Breaks from Social Media

SaritaY. Schoenebeck

U MinEMail: SMS Alert System for Managing Critical Emails Kyle Rector, Joshua M. Hailpern

Overload is Overloaded: Email in the Age of Gmail

Catherine Grevet, David Choi, Debra Kumar, Eric Gilbert
80IA Papers: Smart Homes and Sustainability

CHAIR: RONWAKKARY

Practical Trigger-Action Programming in the Smart Home Blase Ur, Elyse McManus, Melwyn Pak Yong Ho, Michael L. Littman

Doing the Laundry with Agents: A Field Trial of a Future Smart Energy System in the Home

Enrico Costanza, Joel E. Fischer, James A. Colley, Tom A. Rodden, Sarvapali D. Ramchurn, Nicholas R. Jennings

ST] Making Sustainability Sustainable: Challenges in the Design of Eco-Interaction Technologies

Rayoung Yang, Mark W. Newman, Jodi L. Forlizzi

Exploring Sustainable Practices in Workplace Settings through Visualizing Electricity Consumption

Cecilia Katzeff, Loove Broms, Li Jönsson, Ulrika Westholm,

Minna Räsänen

80IB Papers: Multilingual Communication

CHAIR: HAO-CHUANWANG

Global Connectivity and Multilinguals in the Twitter Network Scott A. Hale

Effects of Public vs. Private Automated Transcripts on Multiparty Communication between Native and Non-Native English Speakers

Ge Gao, Naomi Yamashita, Ari M. Hautasaari, Andy Echenique, Susan R. Fussell

Smart Subtitles for Vocabulary Learning

Geza Kovacs, Robert C. Miller

Using Annotations in Online Group Chats

Na Li, Mary Beth Rosson

\section{AB Course: $\mathrm{C} 03-2$}

Methods of Design Synthesis - Moving from Data to Innovation

Jon Kolko 
7:00 - 8:20 Video Previews $\quad$ Exhibit Hall G

$8: 30-8: 50 \quad \begin{aligned} & \text { Exhibit Hall G } \\ & \text { Provoke! Wisdom! Impact! Plenary - Big } \\ & \text { Nathan Eagle, Jana Mobile, Inc. }\end{aligned}$
70IA $\quad$ Papers: Interactive Visualization and Visual Elements

Visualizing Dynamic Networks with Matrix Cubes Benjamin Bach, Emmanuel Pietriga, Jean-Daniel Fekete

A Table! Improving Temporal Navigation in Soccer Ranking Tables

Charles Perin, Romain Vuillemot, Jean-Daniel Fekete

Q Kinetica: Naturalistic Multi-touch Data Visualization Jeffrey M. Rzeszotarski, Aniket Kittur

Traffigram: Distortion for Clarification via Isochronal Cartography

Sungsoo (Ray) Hong, Yea-Seul Kim, Jong-Chul Yoon, Cecilia R. Aragon

70 IB Papers: Understanding and Designing Games

CHAIR: LENNART NACKE

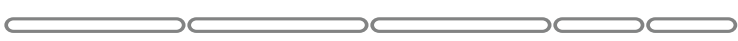

Understanding Procedural Content Generation:

A Design-Centric Analysis of the Role of PCG in Games Gillian Smith

A Systematic Review of Quantitative Studies on the Enjoyment of Digital Entertainment Games

Elisa D. Mekler, Julia A. Bopp, Alexandre N. Tuch, Klaus Opwis

The Effectiveness (or LackThereof) of Aim-Assist Techniques in First-Person Shooter Games

Rodrigo Vicencio-Moreira, Regan L. Mandryk, Carl Gutwin, Scott Bateman

Design Tactics for Authentic Interactive Fiction: Insights from Alternate Reality Game Designers

Elizabeth M. Bonsignore, Vicki Moulder, Carman Neustaedter,

Derek L. Hansen, kari kraus, Allison Druin

Jump and Shoot! - Prioritizing Primary and Alternative Body Gestures for Intense Gameplay

Chaklam Silpasuwanchai, Xiangshi Ren

709 Course: C06

Improving the User Interface for People with Disabilities Terrill Thompson

\section{II Course: C08}

Multimodal Detection of Affective States: A Roadmap through Diverse Technologies

Javier Gonzalez-Sanchez, Maria Elena Chavez-Echeagaray, Robert Atkinson, Winslow Burleson

7I3AB Course: CHInd-F

What $\mathrm{HCl}$ Can Do for Citizen Science

Jennifer Preece, Anne Bowser

$\begin{array}{lll}\text { WIP Posters Rotation I } & \text { Exhibit Hall E } & \text { List on page } 58 \\ \text { Doctoral Consortium } & \text { Exhibit Hall E } & \text { List on page } 54\end{array}$
7I4AB Papers: Personal Values and Preferences

CHAIR: KATHARINA REINECKE

KnowMe and ShareMe: Understanding Automatically Discovered Personality Traits from Social Media and User Sharing Preferences

Liang Gou, Michelle X. Zhou, Huahai Yang

Faces Engage Us: Photos with Faces Attract More Likes and Comments on Instagram

Saeideh Bakhshi, David A. Shamma, Eric Gilbert

Photo Sharing of the Subject, by the Owner, for the Viewer Examining the Subject's Preference

Auk Kim, Gahgene Gweon

Does Content Determine Information Popularity in Social Media? A Case Study of YouTube Videos' Content and their Popularity

Flavio Figueiredo, Jussara M. Almeida, Fabrício Benevenuto, Krishna P. Gummadi

You Read What You Value: Understanding Personal Values and Reading Interests

Gary Hsieh, Jilin Chen, Jalal U. Mahmud, Jeffrey Nichols

Gaining Empathy for Non-Routine Mobile Device Use through Autoethnography

Aisling Ann O'Kane, Yvonne Rogers, Ann E. Blandford

\section{I5A Special Interest Group}

Current Issues in Assessing and Improving Information Usability Stephanie Rosenbaum, Judith Ramey

\section{A Papers: Enabling Interactive Performances}

CHAIR: CLAIRE O'MALLEY

Designing For Movement: Evaluating Computational Models Using LMA Effort Qualities

Diego Silang Maranan, Sarah Fdili Alaoui, Thecla Schiphorst, Philippe Pasquier, Pattarawut Subyen, Lyn Bartram

The Vocal Chorder - Empowering Opera Singers with a Large Interactive Instrument

Carl E. Unander-Scharin, Åsa J. Unander-Scharin, Kristina Höök

Let Me Catch This! Experiencing Interactive 3D Cinema through Collecting Content with a Mobile Phone Jonna R. Häkkilä, Maaret Posti, Stefan Schneegass, Florian Alt, Kunter Gultekin, Albrecht Schmidt

Coding Livecoding

Benjamin Swift, Andrew Sorensen, Michael Martin, Henry J. Gardner

Exploring Percussive Gesture on iPads with

Ensemble Metatone

Charles Martin, Henry J. Gardner, Ben Swift 
7/6B Papers: Battery Life and Energy Harvesting

CHAIR: NICHOLAS CHEN

How Carat Affects User Behavior: Implications for Mobile Battery Awareness Applications

Kumaripaba M. Athukorala, Eemil Lagerspetz, Maria H. von Kügelgen, Antti Jylhä,Adam J. Oliner, Sasu Tarkoma, Giulio Jacucci

EnergyBugs: Energy Harvesting Wearables for Children

Kimiko Ryokai, Peiqi Su, Eungchan Kim, Bob Rollins

OJAS - Open Source Bi-Directional Inductive Power Link Jussi V. Mikkonen, Ramyah Gowrishankar, Miia Oksanen, Harri Raittinen, Arto Kolinummi

Using Asymmetric Cores to Reduce Power Consumption for Interactive Devices with Bi-stable Displays

Jaeyeon Kihm, François V. Guimbretière, Julia Karl, Rajit Manohar

\section{I7AB alt.chi: Ways of Creating in $\mathrm{HCl}$}

CHAIR: SILVIA LINDTNER

Abba-Dabba-Ooga-Booga-Hoojee-Goojee-Yabba-Dabba-Doo: Stupidity, Ignorance \& Nonsense as Tools for Nurturing

Creative Thinking

Dimitris Grammenos

Gamified Co-design with Cooperative Learning

Gabriella Dodero, Rosella Gennari,Alessandra Melonio, Santina Torello

Teaching Digital Craft

Michael Nitsche, Andrew Quitmeyer, Kate Farina, Samuel Zwaan Hye Yeon Nam

Designing for the Internet of Things: Prototyping

Material Interactions

Tom Jenkins, lan Bogost

\section{HALL G Papers: Mid-Air Gestures}

CHAIR: SHAHRAM IZADI

Consumed Endurance: A Metric to Quantify Arm Fatigue of Mid-Air Interactions

Juan David Hincapié-Ramos, Xiang Guo, Paymahn Moghadasian, Pourang P. Irani

9ार

Vulture: A Mid-AirWord-Gesture Keyboard

Anders Markussen, Mikkel R. Jakobsen, Kasper Hornbaek

Understanding Finger Input Above Desktop Devices Chat Wacharamanotham, Kashyap Todi, Marty Pye, Jan O. Borchers

Exploring the Usefulness of Finger-Based 3D Gesture Menu Selection

Arun Kulshreshth, Joseph J. LaViola Jr.
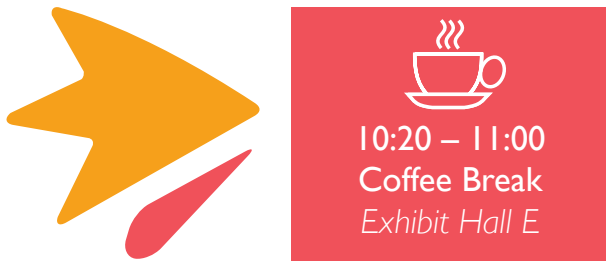

7I8AB Papers: Touch and Stylus Interaction

CHAIR: XIANG CAO

In the Blink of an Eye: Investigating Latency Perception during Stylus Interaction

Albert Ng, Michelle K. Annett, Paul Dietz, Anoop Gupta, Walter F. Bischof

Pinch-Drag-Flick vs. Spatial Input: Rethinking Zoom \&

Pan on Mobile Displays

Martin Spindler, Martin Schuessler, Marcel Martsch, Raimund Dachselt

InkAnchor: Enhancing Informal Ink-Based Note Taking on

Touchscreen Mobile Phones

Yi Ren, Yang Li, Edward Lank

Perception of Ultrasonic Haptic Feedback on the Hand: Localisation and Apparent Motion

Graham Wilson, Thomas Carter, Sriram Subramanian,

Stephen A. Brewster

\section{IA Papers: Quantified Self}

CHAIR: JOHN ZIMMERMAN

Health Mashups: Presenting Statistical Patterns Between Wellbeing Data and Context in Natural Language to Promote Behavior Change

Frank R. Bentley, Konrad Tollmar, Peter Stephenson, Laura M. Levy Brian Jones, Scott L. Robertson, Ed Price, Richard Catrambone, Jeffrey B. Wilson

U Understanding Quantified-Selfers' Practices in Collecting and Exploring Personal Data

Eun Kyoung Choe, Nicole B. Lee, Bongshin Lee, Wanda Pratt, Julie A. Kientz

BodyDiagrams: Improving Communication of Pain Symptoms through Drawing

Amy Jang, Diana L. MacLean, Jeffrey Heer

$\mathbf{Q}$ Personal Tracking as Lived Informatics

John Rooksby, Mattias Rost, Alistair Morrison, Matthew C. Chalmers

\section{I B Papers: Sustainability Perspectives}

CHAIR: ELAINE M. HUANG

Uncovering Practices of Making Energy Consumption Accountable: A Phenomenological Inquiry

Tobias Schwartz, Gunnar Stevens, Leonardo Ramirez, Volker Wulf

Applying the Lens of Sensory Ethnography to Sustainable HCl Sarah Pink, Kerstin Leder Mackley, Val Mitchell, Marcus Hanratty, Carolina Escobar-Tello, Tracy Bhamra, Roxana Morosanu

Towards an Holistic View of the Energy and Environmental Impacts of Domestic Media and IT

Oliver Bates, Mike Hazas, Adrian Friday, Janine Morley, Adrian K. Clear

SIf Beyond Ethnography: Engagement and Reciprocity as Foundations for Design Research Out Here

Margot Brereton, Paul Roe, Ronald Schroeter, Anita Lee Hong

\section{AB Course: $\mathrm{C} 07$}

Card Sorting for Navigation Design

William Hudson 
70IA Papers: Navigating Video

CHAIR: KRZYSZTOF Z. GAJOS

Visualization of Personal History for Video Navigation

Abir Al-Hajri, Gregor Miller, Matthew Fong, Sidney S. Fels

W WaaZam! Supporting Creative Play at a Distance in

8 Customized Video Environments

Seth E. Hunter, Pattie Maes, Anthony Tang, Kori M. Inkpen,

Susan M. Hessey

LACES: Live Authoring through Compositing and Editing of Streaming Video

Dustin E. Freeman, Stephanie Santosa, Fanny Chevalier,

Ravin Balakrishnan, Karan Singh

ThumbReels: Query Sensitive Web Video Previews Based on Temporal, Crowdsourced, Semantic Tagging

Barnaby Craggs, Myles Kilgallon Scott, Jason Alexander

$\Phi$

Panopticon as an eLearning Support Search Tool

James Nicholson, Mark Huber, Daniel Jackson, Patrick Olivier

\section{IB Papers: Crowds and Creativity}

\section{CHAIR: LILLY IRANI}
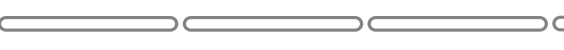

Searching for Analogical Ideas with Crowds

Lixiu Yu, Aniket Kittur, Robert E. Kraut

skWiki: A Multimedia Sketching System for

Collaborative Creativity

Zhenpeng Zhao, Sriram Karthik Badam, Senthil Chandrasegaran,

Deok Gun Park, Niklas L. Elmqvist, Lorraine Kisselburgh, Karthik Ramani

W Distributed Analogical Idea Generation:

Inventing with Crowds

Lixiu Yu, Aniket Kittur, Robert E. Kraut

W Frenzy: Collaborative Data Organization for Creating Conference Sessions

Lydia B. Chilton, Juho Kim, Paul André, Felicia Cordeiro, James A. Landay, Daniel S. Weld, Steven P. Dow, Robert C. Miller, Haoqi Zhang

\section{Course: $\mathrm{CO6}$}

Improving the User Interface for People with Disabilities Terrill Thompson

\section{II Course: C08}

Multimodal Detection of Affective States: A Roadmap through Diverse Technologies

Javier Gonzalez-Sanchez, Maria Elena Chavez-Echeagaray,

Robert Atkinson, Winslow Burleson

\section{7|3AB Course: CHInd-C}

Reflections on Design

Don Norman
7 I AAB Papers: Interacting with the Web

CHAIR: JENNIFER GOLBECK

End-Users Publishing Structured Information on the Web: An Observational Study of What, Why, and How

Edward O. Benson, David R. Karger

Predicting Whether Users View Dynamic Content on the World Wide Web

Caroline Jay, Andy Brown, Simon Harper

Designing Usable Web Forms - Empirical Evaluation of Web Form Improvement Guidelines

Mirjam Seckler, Silvia Heinz, Javier A. Bargas-Avila, Klaus Opwis, Alexandre N.Tuch

Choice Overload in Search Engine Use?

Pawitra Chiravirakul, Stephen J. Payne

\section{I5A Special Interest Group}

Games and Entertainment Community SIG:

Reaching beyond $\mathrm{CHI}$

Lennart Nacke, Pejman Mirza-Babaei, Magy Seif El-Nasr,

Heather Desurvire, Regina Bernhaupt

\section{7/6A Papers: Music, Dance, and Television}

CHAIR: MARKA. BLYTHE

Coming in from the Margins: Amateur Musicians in the Online Age

Michaela Hoare, Steve Benford, Rachel Jones, Natasa Milic-Frayling

Watching the Footwork: Second Screen Interaction at a

Dance and Music Performance

Louise Barkhuus, Arvid Engström, Goranka Zoric

Streaming on Twitch: Fostering Participatory Communities of Play within Live Mixed Media

William A. Hamilton, Oliver Garretson, Andruid Kerne

Long Tail TV Revisited: From Ordinary Camera Phone Use to Pro-Am Video Production

Oskar Juhlin, Arvid Engström, Elin Önnevall

\section{I6B Papers: Social Media and Health}

CHAIR: M.C. SCHRAEFEL

Estimating County Health Statistics with Twitter Aron Culotta

Unraveling Abstinence and Relapse: Smoking Cessation Reflected in Social Media

Elizabeth L. Murnane, Scott Counts

Weaving Clinical Expertise in Online Health Communities Jina Huh, Wanda Pratt

Seeking and Sharing Health Information Online: Comparing Search Engines and Social Media

Munmun De Choudhury, Meredith R. Morris, Ryen W. White 
7/7AB alt.chi: Limits and Futures

CHAIR: MORGAN AMES

Never Mind the Bollocks, I Wanna Be AnarCHI:

A Manifesto for Punk HC

Conor Linehan, Ben Kirman

None of a CHlnd: Relationship Counselling for $\mathrm{HCl}$ and Speech Technology

Matthew P.Aylett, Per O. Kristensson, Steve Whittaker,Yolanda Vazquez-Alvarez

CHI 2039: Speculative Research Visions

Eric P. Baumer, June Ahn, Mei Bie, Elizabeth M. Bonsignore,Ahmet Börütecene, Oğuz Turan Buruk, Tamara Clegg, Allison Druin, Florian Echtler, Dan Gruen,

Mona Leigh Guha, Chelsea Hordatt, Antonio Kü̈ger, shachar maidenbaum, Meethu Malu, Brenna McNally, Michael Muller, Leyla Norooz, Juliet Norton, Oguzhan Ozcan, Donald J. Patterson, Andreas Riener, Steven I. Ross, Karen Rust, Johannes Schöning, M. S. Silberman, Bill Tomlinson, Jason Yip

The Minimal Effective Dose of ReminderTechnology Maria K. Wolters

\section{HALL G Papers: On and Above the Surface}

CHAIR: NADIR WEIBEL

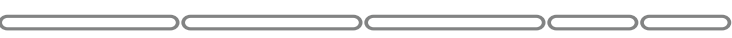

RetroDepth: 3D Silhouette Sensing for High-Precision Input On and Above Physical Surfaces

David Kim, Shahram Izadi, Jakub Dostal, Christoph Rhemann, Cem Keskin, Christopher Zach, Jamie Shotton, Timothy Large, Steven Bathiche, Matthias Niessner, D. Alex Butler, Sean R. Fanello, Vivek Pradeep

SurfaceLink: Using Inertial and Acoustic Sensing to Enable Multi-Device Interaction on a Surface

Mayank Goel, Brendan Lee, Md. Tanvir Islam Aumi, Shwetak N. Patel, Gaetano Borriello, Stacie Hibino, Bo Begole

Comparing Flat and Spherical Displays in a Trust Scenario in Avatar-Mediated Interaction

Ye Pan, William Steptoe, Anthony Steed

PrintSense: A Versatile Sensing Technique to Support Multimodal Flexible Surface Interaction

Nan-Wei Gong, Jürgen Steimle, Simon Olberding, Steve Hodges, Nicholas E. Gillian, Yoshihiro Kawahara, Joseph A. Paradiso

Let's Kick It: How to Stop Wasting the Bottom Third of Your Large Screen Display

Ricardo Jota, Pedro Lopes, Daniel J. Wigdor, Joaquim A. Jorge

7 I 8 AB Papers: Interactive Whiteboards and Public Displays

CHAIR: ANDREAS BUTZ

Communiplay: A Field Study of a Public Display Mediaspace Jörg Müller, Dieter Eberle, Konrad Tollmar

P-LAYERS - A Layered Framework Addressing the Multi-faceted Issues Facing Community-supporting Public Display Deployments

Nemanja Memarovic, Marc Langheinrich, Keith W. Cheverst, Nick Taylor, Florian Alt

Posting for Community and Culture: Considerations for the Design of Interactive Digital Bulletin Boards

Claude Fortin, Carman Neustaedter, Kate Hennessy

I Can Wait a Minute: Uncovering the Optimal DelayTime for Pre-Moderated User-Generated Content on Public Displays Miriam Greis, Florian Alt, Niels Henze, Nemanja Memarovic
80IA Papers: Human-Robot Interaction

CHAIR: WENDY JU

Design Patterns for Exploring and Prototyping

Human-Robot Interactions

Allison Sauppé, Bilge Mutlu

Improving Social Presence in Human-Agent Interaction André T. Pereira, Rui Prada, Ana Paiva

Robot Gestures Make Difficult Tasks Easier: The Impact of Gestures on Perceived Workload and Task Performance Manja Lohse, Reinier Rothuis, Jorge Gallego-Perez, Daphne E. Karreman, Vanessa Evers

Measuring Operator Anticipatory Inputs in Response to Time-delay forTeleoperated Human-robot Interfaces Jonathan Bidwell, Alexandra Holloway, Scott Davidoff

Stay on the Boundary: Artifact Analysis Exploring Researcher and User Framing of Robot Design HEE RIN LEE, Selma Sabanovic, Erik Stolterman

\section{I B Papers: Emergency Response}

CHAIR: LORRIE F. CRANOR

Help Beacons: Design and Evaluation of an Ad-Hoc Lightweight S.O.S. System for Smartphones

Amro Al-Akkad, Leonardo Ramirez, Alexander Boden, Dave Randall, Andreas Zimmermann

Upvoting Hurricane Sandy: Event-Based News Production Processes on a Social News Site

Alex Leavitt, Joshua A. Clark

Online Public Communications by Police \& Fire Services during the 2012 Hurricane Sandy

Amanda L. L. Hughes, Lise A. A. St. Denis, Leysia Palen, Kenneth M.M.Anderson

EmergencyMessenger: A Text Based Communication Concept for Indoor Firefighting

Matthias Betz, VolkerWulf

\section{AB Course: C07}

Card Sorting for Navigation Design

William Hudson
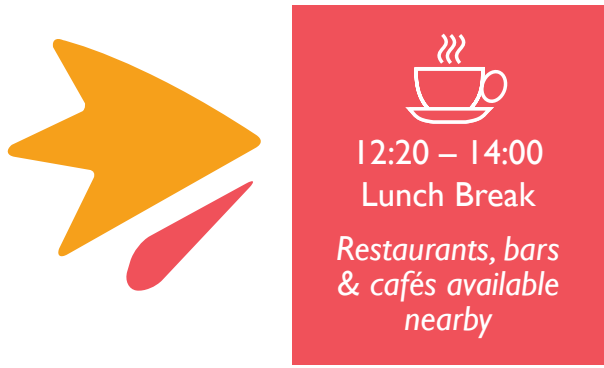


\section{TUESDAY | 4:00 - 15:20}

70IA Papers: Sensemaking and Information in Use CHAIR: JEFFREY P.BIGHAM

Odin: Contextual Document Opinions on the Go Joshua M. Hailpern, Bernardo A. Huberman

Monadic Exploration: Seeing the Whole through Its Parts Marian Dörk, Rob Comber, Martyn Dade-Robertson

Photographing Information Needs: The Role of Photos in Experience Sampling Method-Style Research

Zhen Yue, Eden Litt, Carrie J. Cai, Jeff Stern, Kathy K. Baxter, Zhiwei Guan, Nikhil Sharma, Guangqiang (George) Zhang

Design Insights for the Next Wave Ontology Authoring Tools Markel Vigo, Caroline Jay, Robert Stevens

The Role of Interactive Biclusters in Sensemaking Maoyuan Sun, Lauren Bradel, Chris L. North, Naren Ramakrishnan

70 I B Lifetime Research Award: Steve Whittaker CHAIR: JUDITH OLSON

Technology and Memory: From Lifelogging to Strategic Reminiscence

\section{Course: C09}

Conceptual Models: Core to Good Design

JeffJohnson

\section{II Course: CII}

Online A/B Tests \& Experiments: A Practical But Scientifically Informed Introduction

Joseph Williams, Betsy Williams

\section{I3AB Course: $\mathrm{CI} 2$}

Mobile $\mathrm{HCl}$

Niels Henze, Enrico Rukzio

7| 4AB Papers: Presentation Technologies

CHAIR: SHENGDONG ZHAO

SmartVoice: A Presentation Support System for

Overcoming the Language Barrier

Xiang Li, Jun Rekimoto

PitchPerfect: Integrated Rehearsal Environment for

$\mathbf{U}$ Structured Presentation Preparation

HaTrinh, Koji Yatani, Darren Edge

DemoWiz: Re-Performing Software Demonstrations for a

Live Presentation

Pei-Yu Chi, Bongshin Lee, Steven M. Drucker

TurningPoint: Narrative-Driven Presentation Planning

Q Larissa Pschetz, Koji Yatani, Darren Edge
7I5A Special Interest Group

Interaction Science SIG: Overcoming Challenges

Andrew Howes, Benjamin Cowan, Christian Janssen, Anna Cox, Paul Cairns, Anthony Hornof, Stephen Payne, Peter Pirolli

\section{I6A Panel}

Opportunities and Risks of Discovering Personality Traits from Social Media

Michelle Zhou, Jeffrey Nichols, Tom Dignan, Steve Lohr, Jennifer Golbeck, James Pennebaker

7I6B Papers: Personal Health and Wellbeing

CHAIR: JINA HUH

U Supporting Treatment of People Living with HIV / AIDS in Resource Limited Settings with IVRs

Anirudha N. Joshi, Mandar Rane, Debjani Roy, Nagraj Emmadi,

Padma Srinivasan, N. Kumarasamy, Sanjay Pujari, Davidson Solomon, Rashmi Rodrigues, DG Saple, Kamalika Sen, Els Veldeman,

Romain Rutten

Reflection through Design: Immigrant Women's Self-Reflection on Managing Health and Wellness Deana S. Brown, Victoria Ayo, Rebecca E. Grinter

DDF Seeks Same: Sexual Health-Related Language in Online Personal Ads for Men who Have Sex with Men Oliver L. Haimson, Jed R. Brubaker, Gillian R. Hayes

U Support Matching and Satisfaction in an Online Breast

Cancer Support Community

Tatiana A. Vlahovic,Yi-Chia Wang, Robert E. Kraut, John M. Levine

\section{I7AB Papers: Design Theory}

CHAIR: STEVE HARRISON

Between Theory and Practice: Bridging Concepts in $\mathrm{HCl}$ Research

Peter Dalsgaard, Christian Dindler

Evolution of Design Competence in UX Practice Colin M. Gray

Causal Interactions

Adam Darlow, Gideon Goldin, Steven Sloman

Personas is Applicable - A Study on the Use of

Personas In Denmark

Lene Nielsen, Kira Storgaard Hansen 
HALL G Papers: Novel Keyboards

CHAIR: KENT LYONS

GestKeyboard: Enabling Gesture-Based Interaction on Ordinary Physical Keyboard

Haimo Zhang, Yang Li

Q Gesture Script: Recognizing Gestures and Their Structure Using Rendering Scripts and Interactively Trained Parts Hao Lü, James A. Fogarty, Yang Li

9If Type-Hover-Swipe in 96 Bytes: A Motion Sensing Mechanical Keyboard

Stuart A. Taylor, Cem Keskin, Otmar Hilliges, Shahram Izadi, John Helmes

काp

B\#: Chord-based Correction for Multitouch Braille Input

Hugo Nicolau, Kyle Montague, Tiago Guerreiro, João Guerreiro, Vicki L. Hanson

Representatively Memorable: Sampling the Right Phrase Set to Get the Text Entry Experiment Right

Luis A. Leiva, Germán Sanchis-Trilles

\section{I8AB Papers: DIY and Hacking}

CHAIR: KASPER HORNBAEK

Sketching in Circuits: Designing and Building Electronics on Paper

Jie Qi, Leah Buechley

Do-lt-Yourself Cellphones: An Investigation into the Possibilities and Limits of High-Tech DIY

David A. Mellis, Leah Buechley

Q 3D Printed Interactive Speakers

Yoshio Ishiguro, Ivan Poupyrev

Circuit Stickers: Peel-and-Stick Construction of Interactive Electronic Prototypes

Steve Hodges, Nicolas Villar, Nicholas Chen, Tushar Chugh, Jie Qi,

Diana Nowacka, Yoshihiro Kawahara
80IA Papers: User Models and Prediction

CHAIR: DUNCAN P.BRUMBY

Modeling the Perception of User Performance

Max Nicosia, Antti Oulasvirta, Per Ola Kristensson

Edit Distance Modulo Bisimulation: A Quantitative Measure to Study Evolution of User Models

Himanshu Zade, Santosh Arvind Adimoolam, Sai Gollapudi,

Anind K. Dey, Venkatesh Choppella

The Law of Unintended Consequences: The Case of

External Subgoal Support

J. G. Trafton, Raj M. Ratwani

8 Causality - A Conceptual Model of Interaction History

Mathieu Nancel, Andy Cockburn

\section{I B Papers: Engage and Educate Children}

CHAIR: JULIEA. KIENTZ

W Conversing with Children: Cartoon andVideo People Elicit Similar Conversational Behaviors

Jennifer Hyde, Sara Kiesler, Jessica K. Hodgins, Elizabeth J. Carter

Involving Children in Content Control: A Collaborative and Education-Oriented Content Filtering Approach

Yasmeen Hashish,Andrea Bunt, James E.Young

What Did Spot Hide?: A Question-Answering Game for Preschool Children

Anuj Tewari, John Canny

Rafigh: A Living Media Interface for Speech Intervention Foad Hamidi, Melanie Baljko

A Comparative Study about Children's and Adults'

Perception of Targeted Web Search Engines

Tatiana Gossen, Juliane Höbel, Andreas Nürnberger

\section{AB Course: $\mathrm{Cl} 0$}

ComputerVision in Interaction and UX Jim Parker
WIP Posters Rotation I

- Accessibility

- Making

- Gaming

- Health Care

- Search \& Infoviz

Student Research Competition

Student Design Competition
Exhibit Hall E

- Children \& Teens

- Augmented Reality

- Gestures \& Eye-based Interactions

- Notifications, Awareness \& Distractions

- Interaction Techniques

Exhibit Hall E

Exhibit Hall E
List on page 58

List on page 54

List on page 55

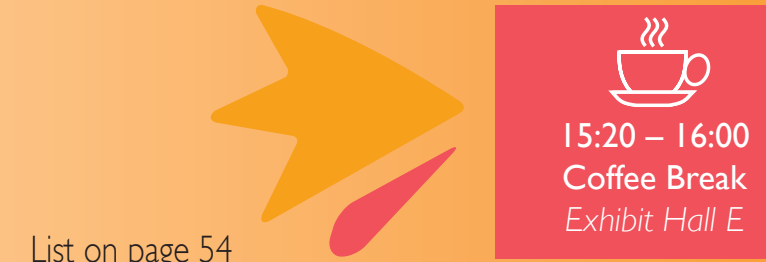




\section{TUESDAY 16:00 - 17:20}

70IA Papers: Studying Visualization

CHAIR: PIERRE DRAGICEVIC

Structuring the Space: A Study on Enriching Node-Link Diagrams with Visual References

Basak E.Alper, Nathalie Henry Riche, Tobias Hollerer

Highlighting Interventions and User Differences: Informing Adaptive Information Visualization Support Giuseppe Carenini, Cristina Conati, Enamul Hoque, Ben Steichen, DereckJ.Toker, James T. Enns

Evaluating a Tool for Improving Accessibility to Charts and Graphs

Leonardo Ferres, Gitte Lindgaard, Livia Sumegi, Bruce H.Tsuji

Understand Users' Comprehension and Preferences for Composing Information Visualizations

Huahai Yang, Yunyao Li, Michelle Zhou

70 IB Papers: Exploring Exergames

CHAIR: DARREN EDGE

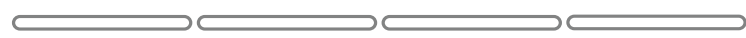

Exertion in the Small: Improving Differentiation and Expressiveness in Sports Games with Physical Controls Mike Sheinin, Carl Gutwin

"Healthifying" Exergames: Improving Health Outcomes through Intentional Priming

Frank X. Chen, Abby C. King, Eric B. Hekler

Q Human Factors of Speed-based Exergame Controllers

Taiwoo Park, Uichin Lee, Scott MacKenzie, Miri Moon, Inseok Hwang Junehwa Song

Establishing Design Guidelines in Interactive Exercise Gaming: Preliminary Data from Two Posing Studies

Monica Zaczynski, Anthony D. Whitehead

709 Course: C09

Conceptual Models: Core to Good Design

Jeff Johnson

7II Course: CII

Online A/BTests \& Experiments: A Practical but

Scientifically Informed Introduction

Joseph Williams, Betsy Williams

\section{7|3AB Course: $\mathrm{Cl} 2$}

Mobile $\mathrm{HCl}$

Niels Henze, Enrico Rukzio
7/4AB Papers: Narratives and Storytelling

CHAIR: AISLING KELLIHER

The Department of Hidden Stories: Playful Digital

Storytelling for Children in a Public Library

Gavin Wood, John Vines, Madeline Balaam, Nick Taylor, Thomas Smith,

Clara Crivellaro, Juliana Mensah, Helen Limon, John Challis,

Linda Anderson, Adam Clarke, Peter C. Wright

Sharing Stories "in the Wild": A Mobile Storytelling Case

Study Using StoryKit

Elizabeth M. Bonsignore,Alexander J. Quinn, Allison Druin,

Benjamin B. Bederson

Visualizing Interactive Narratives: Employing a Branching

Comic to Tell a Story and Show its Readings

Daniel Andrews, Chris Baber

FOCUS: Enhancing Children's Engagement in Reading by Using Contextual BCITraining Sessions

Jin Huang, Chun Yu, Yuntao Wang, Yuhang Zhao, Siqi Liu, Chou Mo,

Jie Liu, Lie Zhang, Yuanchun Shi

Sensing a Live Audience

Chen Wang, Erik N. Geelhoed, Phil P. Stenton, Pablo Cesar

7I5A Special Interest Group

Jogging with Technology: Interaction Design Supporting Sport Activities

Florian Mueller, Joe Marshall, Rohit Khot, Stina Nylander, Jakob Tholander

7I6B Papers: Designing for Older Adults \& Demographic Change CHAIR: VICKI L. HANSON

Interface Design for Older Adults with Varying Cultural Attitudes toward Uncertainty

Shathel Haddad, Joanna McGrenere, Claudia Jacova

Age Differences in Credibility Judgments of Online

Health Information

Q.Vera Liao, Wai-Tat Fu

Social Dependency and Mobile Autonomy -

Supporting Older Adults' Mobility with Ridesharing ICT

Johanna Meurer, Martin Stein, David W. Randall, Markus Rohde,

VolkerWulf

From Checking On to Checking In: Designing for Low Socio-Economic Status Older Adults

Ingrid Arreola, Zan Morris, Matthew Francisco, Kay Connelly, Kelly Caine, Ginger White

Invisible Connections: Investigating Older People's Emotions and Social Relations Around Objects

Kate L. Vaisutis, Margot Brereton, Toni Robertson, Frank Vetere, Jeannette Durick, Bjorn Nansen, Laurie Buys
$17: 30-19: 30$
Job Fair \& Recruiting Board
Exhibit Hall E
$17: 30-19: 00$
Video Showcase \& Golden Mouse Award 
7I7AB Papers: Critical Design

CHAIR: ANDREA G. PARKER

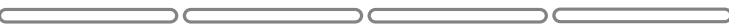

I Always Somewhere, NeverThere: Using Critical Design to

Understand Database Interactions

Melanie Feinberg, Daniel Carter, Julia Bullard

Reading Critical Designs: Supporting Reasoned

Interpretations of Critical Design

Jeffrey Bardzell, Shaowen Bardzell, Erik Stolterman

Sif Designing for Slowness, Anticipation and Re-visitation:

A Long Term Field Study of the Photobox

William T. Odom, Abigail J. Sellen, Richard Banks, David S. Kirk, Tim Regan, Mark Selby, Jodi L. Forlizzi, John Zimmerman

Generating Implications for Design through Design Research

Corina Sas, Steve Whittaker, Steven P. Dow, Jodi L. Forlizzi,

John Zimmerman

\section{HALL G Papers: Understanding and Modeling Touch}

CHAIR: DANIEL VOGEL

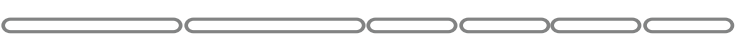

Investigating the Effects of Encumbrance on One- and Two-Handed Interactions with Mobile Devices

Alexander Ng, Stephen A. Brewster, John H. Williamson

Modeling the Functional Area of the Thumb on Mobile Touchscreen Surfaces

Joanna Bergstrom-Lehtovirta, Antti Oulasvirta

Coordination of Tilt and Touch in One- and Two-Handed Use Theophanis Tsandilas, Caroline Appert, Anastasia Bezerianos, David Bonnet

W 28 Frames Later: Predicting Screen Touches from Back-of-Device Grip Changes

Mohammad Faizuddin Mohd Noor, Andrew Ramsay, Stephen Hughes, Simon Rogers, John Williamson, Roderick Murray-Smith

Probabilistic Palm Rejection Using Spatiotemporal Touch Features and Iterative Classification

Julia Schwarz, Robert Xiao, Jennifer Mankoff, Scott E. Hudson, Chris Harrison

Orientation Matters: Efficiency of Translation-Rotation

Multitouch tasks

Quan Nguyen, Michael Kipp
7/8AB Papers: 3D Interaction: Modeling and Prototyping

CHAIR: WOLFGANG STUERZLINGER

MotionMontage: A System to Annotate and Combine Motion Takes for 3D Animations

Ankit Gupta, Maneesh Agrawala, Brian Curless, Michael Cohen

History Assisted View Authoring for 3D Models

Hsiang-Ting Chen, Tovi Grossman, Li-Yi Wei, Ryan M. Schmidt, Björn Hartmann, George Fitzmaurice, Maneesh Agrawala

FrameBox and MirrorBox: Tools and Guidelines to Support Designers in Prototyping Interfaces for 3D Displays

Nora Broy, Stefan Schneegass, Florian Alt, Albrecht Schmidt

Direct Drawing on 3D Shapes with Automated

Camera Control

Michael Ortega, Thomas Vincent

Interactively Stylizing Camera Motion

Neel S. Joshi, Dan Morris, Michael F. Cohen

\section{IA Papers: The Eyes Have It}

CHAIR: JÜRGEN STEIMLE

Stimulating a Blink: Reduction of Eye Fatigue with Visual Stimulus

Tarik Crnovrsanin, Yang Wang, Kwan-Liu Ma

Smart Photo Selection: Interpret Gaze as Personal Interest Tina C. Walber, Ansgar Scherp, Steffen Staab

Q Pupil Responses during Discrete Goal-directed Movements Xianta Jiang, M. Stella Atkins, Geoffrey C. Tien, Roman Bednarik, Bin Zheng

W Collocating Interface Objects: Zooming into Maps Jon May, Tim Gamble

\section{IB Papers: Learning and Education}

CHAIR: DEBORAHTATAR

Showing Face in Video Instruction: Effects on Information Retention, Visual Attention, and Affect

René F. Kizilcec, Kathryn Papadopoulos, Lalida Sritanyaratana

Supporting Learners in Collecting and Exploring Data from Immersive Simulations in Collective Inquiry

Michelle Lui, Alex C. Kuhn,Alisa Acosta, Chris Quintana, James D. Slotta

Learning to See the Body: Supporting Instructional Practices in Laparoscopic Surgical Procedures

Helena M. Mentis, Amine Chellali, Steven D. Schwaitzberg

Information-Building Applications: Designing for Data Exploration and Analysis by Elementary School Students Tia R. Shelley, Leilah B. Lyons, Tom Moher, Chandan Dasgupta, Brenda Lopez Silva, Alexandra Silva

\section{AB Course: ClO}

ComputerVision in Interaction and UX Jim Parker 


$\begin{array}{ll}\text { 7:00 - 8:20 } & \text { Video Previews } \\ 8: 30-8: 50 & \text { Exhibit Hall G } \\ \text { Provoke! Wisdom! Impact! Plenary - A CHI Story - Past, Present, and the Next Chapters } \\ \text { Scooter Morris, University of California, San Francisco }\end{array}$

\section{IA Papers: Telepresence and Connecting over Video}

CHAIR: KORI M. INKPEN

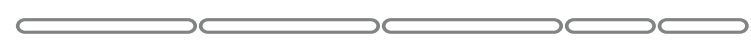

Q Remote Handshaking: Touch Enhances Video-Mediated Social Telepresence

Hideyuki Nakanishi, Kazuaki Tanaka, Yuya Wada

Bodies in Motion: Mobility, Presence, and Task Awareness

in Telepresence

Irene Rae, Bilge Mutlu, Leila A. Takayama

Exploring Video Streaming in Public Settings:

Shared Geocaching Over Distance Using MobileVideo Chat Jason Procyk, Carman Neustaedter, Carolyn Pang, Anthony Tang,

Tejinder K.Judge

A Gaze-preserving Situated Multiview Telepresence System Ye Pan, Anthony Steed

OneSpace: SharedVisual Scenes for Active Freeplay

Maayan Cohen, Kody R. Dillman, Haley MacLeod, Seth Hunter, Anthony Tang

\section{I B Papers: Exergame Design}

CHAIR: SEAN MUNSON

i-dentity: Innominate Movement Representation as Engaging Game Element

Jayden Garner, Gavin Wood, Sebastiaan Pijnappel, Martin Murer,

Florian Mueller

Movement-Based Game Guidelines

Florian Mueller, Katherine Isbister

Effects of Balancing for Physical Abilities on Player Performance, Experience and Self-Esteem in Exergames Kathrin M. Gerling, Matthew Miller, Regan L. Mandryk, Max V. Birk, Jan D. Smeddinck

Supporting the Creative Game Design Process with Exertion Cards

Florian Mueller, Martin R. Gibbs, Frank Vetere, Darren Edge

\section{Course: CI5}

Rapid Design Labs_A Tool to Turbocharge

Design-Led Innovation

Jim Nieters, Carola Fellenz Thompson

\section{II Course: $\mathrm{Cl} 3$}

Agile User Experience and UCD

William Hudson

7/3AB Course: CHInd-D

How Social Media Design Shapes Society

Judith Donath
7/4AB Papers: Designing and Modeling GUls

CHAIR: MICHAEL NEBELING

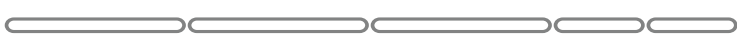

WADE: Simplified GUI Add-on Development for Third-party Software

Xiaojun Meng, Shengdong Zhao, Yongfeng Huang, Zhongyuan Zhang, James Eagan, Ramanathan Subramanian

Pixel-Based Methods for Widget State and Style in a Runtime Implementation of Sliding Widgets Morgan E. Dixon, Gierad Laput, James A. Fogarty

The Usability of CommandMaps in Realistic Tasks Joey Scarr,Andy Cockburn, Carl Gutwin, Andrea Bunt, Jared E. Cechanowicz

Novice Use of a Predictive Human Performance Modeling Tool to Produce UI Recommendations

Kyung Wha Hong, Robert St. Amant

On the Selection of 2D Objects Using External Labeling Jan Balata, Ladislav Cmolik, Zdenek Mikovec

\section{I6A Special Interest Group}

Child Computer Interaction SIG: Towards Sustainable Thinking and Being Janet Read, Juan Pablo Hourcade, Panos Markopoulos, Ole Iversen

716B Papers: Health and Everyday Life CHAIR: MARIA K.WOLTERS

Real-time Feedback for Improving Medication Taking Matthew L. Lee, Anind K. Dey

Don't Forget Your Pill! Designing Effective Medication Reminder Apps That Support Users' Daily Routines Katarzyna Stawarz, Anna L. Cox,Ann E. Blandford

@BabySteps: Design and Evaluation of a System for using Twitter forTracking Children's Developmental Milestones Hyewon Suh, John R. Porter, Alexis Hiniker, Julie A. Kientz

DoDo Game, a ColorVision Deficiency Screening Test for Young Children

Linh Chi Nguyen, Ellen Yi-Luen Do, Audrey Chia, Yuan Wang, Henry Been-Lirn Duh

The Influence of Emotion on Number Entry Errors Paul Cairns, Pratyush Pandab, Christopher D. Power 
7I7AB alt.chi: Navel Gazing

CHAIR: LILLY IRANI

Reflections on a Synergistic Format for Disseminating Research Through Design

Jayne Wallace, Joyce Yee, Abigail Durrant

Quantification in Alt.Chi Open Review: Liking andTicking on a Likert Scale

Rǎzvan Rughiniş, Cosima Rughiniş, Alina Petra Marinescu Nenciu

QnDReview: Read $100 \mathrm{CHI}$ Papers in 7 Hours

JiSoo Yi

Hot Topics in CHI: Trend Maps forVisualising Research Stefano Padilla, Thomas S. Methven, David W. Corne, Mike J. Chantler

\section{HALL G Papers: Text Entry and Evaluation}

CHAIR: ANTTI OULASVIRTA

Both Complete and Correct? Multi-Objective Optimization ofTouchscreen Keyboard

Xiaojun Bi, Tom Y. Ouyang, Shumin Zhai

Disambiguation of Imprecise Input with One-dimensional Rotational Text Entry

Will Walmsley, W. Xavier Snelgrove, Khai N. Truong

Complementing Text Entry Evaluations with a

Composition Task

Keith Vertanen, Per Ola Kristensson

Uncertain Text Entry on Mobile Devices

Daryl Weir, Henning Pohl, Simon Rogers, Keith Vertanen,

Per Ola Kristensson

7/8AB Papers: Emotions and Mobiles

CHAIR: ANTONIO KRUEGER

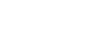

Mobile Attachment - Causes and Consequences for Emotional Bonding with Mobile Phones

Alexander Meschtscherjakov, David Wilfinger, Manfred Tscheligi

Hooked on Smartphones: An Exploratory Study on

Smartphone Overuse among College Students

Uichin Lee, Joonwon Lee, Minsam Ko, Changhun Lee, Yuhwan Kim,

Subin Yang, Koji Yatani, Gahgene Gweon, Kyong-Mee Chung, Junehwa Song

Influence of Personality on Satisfaction with Mobile

Phone Services

Rodrigo de Oliveira, Mauro Cherubini, Nuria Oliver

Broken Display = Broken Interface? The Impact of Display

Damage on Smartphone Interaction

Florian Schaub, Julian Seifert, Frank D. Honold, Michael Müller.

Enrico Rukzio, Michael Weber

\section{IA Papers: Privacy}

CHAIR: SAMEER PATIL

Q Leakiness and Creepiness in App Space: Perceptions of

Privacy and Mobile App Use

Irina A. Shklovski, Scott D. Mainwaring, Halla H. Skúladóttir,

Höskuldur Borgthorsson

Personalisation and Privacy in Future Pervasive

Display Networks

Nigel Davies, Marc Langheinrich, Sarah Clinch, Ivan Elhart, Adrian Friday,

Thomas Kubitza, Bholanathsingh Surajbali

A Field Trial of Privacy Nudges for Facebook

Yang Wang, Pedro G. Leon, Alessandro Acquisti, Lorrie F. Cranor, Alain Forget, Norman Sadeh

In Situ with Bystanders of Augmented Reality Glasses:

Perspectives on Recording and Privacy-Mediating

Technologies

Tamara Denning, Zakariya Dehlawi, Tadayoshi Kohno

\section{IB Papers: Issues That Matter}

CHAIR: ROB COMBER

Listening to the Forest and its Curators: Lessons Learnt from a Bioacoustic Smartphone Application Deployment Stuart Moran, Nadia Pantidi, Tom Rodden, Alan Chamberlain, Chloe Griffiths, Davide Zilli, Geoff Merrett, Alex Rogers

W Making Public Things: How HCl Design Can Express Matters of Concern

Carl DiSalvo, Jonathan Lukens, Thomas J. Lodato, Tom Jenkins, Tanyoung Kim

A Sustainable Design Fiction: Green Practices

Ron Wakkary, Audrey Desjardins, Sabrina Hauser, Leah A. Maestri

Just Awful Enough - The Functional Dysfunction of the Something Awful Forums

Jessica A. Pater,Yacin Nadji, Elizabeth D. Mynatt, Amy S. Bruckman

\section{AB Course: $\mathrm{Cl} 4$}

$\mathrm{HCl}$ Meets Data Mining: Principles and Tools for

Big Data Analytics

Duen Horng (Polo) Chau
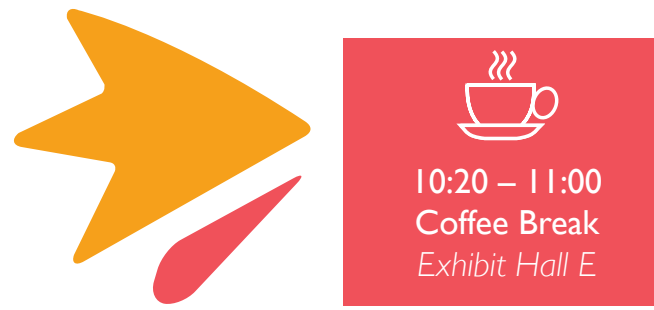
$10: 00-14: 00$
Student Game Competition
Exhibit Hall E
List on page 55
$10: 20-11: 00$
WIP Posters Rotation 2
Exhibit Hall E
List on page 61 
70IA Papers: Understanding and Using Social Media CHAIR: PATRICK GAGE KELLEY

Everyday Ideation: All of My Ideas Are On Pinterest Rhema Linder, Clair Snodgrass, Andruid Kerne

U Understanding User Adaptation Strategies for the

Launching of FacebookTimeline

Pamela J.Wisniewski, Heng Xu, Yunan Chen

Curation through Use: Understanding the Personal Value of Social Media

Xuan Zhao, Siân E. Lindley

Together Alone: Motivations for Live-Tweeting a

Television Series

Steven Schirra, Huan Sun, Frank R. Bentley

70 I B Papers: Working Together

CHAIR: DOMINIC FURNISS

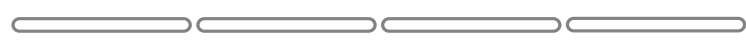

Documentscape: Intertextuality, Sequentiality, \&

Autonomy at Work

Lars Rune Christensen, Pernille Bjorn

Cloudy Forecast: An Exploration of the Factors Underlying

Shared Repository Use

Charlotte Massey, Thomas Lennig, Steve Whittaker

TaskGenies: Automatically Providing Action Plans Helps People Complete Tasks

Nicolas Kokkalis, Thomas Köhn, Johannes Huebner, Moontae Lee, Florian Schulze, Scott R. Klemmer

Designing Information Savvy Societies: An Introduction to Assessability

Andrea Forte, Nazanin Andalibi, Thomas H. Park, Heather Willever-Farr

\section{Course: $\mathrm{Cl} 5$}

Rapid Design Labs_-A Tool to Turbocharge

Design-Led Innovation

Jim Nieters, Carola Fellenz Thompson

\section{II Course: $\mathrm{Cl} 3$}

Agile User Experience and UCD

William Hudson

\section{I3AB Course: CHlnd-E}

Designing for Seniors

Ronald Baecker
7| 4AB Papers: Programming and Development Tools

CHAIR: FANNY CHEVALIER

Addressing Misconceptions About Code with Always-On Programming Visualizations

Tom Lieber, Joel R. Brandt, Rob C. Miller

Emergent, Crowd-scale Programming Practice in the IDE Ethan Fast, Daniel Steffee, Lucy Wang, Joel R. Brandt, Michael S. Bernstein

W Design Considerations for Parallel Performance Tools Roman Atachiants, David Gregg, Kim Jarvis, Gavin Doherty

The Patchworks Code Editor: Toward Faster Navigation with Less Code Arranging and Fewer Navigation Mistakes Austin Z. Henley, Scott D. Fleming

\section{I5A Special Interest Group}

The Usability of Text Entry Systems Now and in the Future James Clawson, Stephen Brewster, Mark Dunlop, Per Ola Kristensson, Poika Isokoski, Antti Oulasvirta, Keith Vertanen, Annalu Waller

\section{A Pane}

Making Cultures: Empowerment, Participation, and Democracy - or Not?

Morgan Ames, Jeffrey Bardzell, Shaowen Bardzell, Silvia Lindtner, David Mellis, Daniela Rosner

7 I6B Papers: Interactive Technologies for Rehabilitation

CHAIR: XIAOMU ZHOU

Novel Knee Rehabilitation System for the Home Mobolaji Ayoade, Lynne Baillie

GaitAssist: A Daily-life Support and Training System for Parkinson's Disease Patients with Freezing of Gait Sinziana Mazilu, Ulf Blanke, Michael Hardegger, Gerhard Tröster, Eran Gazit, Jeffrey M. Hausdorff

A Technology Probe of Wearable In-Home Computer-Assisted PhysicalTherapy Kevin Huang, Patrick J. Sparto, Sara Kiesler, Asim Smailagic, Jennifer Mankoff, Dan Siewiorek

QTe Exploring the Acceptability of Google Glass as an Everyday Assistive Device for People with Parkinson's

Roisin C. McNaney, John Vines, Daniel Roggen, Madeline Balaam, Pengfei Zhang, Ivan Poliakov, Patrick Olivier

Non-Intrusive Tongue Machine Interface Qiao Zhang, Shyamnath Gollakota, Ben Taskar, Raj P. Rao 
7I7AB Special: Student Research Competition

CHAIR: CELINE LATULIPE, FLOYD MULLER

The $\mathrm{CHI} 2014$ Student Research Competition (SRC) is a branch of the ACM Student Research Competition. It is a forum for undergraduate and graduate students to showcase their research, exchange ideas, and improve their communication skills.

HALL G Papers: Shape-Changing Interfaces

CHAIR: ABHIIIT KARNIK

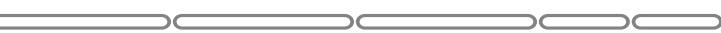

W Causing Commotion with a Shape-changing

Bench - Experiencing Shape-Changing Interfaces in Use

Erik Grönvall, Sofie Kinch, Marianne Graves Petersen,

Majken Kirkegaard Rasmussen

Paddle: Highly Deformable Mobile Devices with

Physical Controls

Raf Ramakers, Johannes Schöning, Kris Luyten

Is my Phone Alive? A Large-Scale Study of Shape Change in Handheld Devices Using Videos

Esben W. Pedersen, Sriram Subramanian, Kasper Hornbæk

Evaluating the Effectiveness of Physical Shape-Change for In-pocket Mobile Device Notifications

Panteleimon Dimitriadis, Jason Alexander

Changibles: Analyzing and Designing Shape Changing

Constructive Assembly

Anne Roudaut, Rebecca Reed,Tianbo Hao, Sriram Subramanian

\section{AB Papers: Touch Input}

CHAIR: DANIEL J.WIGDOR

Expanding Touch Input Vocabulary by Using Consecutive Distant Taps

Seongkook Heo, liseong Gu, Geehyuk Lee

LinearDragger: A Linear Selector for Target Acquisition on Touch Screens

Oscar Kin-Chung Au, Xiaojun Su, Rynson W. Lau

Faster Command Selection on Tablets with FastTap

Carl Gutwin, Andy Cockburn, Joey Scarr, Sylvain Malacria, Scott C. Olson

Q Crossing-Based Selection with Direct Touch Input

Yuexing Luo, Daniel Vogel

\section{IA Papers: Risks and Security}

CHAIR: ALEXANDER DE LUCA

Easy Does It: More Usable CAPTCHAs

Elie Bursztein, Angelique Moscicki, Celine Fabry, Steven Bethard, John C. Mitchell, Dan Jurafsky

Using Personal Examples to Improve Risk Communication for Security and Privacy Decisions

Marian Harbach, Markus Hettig, Susanne Weber, Matthew Smith

"My Religious Aunt Asked Why I Was Trying to Sell HerViagra": Experiences with Account Hijacking Richard Shay, Iulia Ion, Robert W. Reeder, Sunny Consolvo

Experimenting at Scale with Google Chrome's SSL Warning Adrienne P. Felt, Robert W. Reeder, Hazim Almuhimedi, Sunny Consolvo

Betrayed By Updates: How Negative Experiences Affect Future Security

Kami E. Vaniea, Emilee Rader, Rick Wash

\section{I B Papers: CHI for Social Development}

CHAIR: BAN AL-ANI

U Understanding Sustained Community Engagement:

A Case Study in Heritage Preservation in Rural Argentina Mara Balestrini, Jon Bird, Paul Marshall, Alberto Zaro, Yvonne Rogers

STf. Human Values in Curating a Human Rights Media Archive Abigail C. Durrant, David S. Kirk, Stuart Reeves

Protibadi: A Platform for Fighting Sexual Harassment in Urban Bangladesh

Syed Ishtiaque Ahmed, Steven J.Jackson, Nova Ahmed, Hasan Shahid Ferdous, Md. Rashidujiaman Rifat,A.S.M Rizvi, Shamir Ahmed, Rifat Sabbir Mansur

How Technology Supports Family Communication in Rural, Suburban, and Urban Kenya

Erick Oduor, Carman Neustaedter, Tejinder K. Judge, Kate Hennessy, Carolyn Pang, Serena Hillman

\section{AB Course: $\mathrm{Cl} 4$}

$\mathrm{HCl}$ Meets Data Mining: Principles and Tools for Big Data Analytics

Duen Horng (Polo) Chau

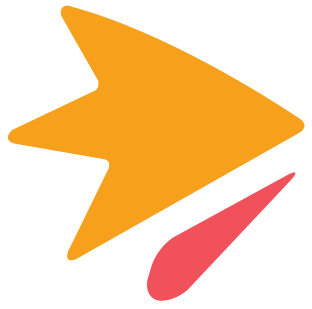

$12: 20-14: 00$ Lunch Break Restaurants, bars \& cafés available nearby 
70IA Papers: Question and Answer Systems CHAIR: JEFFREY NICHOLS

Towards Crowd-based Customer Service: A Mixed-Initiative Tool for Managing Q\&A Sites

Tiziano Piccardi, Gregorio Convertino, Massimo Zancanaro, ji Wang Cedric Archambeau

SIP Estimating the Social Costs of Friendsourcing Jeffrey M. Rzeszotarski, Meredith R. Morris

Expert Voices in Echo Chambers: Effects of Source Expertise Indicators on Exposure to Diverse Opinions Q. Vera Liao, Wai-Tat Fu

Is Anyone Out There? Unpacking Q\&A Hashtags on Twitter Jeffrey M. Rzeszotarski, Emma S. Spiro, Jorge N. Matias, Andrés Monroy-Hernández, Meredith R. Morris

What IfWe Ask A Different Question?: Social Inferences Create Product Ratings Faster Eric Gilbert

\section{I B Special: Lifetime Practice Award: Gillian Crampton Smith}

CHAIR: DON NORMAN

Design: No Longer an Optional Extra

709 Course: Cl6

Introduction to Designing and Building

Musical Interfaces

Michael Lyons, Axel Mulder, Sidney Fels

\section{II Course: $\mathrm{Cl} 8$}

Including Children in Technology Design Processes:

Allison Druin, Jerry Fails, Mona Leigh Guha

\section{I3AB Course: $\mathrm{CI} 9$}

Interaction Design for Online Video and Television David Geerts, Pablo Cesar
7| 4AB Papers: Cross-Device Interaction

CHAIR: FABIO PATERNÒ

Smarties: An Input System for Wall Display Development Olivier Chapuis, Anastasia Bezerianos, Stelios Frantzeskakis

Conductor: Enabling and Understanding

Cross-Device Interaction

Peter Hamilton, Daniel J. Wigdor

Panelrama: Enabling Easy Specification of

Cross-Device Web Applications

jishuo Yang, Daniel J. Wigdor

Interactive Development of Cross-Device User Interfaces Michael Nebeling, Theano Mintsi, Maria Husmann, Moira Norrie

\section{I5A Special Interest Group}

Community Centered Collaborative HC

Design / Research in Developing Countries

Anicia Peters, Heike Winschiers-Theophilus, Nicola Bidwell, Arun Kumar, Daniel Ochieng, Fatoumata Camara, Susan Dray

\section{A Panel}

CROWDFUNDING: An Emerging Field of Research

Elizabeth Gerber, Michael Muller, Rick Wash, Lilly Irani, Amanda Williams, Elizabeth Churchill

7/6B Papers: Exergaming for Health and Fitness

CHAIR: DAN MORRIS

Motivating People with Chronic Pain to do Physical Activity: Opportunities for Technology Design

Aneesha Singh, Annina Klapper, Jinni Jia, Antonio Rei Fidalgo, Ana Tajadura-jiménez, Natalie Kanakam, Nadia B. Bianchi-Berthouze, Amanda Williams

Investigating the Long-Term Use of Exergames in the Home with Elderly Fallers

Stephen Uzor, Lynne Baillie

StepStream: A School-based Pervasive Social Fitness System for Everyday Adolescent Health Andrew D. Miller, Elizabeth D. Mynatt

Social Fabric Fitness: The Design and Evaluation of Wearable E-Textile Displays to Support Group Running Matthew Mauriello, Michael Gubbels, Jon E. Froehlich

\section{I7AB Special: Student Design Competition}

CHAIR: THECLA SCHIPHORST,YOUN-KYUNG LIM

The CHI 2014 Student Design Competition (SDC) challenges students to design an object, interface, system, or service related to bodydata: the qualities of the quantified self. 
HALL G Papers: Sensory Experiences: Smell and Taste CHAIR: JETTIE HOONHOUT

Opportunities for Odor: Experiences with Smell and Implications forTechnology

Marianna Obrist, Alexandre N. Tuch, Kasper Hornbaek

Temporal, Affective, and Embodied Characteristics of Taste Experiences: A Framework for Design

Marianna Obrist, Rob Comber, Sriram Subramanian,

Betina Piqueras-Fiszman, Carlos Velasco, Charles Spence

WensaBubble: A Chrono-Sensory Mid-Air Display of Sight and Smell

Sue Ann Seah, Diego Martinez Plasencia, Peter D. Bennett,Abhijit Karnik, Vlad S. Otrocol, Jarrod Knibbe, Andy Cockburn, Sriram Subramanian

Food Messaging: Using Edible Medium for Social Messaging Jun Wei, Xiaojuan Ma, Shengdong Zhao

7/8AB Papers: Multitouch Interaction

CHAIR: SEBASTIAN BORING

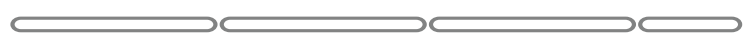

W Multi-finger Chords for Hand-held Tablets: Recognizable and Memorable

Julie Wagner, Eric Lecolinet, Ted Selker

Prospective Motor Control on Tabletops: Planning Grasp for Multitouch Interaction

Halla B. Olafsdottir, Theophanis Tsandilas, Caroline Appert

Quantitative Measurement of Virtual vs. Physical Object Embodiment through Kinesthetic Figural After Effects

Ayman Alzayat, Mark Hancock, Miguel Nacenta

TouchTools: Leveraging Familiarity and Skill with Physical Tools to Augment Touch Interaction

Chris Harrison, Robert Xiao, Julia Schwarz, Scott E. Hudson
80IA Papers: Authentication and Passwords

CHAIR: SERGE EGELMAN

Passhint: Memorable and Secure Authentication

Soumyadeb Chowdhury, Ron Poet, Lewis Mackenzie

Can Long Passwords be Secure and Usable?

Richard Shay, Saranga Komanduri, Adam L. Durity,

Phillip (Seyoung) Huh, Michelle L. Mazurek, Sean M. Segreti, Blase Ur.

Lujo Bauer, Nicolas Christin, Lorrie F. Cranor

Now You See Me, Now You Don't - Protecting Smartphone Authentication from Shoulder Surfers

Alexander De Luca, Marian Harbach, Emanuel von Zezschwitz, Max-Emanuel Maurer, Bernhard E. Slawik, Heinrich Hussmann, Matthew Smith

The Presentation Effect on Graphical Passwords

Julie Thorpe, Muath Al-Badawi, Brent MacRae, Amirali Salehi-Abari

An Implicit AuthorVerification System for Text Messages

Based on Gesture Typing Biometrics

Ulrich Burgbacher, Klaus H. Hinrichs

80 I B Papers: Policies and Practice: Doing the Right Thing CHAIR: VOLKERWULF

Collapse Informatics and Practice: Theory, Method, and Design

Bill Tomlinson, Eli Blevis, Bonnie Nardi, Donald J. Patterson, M. Six Silberman, Yue Pan

$\mathrm{HCl}$ as a Means to Prosociality in the Economy

John Harvey, David Golightly, Andrew Smith

Towards a Closer Dialogue between Policy and Practice: Responsible Design in $\mathrm{HCl}$

Barbara Grimpe, Mark Hartswood, Marina Jirotka

W Towards Community-Centered Support for Peer-to-Peer Service Exchange: Rethinking the Timebanking Metaphor Victoria M. Bellotti, Sara Cambridge, Karen Hoy, Patrick C. Shih, Lisa R. Handalian, Kyungsik Han, John M. Carroll

\section{AB Course: $\mathrm{Cl} 7$}

Make This! Introduction to Electronics Prototyping Using Arduino

David Sirkin, Wendy Ju
WIP Posters Rotation 2

- E-commerce

- Communities

- Displays

- Learning

- Lifestyle

Student Research Competition

Student Design Competition
- Users and UI Design

- Ubicomp, robots \& wearables

- Mobile Interactions

- Trust, Privacy \& Emotions

- Social Computing

Exhibit Hall E

Exhibit Hall E
List on page 61

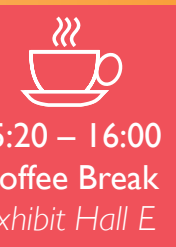

List on page 54

List on page 55 
70IA Papers: Journalism and Social News CHAIR: COYE CHESHIRE

Designing for Dabblers and Deterring Drop-Outs in Citizen Science

Alexandra Eveleigh, Charlene I. Jennett, Ann E. Blandford, Philip Brohan, Anna L. Cox

Utilising Insight Journalism for Community Technology Design Nick Taylor, David M. Frohlich, Paul Egglestone, Justin Marshall, Jon Rogers, Alicia Blum-Ross, John Mills, Mike Shorter, Patrick Olivier

NewsViews: An Automated Pipeline for Creating Custom Geovisualizations for News

Tong Gao, Jessica R. Hullman, Eytan Adar, Brent Hecht, Nicholas Diakopoulos

Finding "Real People": Trust and Diversity in the Interface Between Professional and Citizen Journalists

Andrew T. Garbett, Rob Comber, Paul Egglestone, Maxine Glancy, Patrick Olivier

\section{I B Papers: Interruptions and Distractions}

\section{CHAIR: JASON ALEXANDER}

$\Longleftarrow \Longleftarrow \Longleftarrow$

B Bored Mondays and Focused Afternoons: The Rhythm of Attention and Online Activity in the Workplace

Gloria Mark, Shamsi T. Iqbal, Mary P. Czerwinski, Paul R. Johns

CRISP - An Interruption Management Algorithm based on Collaborative Filtering

Tammar Shrot, Avi Rosenfeld, Jennifer Golbeck, Sarit Kraus

W Interrupted by a Phone Call: Exploring Designs for Lowering the Impact of Call Notifications for Smartphone Users

Matthias Böhmer, Christian Lander, Sven Gehring, Duncan P. Brumby, Antonio Krüger

Large-Scale Assessment of Mobile Notifications

Alireza Sahami Shirazi, Niels Henze, Tilman Dingler, Martin Pielot, Dominik Weber, Albrecht Schmidt

\section{Course: $\mathrm{Cl} 6$}

Introduction to Designing and Building Musical Interfaces Michael Lyons, Axel Mulder, Sidney Fels

\section{II Course: $\mathrm{Cl} 8$}

Including Children in Technology Design Processes:

Techniques and Practices

Allison Druin, Jerry Fails, Mona Leigh Guha

\section{7|3AB Course: $\mathrm{CI} 9$}

Interaction Design for Online Video and Television

David Geerts, Pablo Cesar

7 I AAB Papers: Decisions, Recommendations, and Machine Learning CHAIR: JON E. FROEHLICH

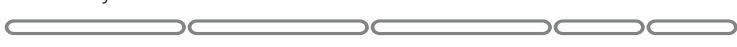

Customization Bias in Decision Support Systems Jacob Solomon

STP Structured Labeling for Facilitating Concept Evolution in Machine Learning

Todd Kulesza, Saleema Amershi, Rich Caruana, Danyel Fisher, Denis Charles

W Choice-Based Preference Elicitation for Collaborative Filtering Recommender Systems

Benedikt Loepp, Tim Hussein, Juergen Ziegler

Finding Dependencies Between Actions Using the Crowd Walter S. Lasecki, Leon Weingard, George Ferguson, Jeffrey P. Bigham

Scalable Multi-label Annotation

jia Deng, Olga Russakovsky, Jonathan Krause, Michael S. Bernstein, Alex Berg, Li Fei-Fei

7I5A Special Interest Group

Interactions Magazine

Ron Wakkary, Erik Stolterman

\section{I6A Panel}

The Meaning of Design in Healthcare:

Industry, Academia,Visual Design, Clinician, Patient and HF Consultant Perspectives

Svetlena Taneva, Waxberg Sara, Goss Julian, Rossos Peter, Nicholas Emily, Cafazzo Joseph 
7I6B Papers: Accessibility

CHAIR: HIRONOBUTAKAG

W Wearables and Chairables: Inclusive Design of Mobile Input and Output Techniques for Power Wheelchair Users

Patrick A. Carrington, Amy Hurst, Shaun K. Kane

The Last Meter: BlindVisual Guidance to a Target

Roberto Manduchi, James M. Coughlan

Current and Future Mobile and Wearable Device Use by

People With Visual Impairments

Hanlu Ye, Meethu Malu, Uran Oh, Leah Findlater

Visually Impaired Users on an Online Social Network

Shaomei Wu, Lada A.Adamic

7I7AB Special: Student Game Competition

\section{CHAIR: SETH COOPER, ALESSANDRO CANOSSA}

The CHI 2014 Student Game Competition (SGC) provides an opportunity for students from a variety of backgrounds $(\mathrm{HCl}$, computer science, game design, fine arts) to participate in $\mathrm{CHI}$ and demonstrate their game design and development skills in an international competition

HALL G Papers: Tangible Interactions and Technologies CHAIR: ERINT.SOLOVEY

Let's Jam the Reactable: Peer Learning during Musical Improvisation with a Tabletop Tangible Interface Anna Xambó, Eva Hornecker, Paul Marshall, Sergi Jordà, Chris Dobbyn, Robin Laney

Kickables: Tangibles for Feet

Dominik Schmidt, Raf Ramakers, Esben W. Pedersen, Johannes Jasper, Sven Köhler, Aileen Pohl, Hannes Rantzsch, Andreas Rau, Patrick Schmidt Christoph Sterz, Yanina Yurchenko, Patrick Baudisch

4 GaussBricks: Magnetic Building Blocks for Constructive

Tangible Interactions on Portable Displays

Rong-Hao Liang, Liwei Chan, Hung-YuTseng, Han-Chih Kuo,

Da-Yuan Huang, De-Nian Yang, Bing-Yu Chen

Q Designing Tangible Video Games: Lessons Learned from the Sifteo Cubes

Clément Pillias, Raphaël Robert-Bouchard, Guillaume Levieux

X A Low-cost Transparent Electric Field Sensor for

3D Interaction on Mobile Devices

Mathieu Le Goc, Stuart A. Taylor, Shahram Izadi, Cem Keskin

\section{I8AB Papers: Head-Worn Displays}

CHAIR: BRIAN P.BAILEY

The Personal Cockpit: A Spatial Interface for Effective Task Switching on Head-Worn Displays

Barrett M. Ens, Rory Finnegan, Pourang P. Irani

Exploring the Use of Hand-To-Face Input for Interacting with Head-Worn Displays

Marcos Serrano, Barrett M. Ens, Pourang P. Irani
Permulin: Mixed-Focus Collaboration on

Multi-View Tabletops

Roman Lissermann, Jochen Huber, Martin Schmitz, Jürgen Steimle, Max Mühlhäuser

In-Your-Face, Yet Unseen? Improving Head-Stabilized

Warnings to Reduce Reaction Time

Felix Lauber, Andreas Butz

\section{IA Papers: Applications of Body Sensing}

CHAIR: SUSAN R. FUSSELL

Kinect-taped Communication: Using Motion Sensing to Study Gesture Use and Similarity in Face-to-Face and Computer-Mediated Brainstorming

Hao-Chuan Wang, Chien-Tung Lai

Is Motion Capture-Based Biomechanical Simulation Valid for $\mathrm{HCl}$ Studies? Study and Implications

Myroslav Bachynskyi, Antti Oulasvirta, Gregorio Palmas, Tino Weinkauf

RecoFit: Using a Wearable Sensor to Find, Recognize, and Count Repetitive Exercises

Dan Morris, T. Scott S. Saponas, Andrew Guillory, llya Kelner

Improving Automatic Speech Recognition Through Head Pose Driven Visual Grounding

Soroush Vosoughi

80 IB Papers: Urban Communities and Social Media CHAIR: N. SADAT SHAMI

Tensions in Scaling-up Community Social Media: A Multi-Neighborhood Study of Nextdoor

Christina A. Masden, Catherine Grevet, Rebecca E. Grinter, Eric Gilbert, W. Keith Edwards

Curated City: Capturing Individual City Guides Through Social Curation

Justin B. Cranshaw, Kurt Luther, Patrick Gage Kelley, Norman Sadeh

ZWERM: a Modular Component Network Approach for an Urban Participation Game

Thomas Laureyssens, Tanguy Coenen, Laurence Claeys, Peter Mechant Johan Criel, Andrew Vande Moere

Studying Digital Graffiti as a Location-Based Social Network David K. McGookin, Stephen A. Brewster, Georgi Christov

\section{AB Course: Cl7}

Make This! Introduction to Electronics Prototyping Using Arduino

David Sirkin, Wendy Ju 


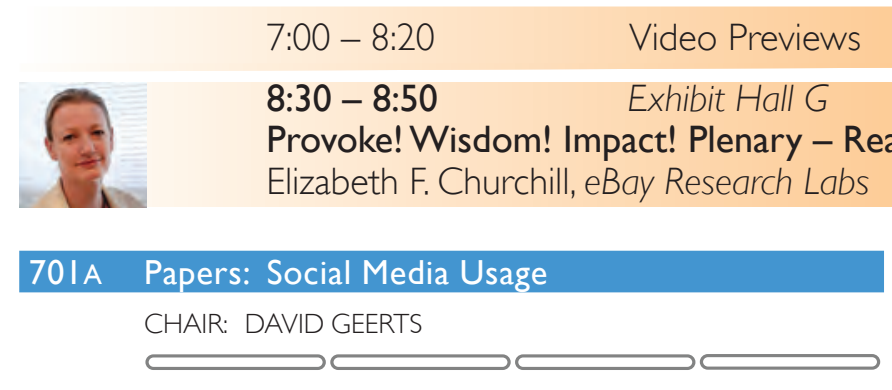

Social Epistemic Cognition in Online Interactions

Rosanna Yuen-Yan Y. Chan, Silu Li, Diane Hui

Share yourView: Impact of Co-Navigation Support and Status Composition in Collaborative Online Shopping Yanzhen Yue, Xiaojuan Ma, Zhenhui jiang

Nutriflect: Reflecting Collective Shopping Behavior and Nutrition

Wolfgang H. Reitberger, Wolfgang Spreicer, Geraldine Fitzpatrick

Didn't You See My Message? Predicting Attentiveness to Mobile Instant Messages

Martin Pielot, Rodrigo de Oliveira, Haewoon Kwak, Nuria M. Oliver

\section{IB Papers: Games and Education}

CHAIR: JODI L. FORLIZZI

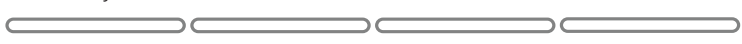

Using Extracted Features to Inform Alignment-Driven Design Ideas in an Educational Game

Erik Harpstead, Christopher J. MacLellan, Vincent Aleven, Brad A. Myers

Brain Points: A Growth Mindset Incentive Structure Boosts Persistence in an Educational Game

Eleanor O'Rourke, Kyla Haimovitz, Christy Ballweber, Carol Dweck, Zoran Popovic

W Towards Automatic Experimentation of

Educational Knowledge

Yun-En Liu, Travis Mandel, Emma Brunskill, Zoran Popovic

Spending Real Money: Purchasing Patterns of Virtual Goods in an Online Social Game

Donghee Yvette Wohn

\section{II Course: C2I-I}

Speech-based Interaction: Myths, Challenges,

and Opportunities

Cosmin Munteanu, Gerald Penn

\section{I3AB Course: C22-I}

The Glass Class: Designing Wearable Interfaces

Mark Billinghurst, Hayes Raffle

\section{I5A Special Interest Group}

Managing UXTeams

Janice Rohn, Carola Thompson

\section{7|4AB Papers: Learning and Games}

CHAIR: AMY OGAN

CADament: A Gamified Multiplayer Software

Tutorial System

Wei Li, Tovi Grossman, George Fitzmaurice

Combining Crowdsourcing and Learning to Improve Engagement and Performance

Mira Dontcheva, Robert R. Morris, Joel R. Brandt, Elizabeth M. Gerber

A Game-Based Learning Approach to Road Safety:

The Code of Everand

lan Dunwell, Sara de Freitas, Panagiotis Petridis, Maurice Hendrix,

Sylvester Arnab, Petros Lameras, Craig Stewart

L.IVE: An Integrated Interactive Video-based

Learning Environment

Toni-Jan Keith P.Monserrat, Yawen Li, Shengdong Zhao, Xiang Cao

\section{I6A Case Studies: Realities of Fieldwork}

CHAIR: MICHAEL ARENT

Challenges at the Bottom of the Pyramid: An Ethnographic Study of South African Mobile Users

Susan Dray

Quick and Participatory: Adopting Users' Designs to Improve a Mobile App

Kate Sangwon Lee, Sun Lee, Hyojung Kim

User-Centered Design for More Efficient Drill Rig

Control System

Katri Koli, Tuula Kärkkäinen, Jaakko Lehikoinen, Tuomo Pirinen,

Sami Hanski, Juha Lassila, Mikko Loimusalo

Questions \& Answers and Discussion for All Case Studies

7/6B Papers: Persuasive Technologies and Applications CHAIR: ERIN CHERRY

Persuasive Technology for Overcoming Food Cravings and Improving Snack Choices

Anne Hsu, Jing Yang, Yigit Han Yilmaz, Md Sanaul Haque, Cengiz Can, Ann E. Blandford

The Effects of Embodied Persuasive Games on Player Attitudes Toward People Using Wheelchairs

Kathrin M. Gerling, Regan L. Mandryk, Max V. Birk, Matthew Miller, Rita Orji

W Spent: Changing Students' Affective Learning Toward Homelessness Through Persuasive Video Game Play Dana N. Ruggiero

Incentives to Participate in Online Research: An Experimental Examination of "Surprise" Incentives Andrew T. Fiore, Coye Cheshire, Lindsay Shaw Taylor, G. A. Mendelsohn 
7/7AB alt.chi: Intimate Interfaces

CHAIR: CONOR LINEHAN

Fifty Shades of $\mathrm{CHI}$ : The Perverse and Humiliating Human-Computer Relationship

Laura Buttrick, Conor Linehan, Ben Kirman, Dan O'Hara

Brave New Interactions: Performance-Enhancing Drugs for Human-Computer Interaction

Henning Pohl

A Three-dimensional Mirror Augmented by Medical Imaging: Questioning Self-portraying at the Limit of Intimacy Tom Giraud, Matthieu Courgeon, Marion Tardieu, Alexandra Roatis, Xavier Maitre

Concordance: Design Ideal for Facilitating Situated Negotiations in Out-of-clinic Healthcare

Naveen L. Bagalkot, Erik Grönvall, Tomas Sokoler

HALL G Papers: Whole Body Sensing and Interaction

CHAIR: OTMAR HILLIGES

Combining Body Pose, Gaze, and Gesture to Determine Intention to Interact in Vision-Based Interfaces Julia Schwarz, Charles C. Marais, Tommer Leyvand, Scott E. Hudson, Jennifer Mankoff

Wave to Me: User Identification Using Body Lengths and Natural Gestures

Eiji Hayashi, Manuel Maas, Jason I. Hong

Haptic Turk: A Motion Platform Based on People Lung-Pan Cheng, Patrick Lühne, Pedro Lopes, Christoph Sterz, Patrick Baudisch

Audience Experience in Social Videogaming: Effects of Turn Expectation and Game Physicality John Downs, Frank Vetere, Steve Howard, Steve Loughnan, Wally Smith

7/8AB Papers: Novel Mobile Displays and Devices CHAIR: CLIFTON L. FORLINES

Exploiting Thermal Reflection for Interactive Systems Alireza Sahami Shirazi,Yomna Abdelrahman, Stefan Schneegass, Mohammadreza Khalilbeigi, Niels Henze, Albrecht Schmidt

MisTable: Reach-through Personal Screens for Tabletops Diego Martinez Plasencia, Edward Joyce, Sriram Subramanian

What is a Device Bend Gesture Really Good for? Teemu T.Ahmaniemi, Johan Kildal, Merja Haveri

SurfacePhone: A Mobile Projection Device for Single- and Multiuser Everywhere Tabletop Interaction

Christian Winkler, Markus Löchtefeld, David Dobbelstein, Antonio Krüger, Enrico Rukzio
80IA Papers: HCl Paradigms: Past, Present and Future CHAIR: JEFFREY BARDZELL

Is Once Enough? On the Extent and Content of Replications in Human-Computer Interaction

Kasper Hornbæk, Søren S. Sander, Javier A. Bargas-Avila, Jakob Grue Simonsen

Binding the Material and the Discursive with a Relational Approach of Affordances

Huatong Sun, William F. Hart-Davidson

The Turn to Practice in $\mathrm{HCl}$ : Towards a Research Agenda Kari Kuutti, Liam J. Bannon

U CHI 1994-20 I3: Mapping Two Decades of Intellectual Progress through Co-word Analysis

Yong Liu, Jorge A. Goncalves, Denzil S. Ferreira, Bei Xiao, Simo J. Hosio, Vassilis Kostakos

\section{IB Papers: PolitiCHI}

CHAIR: DARREN GERGLE

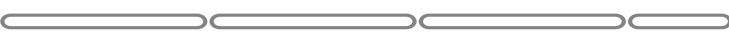

STP "Narco" Emotions: Affect and Desensitization in Social Media during the Mexican Drug War

Munmun De Choudhury, Andres Monroy-Hernandez, Gloria Mark

A Pool of Dreams: Facebook, Politics and the Emergence of a Social Movement

Clara Crivellaro, Rob Comber, John Bowers, Peter C. Wright, Patrick Olivier

W SharedValues/Conflicting Logics: Working Around E-Government Systems

Amy Voida, Lynn S. Dombrowski, Gillian R. Hayes, Melissa Mazmanian

Rethinking Plan A for Sustainable HCl

Bran Knowles, Lynne Blair, Paul Coulton, Mark Lochrie

\section{AB Course: C20-1}

Hands-on Sketching Course

Stephanie Foehrenbach
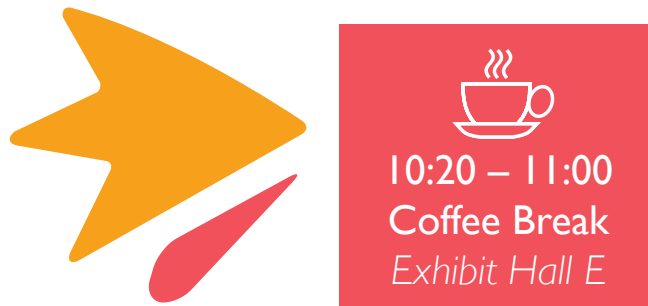
70 I A Papers: Location-Based Services and Navigation CHAIR: MARK PERRY

HaptiMoto: Turn-by-Turn Haptic Route Guidance Interface for Motorcyclists

Manoj Prasad, Paul Taele, Daniel Goldberg, Tracy A. Hammond

Experimental Evaluation of User Interfaces for Visual Indoor Navigation

Andreas Möller, Matthias Kranz, Stefan Diewald, Luis Roalter, Robert Huitl, Tobias Stockinger, Marion Koelle, Patrick A. Lindemann

Q Digitally Driven: How Location Based Services Impact the Work Practices of London Bus Drivers

Gary Pritchard, John Vines, Pam Briggs, Lisa Thomas, Patrick Olivier

Smart Flashlight: Map Navigation Using a

Bike-Mounted Projector

Alexandru Dancu, Zlatko Franjcic, Morten Fjeld

Partially Intelligent Automobiles and Driving Experience at the Moment of System Transition

Key Jung Lee, Yeon Kyoung Joo, Clifford Nass

70IB Papers: Crowdsourcing

CHAIR: STEVEN P.DOW

Slide to X: Unlocking the Potential of Smartphone Unlocking Khai N. Truong, Thariq Shihipar, Daniel J.Wigdor

Twitch Crowdsourcing: Crowd Contributions in Short Bursts of Time

Rajan Vaish, Keith Wyngarden, Jingshu Chen, Brandon Cheung, Michael S. Bernstein

Crowdsourcing the Future: Predictions Made with a Social Network

Clifton L. Forlines, Sarah Miller, Leslie Guelcher, Robert Bruzzi

U Cognitively Inspired Task Design to Improve User Performance on Crowdsourcing Platforms Harini Alagarai Sampath, Rajeev Rajeshuni, Bipin Indurkhya

7|I Course: C2I-2

Speech-based Interaction: Myths, Challenges, and Opportunities

Cosmin Munteanu, Gerald Penn

\section{7|3AB Course: C22-2}

The Glass Class: Designing Wearable Interfaces Mark Billinghurst, Hayes Raffle
7| 4AB Papers: Desktop Search and History

CHAIR: HUAHAIYANG

Searching for Myself: Motivations and Strategies for Self-Search

Catherine C. Marshall, Siân E. Lindley

8 Finder Highlights: Field Evaluation and Design of an Augmented File Browser

Stephen Fitchett, Andy Cockburn, Carl Gutwin

PIM and Personality: What do our Personal File Systems Say About Us?

Charlotte Massey, Sean TenBrook, Chaconne Tatum, Steve Whittaker

U Show Me the Invisible: Visualizing Hidden Content

Thomas Geymayer, Markus Steinberger, Alexander Lex, Marc Streit Dieter Schmalstieg

\section{I5A Special Interest Group}

Effectively Communicating User Research in Order to Drive Design and Product Decisions

Karen Holtzblatt, Shoshana Holtzblatt

\section{A Case Studies: Cross-Perspective Collaboration} CHAIR: CONNOR UPTON

$\mathrm{HCl}$ Interventions with Nonprofit Organizations: Tactics for Effective Collaboration

Vicki Moulder, Lorna Boschman, Ron Wakkary, William Odom, Stacey Kuznetsov

Redefinition of Requirements in the Design and Development of the Project Mapocci:

From Digital Art to $\mathrm{HCl}$ Research Lilia Villafuerte, Laura Malinverni

An Extended Case Study Methodology for Investigating Influence of Cultural, Organizational, and Automation Factors on Human-Automation Trust

Kolina Koltai, Nhut Ho, Gina Masequesmay, David Niedober, Mark Skoog, Walter Johnson, Artemio Cacanindin, Joseph Lyons

Questions \& Answers and Discussion for All Case Studies

7 I6B Papers: Lost and Found in Translation

CHAIR: TIAGO GUERREIRO

"Maybe It Was a Joke" - Emotion Detection in Text-Only Communication by Non-Native English Speakers Ari M. Hautasaari, Naomi Yamashita, Ge Gao

TransPhoner: Automated Mnemonic Keyword Generation Manolis Sawa, Angel X. Chang, Christopher D. Manning, Pat Hanrahan

AudioCanvas: Internet-Free Interactive Audio Photos Simon Robinson, Jennifer S. Pearson, Matt Jones

The Impact of Visual Contextualization on UI Localization Luis A. Leiva, Vicent Alabau

Improving Machine Translation by Showing Two Outputs Bin Xu, Ge Gao, Susan R. Fussell, Dan Cosley 
7I7AB Papers: Participatory Design

CHAIR: MONA LEIGH GUHA

Diversity for Design: A Framework for Involving Neurodiverse Children in the Technology Design Process

Laura J. Benton, Asimina Vasalou, Rilla Khaled, Hilary Johnson, Daniel Gooch

$\mathbf{~ C a n i n e - C e n t e r e d ~ I n t e r f a c e ~ D e s i g n : ~ S u p p o r t i n g ~ t h e ~ W o r k ~ o f ~}$ Diabetes Alert Dogs

Charlotte L. Robinson, Clara Mancini, Janet van der Linden, Claire Guest, Robert Harris

Q Co-constructing Child Personas for Health-Promoting

Services with Vulnerable Children

Pontus Wärnestål, Petra Svedberg, Jens Nygren

Balancing Design Tensions: Iterative Display Design to Support Ad Hoc and Multidisciplinary Medical Teamwork Diana S. Kusunoki, Aleksandra Sarcevic, Nadir Weibel, Ivan Marsic, Zhan Zhang, Genevieve Tuveson, Randall S. Burd

\section{HALL G Papers: Brain Computer Interfaces}

CHAIR: LYNNE BAILLIE

Error Related Negativity in Observing Interactive Tasks Chi Thanh T.Vi, Izdihar Jamil, David Coyle, Sriram Subramanian

D Dynamic Difficulty Using Brain Metrics of Workload

Daniel A. Afergan, Evan M. Peck, Erin T. Solovey, Andrew Jenkins, Samuel W. Hincks, Eli T. Brown, Remco Chang, Robert J.Jacob

Measuring the Effect of Think Aloud Protocols on Workload using $\mathrm{ANIRS}$

Matthew F. Pike, Horia A. Maior, Martin Porcheron, Sarah C. Sharples, Max L.Wilson

W An EEG-based Approach for Evaluating Audio Notifications under Ambient Sounds

Yi-Chieh Lee, Wen-Chieh Lin, Jung-Tai King, Li-Wei Ko, Yu-Ting Huang, Fu-Yin Cherng

\section{I8AB Papers: 3D Printing and Fabrication}

CHAIR: ALEX OLWAL

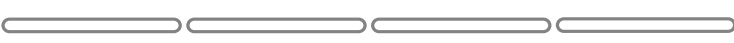

I faBrickation: Fast 3D printing of Functional Objects by Integrating Construction Kit Building Blocks

Stefanie Mueller, Tobias Mohr, Kerstin Guenther, Johannes Frohnhofen, Patrick Baudisch

Understanding Physical Activity through 3D Printed

Material Artifacts

Rohit A. Khot, Larissa Hjorth, Florian ' Mueller

Supporting The Design and Fabrication of Physical Visualizations

Saiganesh Swaminathan, Conglei Shi, Yvonne Jansen, Pierre Dragicevic, Lora A. Oehlberg, Jean-Daniel Fekete

9I8 MixFab: A Mixed-Reality Environment for Personal Fabrication

Christian Weichel, Manfred Lau, David Kim, Nicolas Villar. Hans W. Gellersen
80IA Papers: Modeling Users and Interaction

CHAIR: NIKLAS L. ELMQVIST

$\mathbf{W}$ Model of Visual Search and Selection Time in Linear Menus

Gilles Bailly, Antti Oulasvirta, Duncan P. Brumby, Andrew Howes

9I8 Towards Accurate and Practical Predictive Models of Active-Vision-BasedVisual Search

David E. Kieras, Anthony J. Hornof

978 Understanding Multitasking Through Parallelized Strategy Exploration and Individualized Cognitive Modeling Yunfeng Zhang, Anthony J. Hornof

W How Does Knowing What You Are Looking For Change Visual Search Behavior?

Duncan P. Brumby, Anna L. Cox, Jacqueline Chung, Byron Fernandes

Automated Nonlinear Regression Modeling for $\mathrm{HCl}$

Antti Oulasvirta

80 I B Papers: Engaging Older Adults Through Technology CHAIR: JOANNA MCGRENERE

Understanding Digital and Material Social Communications for Older Adults

Alexis Hope, Ted Schwaba, Anne Marie Piper

W NeverToo Old: Engaging Retired People Inventing the

Future With MaKey MaKey

Yvonne Rogers, Jeni Paay, Margot Brereton, Kate L. Vaisutis,

Gary Marsden, Frank Vetere

What's on Your Mind? Investigating Recommendations for Inclusive Social Networking and Older Adults Chris Norval, John L. Arnott, Vicki L. Hanson

Being Senior and ICT: A Study of Seniors Using ICT in China Yuling Sun, Xianghua Ding, Silvia Lindtner, Tun Lu, Ning Gu

\section{AB Course: C20-2}

Hands-on Sketching Course

Stephanie Foehrenbach

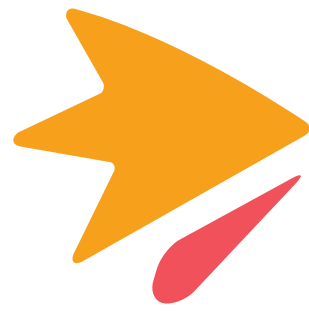

$12: 20-14: 00$

Lunch Break

Restaurants, bars

\& cafés available nearby 
70IA Papers: Computer Mediated Intimacy and Romance CHAIR: JOHNTHOMAS

The Lonely Raccoon at the Ball: Designing for Intimacy, Sociability, and Selfhood Jeffrey Bardzell, Shaowen Bardzell, Guo Zhang, Tyler Pace

Q Room for Interpretation: The Role of Self-Esteem and CMC in Romantic Couple Conflict

Lauren E. Scissors, Michael E. Roloff, Darren Gergle

Exploring Affective Communication Through Variable-Friction Surface Haptics

Joseph M. Mullenbach, Craig Shultz, J. Edward Colgate,Anne Marie Piper

Wrigglo: Shape-Changing Peripheral for Interpersonal Mobile Communication

Joohee Park, Young-Woo Park, Tek-Jin Nam

\section{I B Papers: Network of Care}

CHAIR: PATRICK OLIVIER

Recreating Living Experiences from Past Memories through Virtual Worlds for People with Dementia

Panote Siriaraya, Chee Siang Ang

Addressing the Subtleties in Dementia Care:

Pre-study \& Evaluation of a GPS Monitoring System

Lin Wan, Claudia Müller, Volker Wulf, David W. Randall

Sweet Home: Understanding Diabetes Management via a Chinese Online Community

Xiaomu Zhou, Si Sun, Jiang Yang

Moderated Online Social Therapy: Designing and Evaluating Technology for Mental Health

Reeva M. Lederman, Greg Wadley, John Gleeson, Sarah Bendall, Mario Alvarez-Jimenez

\section{Course: C24}

How You Could Benefit from Using ISO Standards Nigel Bevan

\section{II Course: C25}

Evaluating Children's Interactive Products

Janet Read, Panos Markopoulos

\section{7/3AB Course: CHInd-G}

Uncovering the Ordinary, Inspiring the Extraordinary:

A Conversation with Susan Dray

Susan Dray, Elizabeth Churchill
7|4AB Papers: Tutorials

CHAIR: MORGAN E. DIXON

I Investigating the Feasibility of Extracting Tool

Demonstrations from In-Situ Video Content

Ben Lafreniere, Tovi Grossman, Justin Matejka, George Fitzmaurice

Q Crowdsourcing Step-by-Step Information Extraction to Enhance Existing How-to Videos

Juho Kim, Phu T. Nguyen, Sarah Weir, Philip J. Guo, Robert C. Miller, Krzysztof Z. Gajos

EverTutor: Automatically Creating Interactive Guided Tutorials on Smartphones by User Demonstration Cheng-Yao Wang, Wei-Chen Chu, Hou-Ren Chen, Chun-Yen Hsu, Mike Y. Chen

TaggedComments: Promoting and Integrating User Comments in Online Application Tutorials

Andrea Bunt, Patrick Dubois, Ben Lafreniere, Michael A. Terry, David T. Cormack

\section{I5A Panel}

Can You Do Good and Do Well? Exploring $\mathrm{HCl}$ Careers for Societal Impact

Anupam Jain, Matthew Kam, Michael Best, Elizabeth Gerber, Rowena Luk

716A Case Studies: Creating Methods

CHAIR: VICKI MOULDER

$\Longleftarrow \Longleftarrow \Longleftarrow$

Measuring Product "Coolness" -- Developing a

Measurement Instrument

Carol Farnsworth, Karen Holtzblatt, Shantanu Pai, Theo Held,

Sally Lawler Kennedy, Eli Wylen, Pallavi Kutty, Kelley Wagg

Online Microsurveys for User Experience Research

Victoria Schwanda Sosik, Elie Bursztein, Sunny Consolvo, David Huffaker, Gueorgi Kossinets, Kerwell Liao, Paul McDonald, Aaron Sedley

GREYBOX Scheduling: Designing a Joint Cognitive System for Sustainable Manufacturing

Connor Upton, Fergus Quilligan

Questions \& Answers and Discussion for All Case Studies

\section{7 /6B Papers: Driving Interfaces and Evaluations}

CHAIR: DAVID S. KIRK

A Smartphone-based Sensing Platform to Model Aggressive Driving Behaviors

Jin-Hyuk Hong, Ben Margines, Anind K. Dey

Designing Interfaces for Multiple-Goal Environments: Experimental Insights from In-Vehicle Speech Interfaces Sergej Truschin, Michael Schermann, Suparna Goswami, Helmut Krcmar

X Classifying Driver Workload Using Physiological and Driving Performance Data: Two Field Studies

Erin T. Solovey, Marin Zec, Enrique A. Abdon Garcia Perez, Bryan Reimer, Bruce Mehler

Evaluating Multimodal Driver Displays underVarying Situational Urgency

loannis Politis, Stephen A. Brewster, Frank Pollick 
HALL G Papers: Gesture-Based Interaction

CHAIR: JOERG MUELLER

Multi-Viewer Gesture-Based Interaction for Omni-Directional Video

Gustavo A. Rovelo Ruiz, Davy Vanacken, Kris Luyten, Francisco Abad, Emilio Camahort

Making Big Gestures: Effects of Gesture Size on Observability and Identification for Co-Located Group Awareness

Adrian Reetz, Carl Gutwin

A Chair as Ubiquitous Input Device: Exploring Semaphoric Chair Gestures for Focused and Peripheral Interaction Kathrin Probst, David Lindlbauer, Michael Haller, Bernhard Schwartz, Andreas Schrempf

Exploring the Design Space of Gestural Interaction with Active Tokens through User-Defined Gestures

Consuelo Valdes, Diana Eastman, Casey Grote, Shantanu Thatte, Orit Shaer, Ali Mazalek, Brygg Ullmer, Miriam K. Konkel

7 I 8 AB Papers: Interactive Surfaces and Pervasive Displays

\section{CHAIR: AARON QUIGLEY}

Q Pervasive Information through Constant Personal Projection: The Ambient Mobile Pervasive Display (AMP-D)

Christian Winkler, Julian Seifert, David Dobbelstein, Enrico Rukzio

Bigger is Not Always Better: Display Size, Performance, and Task Load during Peephole Map Navigation

Roman Rädle, Hans-Christian Jetter, Jens Müller, Harald Reiterer

Mechanical Force Redistribution: Enabling Seamless, Large-Format, High-Accuracy Surface Interaction Alex M. Grau, Charles Hendee, John-Ross Rizzo, Ken Perlin

Effects of Display Size and Navigation Type on a Classification Task

Can Liu, Olivier Chapuis, Michel Beaudouin-Lafon, Eric Lecolinet, Wendy E. Mackay
80IA Papers: Research and Deployment in the Wild

CHAIR: WENDY MONCUR

Performance-led Research In The Wild

Steve Benford, Chris Greenhalgh, Andy Crabtree, Martin Flintham Brendan Walker, Joe Marshall, Boriana Koleva,

Stefan J. Rennick-Egglestone, Gabriella Giannachi, Matt Adams

Wild at Home: The Neighborhood as a Living Laboratory for $\mathrm{HCl}$

John M. Carroll, Mary Beth Rosson

Of Catwalk Technologies and Boundary Creatures Anne Adams, Elizabeth FitzGerald, Gary Priestnall

A Large Scale Study of Daily Information Needs

Captured In-Situ

Karen Church, Mauro Cherubini, Nuria Oliver

\section{IB Papers: Social Media for Relationships}

CHAIR: WILLIAM ODOM

Stewarding a Legacy: Responsibilities and Relationships in the Management of Post-mortem Data

Jed R. Brubaker, Lynn S. Dombrowski, Anita M. Gilbert,

Nafiri Kusumakaulika, Gillian R. Hayes

Captioned Photographs in Psychosocial Aged Care:

Relationship Building and Boundary Work

Jenny Waycott, Hilary Davis, Frank Vetere, Amee Morgans, Alan Gruner, Elizabeth Ozanne, Lars Kulik

The Routines and Needs of Grandparents and Parents for Grandparent-Grandchild Conversations Over Distance

Azadeh Forghani, Carman Neustaedter

SIP Growing Closer on Facebook: Changes in Tie Strength

Through Social Network Site Use

Moira Burke, Robert E. Kraut

802AB Course: C23

A Crash Course in Modern Geography for HCl Researchers and Practitioners

Brent Hecht, David Shamma

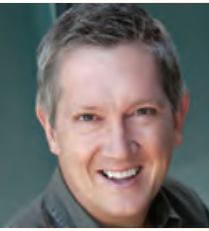

Closing Keynote

16:00 - 17:20

Exhibit Hall G
Scott Jenson, Google, Inc. The Physical Web 
WORKSHOPS

$\mathrm{CHI} 2014$ workshops take place at the Convention Center levels 700 and 800 except the workshop W0I which will take place at the University of Toronto. Workshops are accessible only to pre-registered attendees.

2-Day Workshops: Saturday 26 - Sunday 27 April Room

WOI Critical Making Hackathon: Situated Hacking,

Surveillance and Big Data - K. Tanenbaum, J. Tanenbaum,

A. Williams, M. Ratto, G. Resch, A. G. Bari

This workshop will be held at the Critical Making Lab which is located in the Semaphore Research Cluster at the University of Toronto, 7th floor of Robarts Library, I30 St. George Street, on the St. George (downtown) campus. Please take the P4 elevator on the 2nd floor of Robarts - this is the only elevator that goes to the 7 th floor.

W02 Curating the Digital: Spaces for Art and Interaction - 70।B D. England, I. Spence, C. Latulipe, E. Edmonds, L. Candy, T. Schiphorst, N. Bryan-Kinns, K. Woolford

W03 Game Jam [4 Research] - M. Deen, R. Cercos, A. Chatman, 80IA A. Naseem, R. Bernhaupt, A. Fowler, B. Schouten, F. Mueller

W04 Interaction and Architectural Space - N. Dalton, K. Green, R. Dalton, A. Mathew, C. Hoelscher, M. Wiberg, H. Schnädelbach, T. Varoudis

I-Day Workshop: Saturday 26 April

W06 Autonomy in Technology Design - R. Calvo, D. Peters, D. Johnson, Y. Rogers

W07 "Touch me" Workshop on Tactile User Experience Evaluation Methods - M. Tscheligi, K. Isbister, K. Höök, M. Obrist, M. Busch, C. Hochleitner

W08 Alternate Endings: Using Fiction to Explore Design Futures - C. Linehan, B.Kirman, S. Reeves, M. Blythe, J. Tanenbaum, A. Desjardins, R. Wakkary

W09 Participatory Design with People Living with Cognitive or Sensory Impairments - K. Slegers, P. Duysburgh, N. Hendriks

WIO Perspectives on Gender and Product Design S. Dray, D. Busse, A. Brock, A. Peters, S. Bardzell, A. Druin, M. Burnett, E. Churchill, G. Williams, K. Holtzblatt, D. Murray

WI2 Gesture-based Interaction Design: Communication and Cognition - M. L. Maher, T. Clausner, B. Tversky, D. Kirsh, J. Kay, A. Danielescu, K. Grace

WI3 Refusing, Limiting, Departing: Why We Should Study 7I4A Technology Non-use - E. Baumer, M. Ames, J. Brubaker, J. Burrell, P. Dourish

WI4 Socially Engaged Arts Practice in $\mathrm{HCl}-\mathrm{R}$. Clarke, J. Briggs, A. Light, S. Heitlinger, C. Crivellaro

WI5 Designing Speech and Language Interactions C. Munteanu, M. Jones, S. Whittaker, S. Oviatt, M. Aylett, G. Penn, S. Brewster, N. d'Alessandro

WI6 Understanding Teen UX: Building a Bridge to the Future - D. Fitton, B. Bell, J. Read, O. Iversen, L. Little, M. Horton

WI7 Designing Technology for Major Life Events M. Massimi, S. Yarosh, M. Smith, J. Kaye

WI8 HCl Research in Healthcare: Evidence to Practice K. Sellen, D. Furniss, Y. Chen, S. Taneva, A. A. O'Kane, A. Blandford

WI9 Workshop on Inconspicuous Interaction D. Marques, L. Carriço, T. Guerreiro, A. De Luca, P. Maes, 1. Oakley, E. von Zezschwitz, I. Muslukhov
$715 \mathrm{~A}$
Room

I-Day Workshop: Sunday 27 April

Room

W20 Beyond Quantified Self: Data for Wellbeing J. Meyer, S. Simske, K. Siek, C. Gurrin, H. Hermens

W2I Peripheral Interaction: Shaping the Research and Design Space - S. Bakker, D. Hausen, T. Selker, E. van den Hoven, A. Butz, B. Eggen

W22 Workshop on Assistive Augmentation - J. Huber J. Rekimoto, M. Inami, R. Shilkrot, P. Maes, W. Meng, G. Pullin, S. Nanayakkara

W23 Personalizing Behavior Change Technologies G. Hsieh, S. Munson, M. Kaptein, H. Oinas-Kukkonen, O. Nov

W24 \#CHIMoney: Financial Interactions, Digital Cash, Capital Exchange and Mobile Money - J. Ferreira, J. Vertesi, J. Kaye, B. Brown, M. Perry

W25 $\mathrm{HCl}$ and Sports - S. Nylander, J. Tholander, F. Mueller, J. Marshall

W26 Supporting Children with Complex Communication Needs - J. P. Hourcade, F. Garzotto, A. Rozga, M. Tentori, P. Markopoulos, N. Pares, J. Good, H. Pain, M. Alper

W27 Biological Rhythms and Technology - M. Matthews, E. Carroll, S. Abdullah, J. Snyder, M. Kay, T. Choudhury, G. Gay, J. Kientz

W28 Values \& Design in $\mathrm{HCl}$ Education - J.A. Koepfler, C. L. Stark, P. Dourish, P. Sengers, K. Shilton

W29 Learning Innovation at Scale - J. Williams, R. Kizilcec, S. Klemmer, D. Russell

W30 Developing a Living $\mathrm{HCl}$ Curriculum to Support a Global Community - E. Churchill, J. Preece, A. Bowser

$716 \mathrm{~A}$

$802 A B$

W3I Enabling Empathy in Health and Care: Design Methods and Challenges - A. Thieme, J. Vines, J. Wallace, R. Clarke, P. Slovák, J. McCarthy, M. Massimi, A. G. Parker

W32 What Have We Learned? A SIGCHI HCl \& Sustainability Community Workshop - M. Six Silberman, E. Blevis, E. Huang, B. Nardi, L. Nathan, D. Busse, C. Prei, S. Mann

W33 Player Experience: Mixed Methods and Reporting 713B Results - V. Zammitto, P. Mirza-Babaei, I. Livingston, M. Kobayashi, L. Nacke
$716 \mathrm{~B}$

$718 \mathrm{~A}$ 


\section{DOCTORAL CONSORTIUM}

Selected doctoral students present and explore their research topics with senior researchers and other students in a two-day interdisciplinary workshop. Doctoral Consortium posters are displayed in Exhibit Hall E and brief descriptions appear in the $\mathrm{CHI} 2014$ Extended Abstracts.

Saturday - Sunday

Doctoral Consortium

(Room 7| I)

Tuesday

10:20 - | 1:00 Meet the poster authors

(Exhibit Hall E)

Tuesday - Thursday

Posters on display during opening hours $\quad$ (Exhibit Hall E)

Doctoral Consortium Faculty

Bill Buxton

Microsoft Research

Adrian Cheok

Kristina Höök

City University London, UK

Katherine Isbister (Co-Chair)

Clifford Nass (In Memory)

Yvonne Rogers

Manfred Tscheligi (Co-Chair)

Stockholm University \& KTH, Sweden

New York University, USA

Stanford University, USA

University College London, UK

University of Salzburg, Austria

Participants

A Beep, a Flash, a Rumble? Evaluating Multimodal Displays

for Drivers

I. Politis

Making Bare Hand Input More Accurate

C. Wacharamanotham

Digital Naturalism: Designing Holistic Ethological Interaction

A. Quitmeyer

Supporting Teaching and Learning of Situational Empathy

by Technology

P. Slovák

Investigating the Adoption of Local Online Communities

C. López

Happy is Pink: Designing for Intuitive Use with

Color-to-Abstract Mappings

D. Löffler

The Development of Novel Eyes-Free Exercise Technologies Using

Participatory Design

K. Rector

Persistent Workplace Plug-load Energy Savings and Awareness

through Energy Dashboards: Eco-feedback, Control, and

Automation

R.Yun

User Experience and the Human Spirit

E.A. Buie

Intelligent Sketching Interfaces for Richer Mid-Air

Drawing Interactions

P.Taele

The Afterlife of Digital Identity

J.R. Brubaker

Human Interaction with Assistive Free-Flyers

D. J. Szafir

Theory-driven Design for Healthy Eating

J. Hou

Fashion Thinking and Sustainable HCl

Y.Pan

EngageME: A Tool to Simplify the Conveyance of Complicated Data S.S. S. Darnell

\section{STUDENT RESEARCH COMPETITION}

The Student Research Competition (SRC) is a forum for undergraduate and graduate students to showcase their research, exchange ideas, and improve their communication skills while competing for prizes. Sponsored by Microsoft Research, the SRC is a branch of the ACM SRC. Winners are announced at the Closing Plenary.

Monday

16:00 - 17:20 Judging (jury \& competitors only) (Room 7|5B) Tuesday
15:20 - 16:00 Posters highlighted during the afternoon break
(Exhibit Hall E)

Wednesday

1 1:00 - 12:20 Posters presentations open to all conference attendees

(Room 7|7AB)

Jury

Melanie Feinberg

Mary Czerwinski

Uni. of Texas at Austin, USA

Edward Lank

Microsoft Research, USA

Finalists

A Mobile Point-of-Care Diagnostic System for

Low-Resource Settings

Nicola Lee Dell

Cassandra: A Crowdsourced Testbed for Content Assessment of Potential Social Media Posts

Himel Dev

Okinawa in Japanese and English Wikipedia

Scott A. Hale

Designing Ballot Interfaces for Voters with Vision Disabilities Seunghyun Lee

Shoulder Surfing Susceptibility of Bend Passwords

Sana Maqsood

Low-Income Parents' Perceptions of Technology: Value-based

Design Insights

David Munoz

Virtual Inclusion Via Telepresence Robots In The Classroom Veronica Ahumada Newhart

Flying Display: A Movable Display Pairing Projector and Screen in the Air

Hiroki Nozaki

Exploring Tapping with Thumb Input for Flexible Tablets Md Riyadh

The Perceptual Benefits of a Tangible Interface Decrease with

Users' Expertise

Bertrand Schneider

Autonomy-based Rehabilitation Design: Balancing Capability and Complexity

Kyoungwon Seo

Digital Classroom Magazines: Design Considerations for

Young Learners

Jeff Stern

The Agony of Passwords: Can We Learn from User

Coping Strategies?

Elizabeth Stobert

VisiStat: Visualization-driven, Interactive Statistical Analysis Krishna Subramanian

Learnersourcing Subgoal Labels for How-to Videos Sarah A. Weir 


\section{STUDENT DESIGN COMPETITION}

This is the 12th year of the CHI Student Design Competition (SDC). This year's conference theme "One of a CHInd" focuses our SDC design challenge on the one of a kind diversity that is made up of the individual selves that create our community. The growing design domain of the Quantified Self has been made possible through the integration of low-cost sensing technologies with proliferating applications available through mobile and internet technologies. There is a context of sensory-rich data from biometric, health, neoanalog, DIY culture and geophysical sensing that expands our ability to augment or shift our perspectives and our knowledge. Self-tracking, self-management and self-awareness are activities that promote agency and transformation of our own growing accumulation of bodydata. How can we transform this overwhelming incoming bodydata into self-knowledge?

Monday

| 1:00 - 12:20 Judging (jury \& competitors only) (Room 7।5B) Tuesday

15:20 - 16:00 Meet the poster authors

(Exhibit Hall E)

Wednesday

| 4:00 - | 5:20 Finalist presentations

(Room 7I7AB)

Tuesday-Thursday

Posters on display during opening hours (Exhibit Hall E) Jury

Mark Blythe

Aisling Kelliher

Tek-Jin Nam

llona Posner

Northumbria University, UK

Carnegie Mellon University, USA

KAIST, South Korea

User Experience Consultant, Canada

Finalists

Oris: Enhance Social Self-Awareness forVisually Impaired People Xuan Luo, Yu Xu, Clark Mullen

MAES:TRO: A Practice System to Track, Record, and Observe for Novice Orchestral Conductors

Ekaterina Ivanova, Lulu Wang, Yihe Fu, Jeffrey Gadzala

KNEE: An Everyday Wearable Goniometer for Monitoring Physical Therapy Adherence

David Munoz, Andy Pruett, Graceline Williams

Sisyphorest: Maintenance Goal Support by Responding to Trends William Saunders, Filip Krynicki, Valerie Sugarman

Beam: A Mobile Application to Improve Happiness and

Mental Health

Joyce Sakata, Mengdi Zhang, Shi Pu, Jianqi Xing, Kritika Versha

NeckGraffe: A Postural Awareness System

Rushil Khurana, Elena Marinelli, Tulika Saraf, Li Shan

InnoMotion - A Web-Based Rehabilitation System Helping Patients Recover and Gain Self-Awareness of their Body Away from the Clinic Luxi Chen, Ni Yan, Miranda Kiang, Anna S. Muth, Kruthi Sabnis Krishna

Fitnamo - Exercise Motivation App For Google Glass

Edward Nguyen, Tanmay Modak, Elton Dias, Yang Yu, Liang Huang

Bloom: Fostering Healthy and Peaceful Pregnancies with Personal Analytics

Max S. Wenger, Jarad Bell, Peter McEvoy, Asuka Cherie Yamaguchi, Auriana Shokrpour

DAYA: A System for Monitoring and Enhancing Children's Oral Hygiene

Kejia Shao, Jiye Huang, Huaying Song, Runze Li, Jinxi Wu

Nuwa: Enhancing The Pregnancy Experience for Expectant Parents Yuan Gao, Xinying Li, Yu-Hsuan Lin, Xin Liu, Lin Pang

Baby Lucent: Pitfalls of Applying Quantified Self to Baby Products Kevin Gaunt, Júlia Nacsa, Marcel Penz

\section{STUDENT GAME COMPETITION}

The Games and Entertainment Special Community created this competition to showcase student work in areas of game design and development that connect strongly to the $\mathrm{CHI}$ community of research and practice. Students submitted games as well as extended abstracts clarifying innovative aspects of their work. The jury selected three finalist games in each category-Games for a Purpose, Innovative Interface and Innovative Game Design — and the winner in each category will be announced at the awards session on Wednesday afternoon

$\mathrm{CHI}$ attendees can play the games on Wednesday morning in Exhibit Hall E.The SGC winners are announced at the Closing Plenary.

Games for a Purpose: Games submitted to this category are designed not just to entertain, but also to accomplish some end goal. Examples include games for health, learning games, journalistic games. Innovative Interface: Games submitted to this category push the boundaries of current interface practice. Examples include the use of gesture, multi-touch, or haptics; voice input; use of sensors such as breathing or heart rate; and augmented reality games for mobile platforms.

Innovative Game Design: Games submitted to this category push the boundaries of current game mechanics and/or design. Examples include games that add novel mechanics that have not been used before, add new visual or audio themes/dynamics, explore new mixes of mechanics, story and character elements, automated techniques for adaptive designs, or explore new forms of interaction that are thought provoking.

Wednesday

10:00 - 14:00 Demonstrations by the finalists (Exhibit Hall E) 16:00 - 17:20 Presentations and awards

(Room 7|7AB)

Jury
Seth Cooper
University of Washington, USA
Alessandro Canossa Northeastern University, USA

Finalists

Disguise: A Game that Evaluates Visualization Algorithms Nafees U.Ahmed

Find the Jackalop: A Game Enhancing Young Children's

Spatial Thinking

George Kalmpourtzis

Chorlody: A Music Learning Game

Yang Liu, Ni Yan, Dili Hu

Mute Robot - Cooperative Gameplay through Body

Language Communication

Chun-Yen Hsu, Ying-Chao Tung, Wei-Han Wang, Han-Yu Wang

i-dentity: Concealing Movement Representation Associations

in Games

Jayden Garner, Gavin Wood

Drunken Ed: A Balance Game for Public Large Screen Displays Alexander Biskupski, Andreas R. Fender, Tiare M. Feuchtner, Marcel Karsten, Jonas D. Willaredt

Foot Motion Sensing: Augmented Game Interface Based on Foot Interaction for Smartphone

Zhihan Lu

Volcano Salvation: Interaction through Gesture and HeadTracking Sheila Christian, Júlio Alves, André Ferreira, Dinarte Jesus, Rúben Freitas, Nelson Vieira 


\section{COURSES}

Courses allow $\mathrm{CH}$ attendees to extend their knowledge beyond their current community and their current areas of expertise. Courses are taught in one to three 80-minute units.

This year, $\mathrm{CHI}$ is pleased to offer six "One of a CHInd Courses". These are special invited courses that will be given by distinguished members of the $\mathrm{HCl}$ community.

Pre-registration is required. The Course Notes you receive at registration serve as your entry ticket. You may register for courses that have not yet been filled at the Registration Desk in the lobby area on the ground level.
Monday Courses, 28 April

CHInd-A Sampling \& Synthesis: The Two Sides of Experience Sketching - W. Buxton I-session: 11:00-12:20

COI Designing Unbiased Surveys for $\mathrm{HCl}$ Research H. Müller, A. Sedley, E. Ferrall-Nunge I-session: 11:00-12:20

C02 Introduction to Human-Computer Interaction Jonathan Lazar, Simone Barbosa

2-sessions: 14:00 - 15:20 and 16:00 - 17:20

C03 Methods of Design Synthesis - Moving from Data to Innovation - J. Kolko 2-sessions: 14:00 - 15:20 and 16:00 - 17:20

C04 HTML5 Game Development - J. Parker 2-sessions: 14:00 - 15:20 and 16:00-17:20

C05 Empirical Research Methods for Human-Computer 7II Interaction - S. MacKenzie, S. Castellucci 2-sessions: $14: 00-15: 20$ and 16:00 - 17:20

Tuesday Courses, 29 April

Room

$\mathrm{CH}$ nnd-F What $\mathrm{HCl}$ Can Do for Citizen Science - J.J. Preece I-session: 9:00 - 10:20

CHInd-C Reflections on Design - D. Norman I-session: 11:00- 12:20

C06 Improving the User Interface for People with Disabilities - T.Thompson

2-sessions: 9:00 - 10:20 and 1 1:00 - 12:20

C07 Card Sorting for Navigation Design - W. Hudson 2-sessions: 9:00 - 10:20 and 1 1:00 - 12:20

C08 Multimodal Detection of Affective States: A Roadmap Through Diverse Technologies J. Gonzalez-Sanchez, M. E. Chavez-Echeagaray, R. Atkinson, W. Burleson

2-sessions: 9:00 - 10:20 and 11:00 - 12:20

C09 Conceptual Models: Core to Good Design J.Johnson

2-sessions: 14:00 - 15:20 and 16:00 - 17:20

ClO Computer Vision in interaction and UX-J. Parker 2-sessions: $14: 00-15: 20$ and 16:00 - 17:20 Scientifically Informed Introduction - J. Williams, B. Williams

2-sessions: 14:00 - 15:20 and 16:00 - 17:20

$\mathrm{Cl} 2$ Mobile $\mathrm{HCl}-\mathrm{N}$. Henze, E. Rukzio

2-sessions: 14:00 - 15:20 and 16:00 - 17:20

$713 A B$

$802 A B$
CII Online A/B Tests \& Experiments: A Practical but
Wednesday Courses, 30 April

Room

CHInd-D How Social Media Design Reshapes Society J. Donath

I-session: 9:00 - 10:20

CHInd-E Designing for Seniors - R. Baecker I-session: | | 1:00 - 12:20

CI3 Agile User Experience and UCD - W. Hudson 2-sessions: 9:00 - 10:20 and 1 1:00 - 12:20

Cl4 HCl Meets Data Mining: Principles and Tools for Big Data Analytics - D. H. (Polo) Chau

2-sessions: 9:00 - 10:20 and 1 1:00 - 12:20

Cl5 Rapid Design Labs-A Tool to Turbocharge

Design-Led Innovation - J. Nieters, C. F.Thompson 2-sessions: 9:00 - 10:20 and 11:00 - 12:20

Cl6 Introduction to Designing and Building Musical Interfaces - M. Lyons, A. Mulder, S. Fels 2-sessions: 14:00 - 15:20 and 16:00 - 17:20

Cl7 Make This! Introduction to Electronics Prototyping Using Arduino - D. Sirkin, W. Ju 2-sessions: 14:00 - 15:20 and 16:00 - 17:20

Processes: Techniques and Practices - A. Druin, J. Fails, M. L. Guha 2-sessions: 14:00 - 15:20 and 16:00 - 17:20

C19 Interaction Design for Online Video and

Television - D. Geerts, P. Cesar

2-sessions: $14: 00-15: 20$ and 16:00 - 17:20

Thursday Courses, I May Room

CHInd-G Uncovering the Ordinary, Inspiring the 7/3AB Extraordinary: A Conversation with Susan Dray S. Dray, E. F. Churchill

I-sessions: 14:00 - 15:20

C20 Hands-on Sketching Course - S. Foehrenbach

$802 \mathrm{AB}$ 2-sessions: 9:00 - 10:20 and 11:00 - 12:20

C21 Speech-based Interaction: Myths, Challenges, and Opportunities - C. Munteanu, G. Penn 2-sessions: 9:00 - 10:20 and 11:00 - 12:20

C22 The Glass Class: Designing Wearable Interfaces - 7I3AB M. Billinghurst, H. Raffle

2-sessions: 9:00 - 10:20 and 1 1:00 - 12:20

A Crash Course in Modern Geography for

$\mathrm{HCl}$ Researchers and Practitioners - B. Hecht, D. Shamma

I-session: 14:00 - 15:20

C24 How You Could Benefit from Using ISO

Standards - N. Bevan I-session: 14:00 - 15:20

Evaluating Children's Interactive Products -

I-session: 14:00 - 15:20

$713 A B$

$7 \mid 3 A B$

$82 A B$

$2 \mathrm{AB}$

$3 A B$

9

Cl8 Including Children in Technology Design 


\section{VIDEO SHOWCASE}

Video Showcase features engaging videos that offer a variety of perspectives on human-computer interaction, including novel interfaces, reflective pieces and future envisionments. Come and enjoy the videos on Tuesday (17:30) followed by the Golden Mouse award ceremony.

Tuesday

$$
\text { 17:30 - 19:00 Video Showcase }
$$

Videos

The Secret Life of Computers Jonathan Aceituno, Ludovic Potier

Medi, Human Robot Interaction in Pediatric Health Setareh Aghel Manesh, Tanya Beran, Ehud Sharlin, Saul Greenberg

Electronic Kit with No Current Flow that Uses Projection Mapping Yoh Akiyama, Homei Miyashita

How I Found My Research Question

Halimat I. Alabi

Is Anyone Looking? Mediating Shoulder Surfing on Public Displays (The Video)

Frederik Brudy, David Ledo, Saul Greenberg

Paper Generators - Harvesting Energy from Touching, Rubbing and Sliding

Joanna Maria Dauner, Mustafa Emre Karagozler, Ivan Poupyrev

Plenopticon: Video Playback for Dynamically Adaptive

Depth-of-Field

David Philip Green, Thomas Smith, Guy Schofield

Learning with CyberPLAYce, a Cyber-Physical Learning Environment for Elementary Students Promoting Computational Expression Arash Soleimani, Kyle Smith, Jiawei Zeng, Keith E. Green, Danielle Herro, Jessie Santiago, Surya Sharma, Manas Tonapi, Amith Vijaykumar, lan Walker, Christina Gardner-McCune

TouchSense: Expanding Touch Input Vocabulary Using Different Areas of Users' Finger Pads

Da-Yuan Huang, Ming-Chang Tsai, Ying-Chao Tung, Min-Lun Tsai, Yen-Ting Yeh, Liwei Chan, Mike Y. Chen

Augmented Climbing: Testing Prototypes in Wizard of

Oz Experiment

Raine Kajastila, Perttu Hämäläinen

Draco: Living Illustrations

Rubaiat Habib Kazi, Fanny Chevalier, Tovi Grossman, Shengdong Zhao,

George Fitzmaurice

SweatAtoms: Understanding Physical Activity through

Material Artifacts

Rohit Ashok Khot, Jeewon Lee, Larissa Hjorth, Florian 'Floyd' Mueller

HandyScope: A Remote Control Technique using Pull-out Gesture Takuro Kuribara, Takuto Yoshikawa, Buntarou Shizuki, Jiro Tanaka

Ziklo: Bicycle Navigation Through Tactile Feedback

Brianna Jean Huxtable, Carlo Ka-Ho Lai, Johnson Wen Jun Zhu,

Paulina Mun-Yee Lam, Yeseul Tracy Choi, Carman Neustaedter, Greg J. Corness

Loopo: A Tangible Programming Game For Kids

Paulina Mun-Yee Lam, Carlo Ka-Ho Lai, Yeseul Tracy Choi, Brianna Jean Huxtable, Jan Rainier Castro, Andrew Hawryshkewich, Carman Neustaedter

GaussBricks: Magnetic Building Blocks for Constructive Tangible Interactions on Portable Displays

Rong-Hao Liang, Liwei Chan, Hung-Yu Tseng, Han-Chih Kuo, Da-Yuan Huang, De-Nian Yang, Bing-Yu Chen

ShoeSoleSense: Demonstrating A Wearable Foot Interface For Locomotion In Virtual Environments

Denys Matthies, Franz Müller, Christoph Anthes, Dieter Kranzlmüller

L.IVE: An Integrated Interactive Video-based Learning Environment Toni-Jan Keith Palma Monserrat, Shengdong Zhao, Yawen Li, Xiang Cao
faBrickation: Fast 3D printing of Functional Objects by Integrating Construction Kit Building Blocks

Stefanie Mueller, Tobias Mohr, Kerstin Guenther, Johannes Frohnhofen,

Patrick Baudisch

Wrigglo: Shape-Changing Peripheral for Interpersonal

Mobile Communication

Joohee Park, Young-Woo Park, Tek-Jin Nam

Paddle: Highly Deformable Mobile Devices with Physical Controls Raf Ramakers, Johannes Schöning, Kris Luyten

A Wearable Text-Reading Device for the Visually-Impaired Roy Shilkrot, Jochen Huber, Connie Liu, Pattie Maes,

Suranga Chandima Nanayakkara

GestKeyboard: Enabling Gesture-Based Interaction on Ordinary Physical Keyboard

Haimo Zhang, Yang Li 


\section{WORKS IN PROGRESS}

Authors are scheduled to stand by their posters during "meet the author" sessions indicated below. Please visit both rotations to see all of the exciting work being done and discuss new ideas with Poster authors.

\section{First Rotation: Tuesday all day}

Authors present their posters during the morning and afternoon breaks.

The following poster collections are on display:

$\begin{array}{lc}\text { Children and Teens } & 10101-10108 \\ \text { Accessibility } & 10201-10212 \\ \text { Augmented Reality } & 10301-10309 \\ \text { Search and InfoViz } & 10401-10410 \\ \text { Making } & 10501-10510 \\ \text { Gaming } & 10601-10614 \\ \text { Gesture and Eye-Based Interactions } & 10701-10715 \\ \text { Healthcare } & 10801-10814 \\ \text { Notifications, Awareness and Distractions } & 10901-10916 \\ \text { Interaction Techniques } & \mid 1001-11016\end{array}$

Second Rotation: Wednesday all day

Authors present their posters during the morning and afternoon breaks.

The following poster collections are on display:

$\begin{array}{ll}\text { E-Commerce } & 20101-20107 \\ \text { Communities } & 20201-20212 \\ \text { Displays } & 20301-20309 \\ \text { Social Computing } & 20401-20411 \\ \text { Ubicomp, Robots, and Wearables } & 20501-20511 \\ \text { Learning } & 20601-20614 \\ \text { Mobile Interactions } & 20701-20712 \\ \text { Lifestyle } & 20801-20813 \\ \text { Trust, Privacy, and Emotions } & 20901-20913 \\ \text { Users and UI Design } & 21001-21015\end{array}$

\section{FIRST ROTATION - TUESDAY 29 APRIL}

\section{CHILDREN AND TEENS}

$10101-10108$

Narrative-Based Elicitation: Orchestrating Contributions from Experts and Children

1. Mora Guiard

Find the Jackalop: A Game Enhancing Young Children's

Spatial Thinking

G. Kalmpourtzis

SpeakUp in the Classroom: Anonymous Temporary Social Media for Better Interactions

S. Govaerts

How Do Children Adapt Strategies when Drawing on a Tablet? M. Shukri, S. Rohkmah

Scaffolding Design Sessions with Teenagers: The PDA Approach D. Fitton

"Smiles, Kids, Happy Songs!": How to Collect Metaphors with

Older Adults

S. Panëels

CopyMe: A Portable Real-Time Feedback Expression Recognition Game for Children

C.T.Tan

A Robot with Style, because you are Worth it!

W. Johal

\section{ACCESSIBILITY}

$10201-10212$

Designing Games for the Rehabilitation of Functional Vision for

Children with Cerebral Visual Impairment

C. Linehan

Supporting Autism Therapists: Co-designing Interventions C. Duarte

Designing a Multimodal Email Support Tool for Persons

with Aphasia

A. Al Mahmud

Use Octopus Launcher Like Your Hands: Joystick-based Smartphone Control Solution for Motor Impaired People in Electric Wheelchairs H.Ahn

Blind in a Virtual World: Vision-deprived Virtual Navigation Patterns Using Depth Cues and The Effect of Extended Sensory Range S. Maidenbaum

Design of an Accessible and Portable System for Soccer Players with Visual Impairments

K. McMullen

Design for One: A Game Controller for a Quadriplegic Gamer H. Lin

Technology to Support Emergent Literacy Skills in Young Children with Visual Impairments

A. Stangl

Making Electronics More Accessible to People with

Learning Disabilities

N. Hollinworth

HoverZoom: Making On-screen Keyboards More Accessible F. Pollmann

Welcoming Gesture Recognition into Autism Therapy

C. Duarte

HamsaTouch: Tactile Vision Substitution with Smartphone and

Electro-Tactile Display

H. Kajimoto

\section{AUGMENTED REALITY}

$10301-10309$

Augmented Climbing: Interacting With Projected Graphics on a Climbing Wall

R. Kajastila

An Augmented Workplace for Enabling User-Defined Tangibles M. Funk

Shvil: Collaborative Augmented Reality Land Navigation N.Li

Really, It's for Your Own Good...Making Augmented Reality

Navigation Tools Harder to Use

J.Wen

Enhancing Augmented Reality For Use In Product Design T. Purdy

Generic Method for Crafting Deformable Interfaces to Physically Augment Smartphones

C. Watanabe

CAPTIVE: A Cube with Augmented Physical Tools

A. Chakraborty

Using 3D Hand Gestures and Touch Input for Wearable

AR Interaction

H. Bai

Rubikon: A Highly Reconfigurable Device for Advanced Interaction A. Roudaut 
SEARCH AND INFOVIZ

$10401-10410$

Babywijzer: An Application to Support Women During

their Pregnancy

A. Al Mahmud

Lightweight Support for Collaborative Web Browsing

Through SpreadVector

T. Gross

Linking External and Internal Search: Investigating the Site Searching

Patterns of Referred Searchers

B. Jansen

What People Inquire about Locations? A Study on the Taxonomy of Location-based Questions in Campus

L. Chen

Should I Stay or Should I Go: Two Features to Help People Stop an Exploratory Search Wisely

Y. Jia

Unified Visualization of Quantitative and Qualitative

Playtesting Data

P. Mirza-Babaei

Visualizing Vocal Expression

M. Pietrowicz

GLOs: Graph-Level Operations for Exploratory

Network Visualization

C. Stolper

Beyond Physical Bar Charts - An Exploration of Designing

Physical Visualizations

S. Stusak

Annotation of Graphical Elements in Visualizations for an Efficient

Analysis of Visual Tasks

M. Raschke

MAKING

$10501-10510$

Doing Gender in Input Fields

N. Marsden

From DIY Tutorials to DIY Recipes

M. Dalton

Towards an Integrated Methodological Framework for

Understanding Embodiment in $\mathrm{HCl}$

A. Xambó

Programming in the Pond: A Tabletop Computer

Programming Exhibit

D. Weintrop

The Timeline as a Programming Interface

B. Cardoso

Exploring the Need for Visualizations in System Administration Tools J. Mahendiran

Making 3D Printed Objects Interactive Using

Wireless Accelerometers

J. Hook

NatCut: An Interactive Tangible Editor for Physical

Object Fabrication

S. Schneegass

A Half-Implant Device on Fingernails

K. Iwasaki

CapStudio: An Interactive Screencast for Visual

Application Development

K. Fukahori
MAKING

$10601-10614$

Gamification of Collaborative Idea Generation and Convergence

A. Moradian

RoVatar: Semi-autonomous Robot Boxing Game by

Miniature Avatars

B. Yoo

What Nouns and Adjectives in Online Game Reviews Can Tell Us

About Player Experience?

$X$. Fang

Is 60 FPS Better than 30? The Impact of Frame Rate and Latency on

Moving Target Selection

R. Teather

Civic Engagement Meets Pervasive Gaming: Towards Long-term

Mobile Participation

M. Baldauf

The Effect of Multiplayer Dynamic Difficulty Adjustment on the

Player Experience of Video Games

A. Baldwin

Performance of Modern Gaming Input Devices in First-Person

Shooter Target Acquisition

R. Teather

Geo-Sociograms: A Method to Analyze Movement Patterns and

Characterize Tasks in Location-Based Multiplayer Games

G. Herkenrath

Playful Science: Deriving Computer Games from Complex Systems R. Kirkham

Investigating Players' Responses to Wayfinding Cues in

3DVideo Games

D. Moura

Common Playability Problems in Social Network Games

J. Paavilainen

A BriefTechnical Note on Haptic Jellyfish with Falcon and OpenGL

S. Mokhov

QuoDocs: Improving Developer Engagement in Software

Documentation through Gamification

R. Sukale

Improving Guide Dog Team Play with Accessible Dog Toys

S. Hauser

\section{GESTURES AND EYE-BASED INTERACTIONS}

$10701-10715$

Multimodal Target Prediction Model

P. Biswas

Suit Up!: Enabling Eyes-Free Interactions on Jacket Buttons

K.Todi

EyeDE: Gaze-enhanced Software Development Environments

F. Raab

Eye Contact overVideo

J. Kjeldskov

Multilevel Auditory Displays for Mobile Eyes-Free

Location-Based Interaction

Y.Vazquez-Alvarez

Design and Evaluation of a Dwell-free Eye Typing Technique

T. Chakraborty

Dynamic Edge: Finding Eyes-Free Controls on

Orientation-Agnostic Devices

J. Kildal

AirAuth: Towards Attack-Resilient Biometric Authentication Using

In-Air Gestures

S. Kratz 


\section{WORKS IN PROGRESS}

Robot Conferencing: Physically Embodied Motions Enhance Social Telepresence

K.Tanaka

Glasses with Haptic Feedback of Gaze Gestures

J. Rantala

Error Behaviours in an Unreliable In-air Gesture Recognizer A. Arif

U-Remo: Projection-assisted Gesture Control for Home Electronics A. Kadomura

Personal Space: User Defined Gesture Space for GUI Interaction A. Jude

Using Audio Cues to Support Motion Gesture Interaction on Mobile Devices

S. Morrison-Smith

Trampoline: A Double-sided Elastic Touch Device for Repoussé and Chasing Techniques

G. Lee

HEALTHCARE

$10801-10814$

Evaluating a Clinical Decision Support Interface for End-of-Life

Nurse Care

A. Febretti

Comparing Direct and Indirect Interaction in Stroke Rehabilitation M. Khademi

Point-of-Care Testing for Diabetes Patients: Investigating Diabetes Management by Older Adults

A. Al Mahmud

Physio@Home: Design Explorations to Support

Movement Guidance

R. Tang

Supporting Longitudinal Change in Many Health Behaviors J. Ren

Free-Hand Interaction with Leap Motion Controller for Stroke Rehabilitation

M. Khademi

Afraid to Ask: Proactive Assistance with Healthcare Documents Using Eye Tracking

S. Zhou

Designing Engaging Camera Based Mobile Games for Implicit Heart Rate Monitoring

J. Wang

SensoryPaint: A Natural User Interface Supporting Sensory Integration in Children with Neurodevelopmental Disorders K. Ringland

Lessons from ICT Design of a Healthcare Worker-Centered System for a Chronic Mental Care Hospital

S. Fels

Automated Virtual Observation Therapy

Y-L.Theng

HeartiSense: A Novel Approach to Enable Effective Basic Life

Support Training without an Instructor

W. Kim

VizCom: A Novel Workflow Model for ICU Clinical

Decision Support

A. Faiola

The Application of Eye Movement Biometrics in the Automated Detection of Mild Traumatic Brain Injury

C. Holland
NOTIFICATIONS,AWARENESS AND DISTRACTIONS

$10901-10916$

Attention in Mobile Interactions: Gaze Recovery for Large

Scale Studies

L. Paletta

Attention Approximation of Mobile Users towards their Environment

J. Schrammel

Studying How Character of Conversation Affects Personal

Receptivity to Mobile Notifications

F. Schulze

Understanding Notification Stress of Smartphone Messenger App S.Yoon

Supporting the Mobile Notification Process through Tactile Cues

Selected using a Paired Comparison Task

R. Kuber

Designing a Visual Cue Invocation Scheme to Aid Monitoring

Behavior on a Digital Map Display

F. Fortmann

Spatial Perception Orientation Task (SPOT): Developing an

Accessible Tool for Measuring Spatial Working Memory.

D. Blasko

Supporting Non-Verbal Visual Communication in Online Group

Art Therapy

B. Jones

SomaTech: An Exploratory Interface for Altering Movement Habits Q. Wang

Leveraging the Design of Child Restraint Systems to Reduce

Driver Distraction

O. Mubin

Quantifying Driver Frustration to Improve Road Safety R. Taib

Exploring Virtual Depth for Automotive Instrument

Cluster Concepts

N. Broy

Beyond Eye Tracking Analogies: Cursor Trajectories as Subtle Cues to Detect Distracting UI Elements

J. Hurtienne

Understanding In-Car Smartphone Usage Pattern with an Un-obfuscated Observation

C. Oh

Resumption Lag at Interruptible Timing might not be short in

Actual Environment

T.Tanaka

Working With The Television On: An Investigation into

Media Multitasking

D. Brumby

INTERACTIONTECHNIQUES

$1100 \mid-11016$

Output to Input: Concepts for Physical Data Representations and

Tactile User Interfaces

S. Szigeti

Interaction Techniques for Co-located Collaborative TV

K. Buchner

ExtendedThumb: A Motion-Based Virtual Thumb for Improving One-Handed Target Acquisition on Touch-Screen Mobile Devices J. Lai 
Chiron: Interpreting Signals from Capacitive Patterns and Inertial Sensors for intuitive Shape Modeling.

A. Verma

Origami Tessellation Display: Interaction Techniques Using

Origami-based Deformable Surfaces

Y. Kinoshita

Classifying Physical Strategies in Tangible Tasks: A Video-Coding

Framework For Epistemic Actions

A. Esteves

LightBundle: Grasping Light through Plant-Inspired Interactions H.-L.. Kao

How is Your Laugh Today?

M. Mancini

Place-onas: Shared Resource for Designing Body

Tracking Applications

C. Morrison

Understanding Expert-Novice Differences in Geometry Problem-

Solving Tasks: A Sensor-based Approach

S. Kim

An Interaction Model for Touch-Aware Tangibles on

Interactive Surfaces

S. Voelker

SPad: A Bimanual Interaction Technique for Productivity

Applications on Multi-Touch Tablets

C. Foucault

Whirlstools: Kinetic Furniture with Adaptive Affordance Y.Takeuchi

Extending Interaction for Smart Watches: Enabling Bimanual

Around Device Control

J. Knibbe

Empa Talk: A Physiological Data Incorporated

Human-Computer Interactions

S.J. Kim

Perceived Distance from Hitting with a Stick Is Altered by

Overlapping Vibration to Holding Hand

R. Okazaki

\section{SECOND ROTATION - WEDNESDAY 30 APRIL}

\section{E-COMMERCE 2010I - 20I07}

Mobile Payment Systems in North America: User Challenges

\& Successes

S. Hillman

A Methodological Inquiry into Predictors of Consumer Satisfaction S. Cavrak

Towards a Novel Digital Household Account Book

F. Kerber

"What do you think of the return of dungarees?": Social Media Interactions between Retail Locations and their Customers J. Mahoney

BARTER - Promoting Local Spending Behavior

B. Knowles

Exploring the Opportunities of Mobile Technology Use in

Nonprofit Organizations

S. Kim

Analyzing Employment Technologies for Economically

Distressed Individuals

T. Dillahunt
COMMUNITIES

$20201-20212$

Testing a Grassroots Citizen Science Venture Using Open Design,

"the Bee Lab Project"

R. Phillips

Layers of User Expectations of Future Technologies:

An Early Framework

T. Olsson

Designing for Neighborhoods: Lessons Learned from Paper-based

Bulletin Boards

C. López

Collaborating with Communities in Africa: A Hitchhikers Guide A. Peters

LocaLudo: Card-based Workshop For Interactive Architecture J. Huyghe

The Young and the Vulnerable? Perceived Negative Effects of

Robots on Youngsters Prevent Older Adults from Adopting

Companion Robots

T.Waddell

NewsPad: Designing for Collaborative Storytelling

in Neighborhoods

J. Matias

Mixing Languages? Image Schema Inspired Designs for Rural Africa D. Löffler

'Sometimes it's the Weather's Fault' - Sustainable $\mathrm{HCl}$ \&

Political Activism

S. Prost

Making Sense of Haul Videos: Self-created Celebrities Fill a Fashion

Media Gap

S. Sykes

Helping Users Review and Make Sense of Access Policies

in Organizations

P. Jaferian

Using Personalized Radio to Enhance Local Music Discovery

D. Turnbull

DISPLAYS

2030 I - 20309

Tablet Interaction Techniques for Viewport Navigation on

Large Displays

K. Cheng

Midair Displays: Exploring the Concept of Free-Floating

Public Displays

S. Schneegass

Assessing the Zone of Comfort in Stereoscopic Displays

using EEG

J. Frey

Expanding the Porthole: Leveraging Large, High-Resolution Displays

in Exploratory Visual Analysis

K. Reda

Screen Scaling: Effects of Screen Scale on Moving Target Selection

R. Teather

User Centered Design of a Hybrid-Reality Display for

Weld Monitoring

W. Seidelman

Towards Understanding Spontaneous Interaction on

Curved Displays

H. Palleis

ReflectoSlates: Personal Overlays for Tabletops Combining

Camera-projector Systems and Retroreflective Materials

D. Martinez Plasencia

TangramTheatre: Presenting Children's Creation on

Multimodal Tabletops

Z. Qu 


\section{WORKS IN PROGRESS}

SOCIAL COMPUTING

$2040|-204| I$

Understanding and Leveraging Social Networks for Crowdfunding: Implications for Support Tools

J. Hui

Influence of Dining-Progress Synchrony in Time-Shifted Tele-Dining T. Inoue

Social Comparison in Social Media: A Look at Facebook and Twitter G. Panger

International Students' Use of Facebook vs. a Home Country Site

C.W.Yuan

Watchboard: Curated Microblogging for the Enterprise

N. Sultanum

Affordances of Social Technologies as Social Microworlds

A. Parmaxi

Evaluation of Automated Friend Grouping in Online

Social Networks

M. Eslami

Pact: Leveraging Social Networks for Goal Achievement

Z. Porges

Predicting Potential Responders in Social Q\&A Based on non-QA Features

Z. Liu

I'm Here with My Kids: Investigating Location sharing Preferences of Parents with Young Children

P. Massa

The Laughing Dress: Evoking Prosocial Interaction Among Strangers S. Lee

\section{UBICOMP, ROBOTS AND WEARABLES 2050I - 205II}

Towards Effective Ethical Behavior Design

R. de Oliveira

Integrative Workplace: Studying the Effect of Digital Desks on

Users'Working Practices

C. Gebhardt

Casalendar: A Temporal Interface for Automated Homes

S. Mennicken

The Effects of Pitch Contour and Flanging on Trust in Speaking Cognitive Agents

L. Muralidharan

AR Browser for Points of Interest in Disaster Response in

UAV Imagery

D. Crowley

Offlinetags - A Novel Privacy Approach to Online Photo Sharing F. Pallas

The Editable Self: A Workbench for Personal Activity Data D. Smith

Biosignal Sharing for Affective Connectedness

H. Min

TagMe: An Easy-to-Use Toolkit for Turning the Personal

Environment into an Extended Communications Interface

J.Amores

Passive Haptic Learning of Typing Skills Facilitated by

Wearable Computers

C. Seim

Workscape Explorer: Using Group Dynamics to Improve Performance

J-I. Watanabe
LEARNING

$2060 I-206 \mid 4$

Learning the Game: Breakdowns, Breakthroughs and

Player Strategies

I. lacovides

l'd Tap That! Providing Real Time Feedback on Roller Derby Skills C. Stewart

Human SUGOROKU: Learning Support System of Vegetation

Succession with Full-body Interaction Interface

T. Nakayama

Measuring Learned Skill Behaviors Post-MOOC

D. Russell

Wait-Learning: Leveraging Conversational Dead Time for Second Language Education

C. Cai

Supporting Second Language Reading with Picture Note-Taking C-L.Yang

The Impact of Interactive Visual Simulations on Learning Statistics G. Iten

Supporting Debates with a Real-Time Feedback System B. Huber

The Effects of Physical and Virtual Manipulatives on Learning Basic Concepts in Electronics

B. Schneider

Learning Online via Prompts to Explain

J.Williams

Understanding Meditation and Technology Use

K. Derthick

MOODs: Building Massive Open Online Diaries for Researchers,

Teachers and Contributors

S. Gould

The Informatics Needs of Amateur Endurance Athletic Coaches

C. Neustaedter

Personalized Presentation Builder

A. Khataei

\section{MOBILE INTERACTIONS}

$2070 I-207 I 2$

Mobile and Computer-based Talent Assessments: Implications of Workload and Usability.

A. Proaps

Using a Touch-Sensitive Wristband for Text Entry on Smart Watches M. Funk

A Study of Direction's Impact on Single-Handed Thumb Interaction with Touch-Screen Mobile Phones

J. Lai

Generating Highlights Automatically from Text-Reading Behaviors on Mobile Devices

J. Oh

MIMIC: Leveraging Sensor-based Interactions in Multimodal

Mobile Applications

N. Elouali

MochaTop: Building Ad-hoc Data Spaces with Multiple Devices P.Woźniak

100 Days of iPhone Use: Mobile Recording in the Wild M. McGregor

Medical Imaging Specialists and 3D: A Domain Perspective on Mobile 3D Interactions

T. Seyed

Android Apps Consistency Scrutinized

K. Alharbi 
Detection of Tangential Force for a Touch Panel Using Shear

Deformation of the Gel

Y. Nakai

FingerReader: A Wearable Device to Support Text Reading on the Go

R. Shilkrot

Towards High Quality Text Entry on Smartwatches

M. Dunlop

LIFESTYLE

$20801-20813$

StepCity: A Preliminary Investigation of a Personal

Informatics-Based Social Game On Behavior Change

G. Walsh

Comparing Modalities for Kinesiatric Exercise Instruction

J. Smeddinck

Sonic Respiration: Controlling Respiration Rate Through

Auditory Biofeedback

R. Gutierrez-Osuna

EZwakeup: A Sleep Environment Design for Sleep

Quality Improvement

M-C. Huang

UbiSpoon: Pervasive Monitoring of Nervous System Diseases through Daily Life

F.Tian

Haptics in Remote Collaborative Exercise Systems for Seniors H. Alizadeh

BreakOut: Predicting and Breaking Sedentary Behaviour at Work M.J. Ferreira

OmniSports - Encouraging Physical Activities in Everyday Life P. Lessel

AirFlow: Designing Immersive Breathing Training Games for COPD Y. Qin

To Switch off the Coffee-maker or Not: That is the Question to be Energy-efficient at Work

D. Casado-Mansilla

Social Recipe Recommendation to Reduce Food Waste F.Yalvaç

Persuasive Content Development: Application of

Protection Motivation Theory in Promoting Heritage Site

Preservation Awareness

Y.S. Poong

Understanding Context Governing Energy Consumption in Homes G. Irwin

\section{TRUST, PRIVACY \& EMOTIONS}

$20901-20913$

Trust, Transparency \& Control in Inferred User Interest Models S. Schnorf

Understanding Information Practices of Interactive Personal

Genomics Users

O. Shaer

KinChat: Veiling Your Face without Suppressing Facial Expression in Text Communication

A-J. Huang

Using Icon Arrangement for Fallback Authentication

on Smartphones

A. Hang

Vibralnput: Two-step PIN Entry System based on Vibration and

Visual Information

T. Kuribara
Measuring Snooping Behavior with Surveys: It's How You Ask It D. Marques

Who Says Personas Can't Dance? The Use Of Comic Strips To Design Information Security Personas

M. Lewis

A Visual Feedback Design based on a Brain-Computer Interface to Assist Users Regulate their Emotional State

Y. Hao

GamIM: Affecting Chatting Behavior by Visualizing Atmosphere of

Conversation

S. H. Hsu

Measuring User Experience through Future Use and Emotion

C. Paul

Measuring Product Happiness

I. Kamp

Designing Multi-Touch Gestures to Support Emotional Expression

in IM

A. Pirzadeh

The Art of Deleting Snapshots

M. Wolters

USERS AND UI DESIGN

$21001-21015$

Selfsourcing Personal Tasks

J. Teevan

Who's the Boss? Requester Transparency and Motivation in a

Microtask Marketplace

J. Marlow

Wiredln: Using Visual Feedback to Support Task Resumption Y. Liu

Everyday Peripheral Tasks vs. Digital Peripheral Tasks

D. Hausen

Copyright Terms in Online Creative Communities

C. Fiesler

Mental Models for Web Objects in Different Cultural Settings

S. Linxen

Diverse Information Fragments to Enhance

Troubleshooting Efficiency

R. Yamashita

Designing for Negative Affect and Critical Reflection

H. Halbert

Improving Data-Driven Design and Exploration of Digital

Musical Instruments

C. Laguna

Pdot: Participatory Design Online Tool

M. Heintz

An Aesthetic Perspective to Explore Aesthetic Components of Interactive System: a Case Study on Music Player M. Wu

I Remember/Know/Guess What I Saw: A False 'Belief'Technique to Features Selection

J. Lee

Exploring Personality's Effect on Users' Rating Behavior

R. Hu

Characteristics of Narrative Textual Data Linked to

User Experiences

T. Meneweger

Assisting Older Adults in Assessing the Reliability of

Health-Related Websites

C. Stewart 


\section{INTERACTIVITY}

Interactivity offers hands-on demonstrations that let you see, hear and touch interactive visions of the future. They take the form of prototypes, demonstrations, artworks, design experiences and inspirational technologies. Interactivity offers an alternative to CHI's traditional text format to disseminate advances in the field. Interactivity promotes and provokes discussion about the role of technology by actively engaging attendees one-on-one.

Interactivity demonstrations are available from the Monday evening Conference Reception through the Thursday morning break. Presenters will be stationed at their exhibits throughout the Monday evening session and during coffee breaks all day Tuesday, Wednesday and on Thursday morning.

This year, Interactivity will also include flexible demonstration spaces. These spaces will be used by authors of accepted papers and notes to give a short demonstration of their work during one of the breaks. A schedule of these research demonstrations will be posted in the Interactivity area.

Monday

$$
\text { 17:30 - 19:30 Grand opening }
$$

Tuesday - Wednesday

10:20 - 1 1:00 Presenters available during the morning break

15:20 - 16:00 Presenters available during the afternoon break Thursday
10:20 - 1 1:00 Presenters available during the morning break

$11: 30$ Interactivity closes
int0I The CBC Newsworld Holodeck - M. Ladly, G. Penn, C. P. C. Chen, P. Chintraruck, M. Ghaderi, B. A. Ludlow, J. Peter, R. Tanyag, P. Zhou, S. Kazemian

int02 Interaction Opportunities Around Helmet Design W. Walmink, A. D. Chatham, F. Mueller

int03 zPots: A Virtual Pottery Experience With Spatial Interactions Using the Leap Motion Device - Vinayak, K. Ramani, K. Lee Jr., R. Jasti

int04 i-dentity: Innominate Representation as Engaging Movement Game Element - J. Garner, G. Wood, S. Pijnappel, M. Murer, F. Mueller

int05 Text Blaster: A Multi-Player Touchscreen Typing Game K. Vertanen, J. Emge, H. Memmi, P. O. Kristensson

int06 The Muses of Poetry - D. Arellano, V. Helzle

int07 Exploring the Design Space of Ambient Light Displays A. Löcken, H. Müller, W. Heuten, S. CJ Boll

int08 Scopophobic Kitties in Wonderland: Stories Behind the Scene of a Gaze Contingent Environment - M. Chen, K-Y.Wu, Y-C. Huang

int09 SonicExploratorium: An Interactive Exhibit of Sonic Discovery - B. Gonzalez, A.T.Adams, C. E. Latulipe

int I0 Scale: Human Interactions with Broken and Discarded Technologies - L. Kang, T. Park, S. Jackson

int I Using Mobile Tools in Immersive Environments to Support Science Inquiry - M. Lui, A. C. Kuhn, A. Acosta, M. Nino-Soto, C. Quintana, J. D. Slotta

int 3 Rafigh: A Living Media Interface for Learning Games F. Hamidi, M. Baljko

int I4 Game of Tones: Learning to Play Songs on a Piano Using Projected Instructions and Games - L. Raymaekers, J. Vermeulen, K. Luyten, K. Coninx

int 5 Haptic Turk: A Motion Platform Based on People - L-P. Cheng, P. Lühne, P. Lopes, C. Sterz, P. Baudisch

int 16 The New pCubee: Multi-touch Perspective-corrected Cubic Display - Y. Tang, I. Stavness, S. S. Fels

int 17 Adapting Games From Literature: Edgar Allen Poe Embodied in Players - L. Grace

int 8 Rainbowfish: Visual Feedback on Gesture-Recognizing Surfaces - T. Grosse-Puppendahl, S. Beck, D. Wilbers

int19 HeartiSense: A Novel Approach to Enable Effective Basic Life Support Training without an Instructor - Y. Kwon, S. Lee, J. Jeong, W. Kim

int20 TransWall: A Transparent Double-sided Touch Display Facilitating Co-located Face-to-face Interactions - H. Heo, H. K. Park, S. Kim, J. Chung, G. Lee, W. Lee

int2I Computational Creativity for Culinary Recipes - F. Pinel, L. R. Varshney

int22 Swing Sound - Experiencing the Golf Swing through Sound S. Nylander, A. Kent, J. Tholander

int23 COMP*PASS: A Compass-based Drawing Interface K. Nakagaki, Y. Kakehi

int24 Muzlog: Instant Music Transcribing System for Acoustic Guitarists - H-J. Kim, T-J. Nam

int25 IntentRadar: Search User Interface that Anticipates User's Search Intents - T. Ruotsalo, J. Peltonen, M. J.A. Eugster, D. Glowacka, A. Reijonen, G. Jacucci, P. Myllymäki, S. Kaski 
int26 The Talking Plants: an Interactive System for Grassroots Urban Food-Growing Communities - S. Heitlinger, N. Bryan-Kinns, J. K. Jefferies

int28 Object and Arm Shadows: Visual Feedback for Cross Device Transfer - G. Besacier, J. Tournet, N. Goyal, F. Cento, S. D. Scott

int29 TastyBeats: Making Mocktails with Heartbeats - R.A. Khot, J. Lee, H. Munz, D. Aggarwal, F. Mueller

int30 Step Kinnection: A Hybrid Clinical Test for Fall Risk Assessment in Older Adults - J.A. Garcia, Y. Pisan, C. T. Tan, K. F. Navarro

int3 PaperDude: A Virtual Reality Cycling Exergame - J. Bolton, M. Lambert, D. Lirette, B. Unsworth

int32 Bidirectional Feedback in Motor Imagery BCls: Learn to Control a Drone within 5 Minutes - N. Kos'myna, F.Tarpin-Bernard, B. Rivet

int33 How Far is UP? Encouraging Social Interaction Through Children's Book App Design - B. Sargeant, F. Mueller

int34 LinearDragger: a Linear Selector for One-finger Target Acquisition - O. K-C.Au, X. Su, R. Lau

int35 BeFaced: a Casual Game to Crowdsource Facial Expressions in the Wild - C. T.Tan, H. Sapkota, D. Rosser

int36 Billboard: Interacting with Personal Public Displays L. Kleinman, A. Carney, A. Ma

int37 AirAuth: A Biometric Authentication System using In-Air Hand Gestures - S. Kratz, M. T. I. Aumi

int38 CopyMe: an Emotional Development Game for Children N. Harrold, C. T.Tan, D. Rosser, T. W. Leong

int39: Interacting with the Kiwi Move: A Platform for Motion-based Applications - A. Beattie, D. Chen, J. Chibuk, O. Mayrand, Z. Patel

int40 Glance: Enabling Rapid Interactions with Data Using the Crowd - W. S. Lasecki, M. Gordon, S. P. Dow, J. P. Bigham

int4I Move Your Phone: Spatial Input-based Document Zoom \& Pan on Mobile Displays Revisited - M. Spindler, M. Schuessler, M. Martsch, R. Dachselt

int42 FishTank Fitts: A Desktop VR Testbed for Evaluating 3D Pointing Techniques - R. J. Teather, W. Stuerzlinger, A. Pavlowych

int43 Plant Guild Composer: An Interactive Online System to Support Back Yard Food Production - J. Norton, S. Nayebaziz, S. Burke, B. J. Pan, B. Tomlinson

int44 faBrickation: Fast 3D printing of Functional Objects by Integrating Construction Kit Building Blocks - S. Mueller, T. Mohr, K. Guenther, J. Frohnhofen, P. Baudisch

int45 Engaging with Virtual Characters Using a Pictorial Interaction Language - B. Endrass, L. Hall, C. Hume, S. Tazzyman, E. Andre, R. Aylett

int46 PaperFold: A Shape Changing Mobile Device with Multiple Reconfigurable Electrophoretic Magnetic Display Tiles A. Gomes, R. Vertegaal

int47 "Did you pack your keys?" Smart Objects and Forgetfulness C. Farion, M. Purver

int48 Creating Physical Visualizations With MakerVis - S. Swaminathan C. Shi, Y. Jansen, P. Dragicevic, L. A. Oehlberg, J-D. Fekete

int49 MetaTravels and MetaLonsdale: iPad Apps for Percussive Improvisation - C. Martin, H. J. Gardner, B. Swift

int50 Interactive Experiences Designed for Agricultural Communities - R. C. L. Suen, K. T.T. Chang, M. P-H.Wan, Y. C. Ng, B. C.Y.Tan int5 I BackPat: Improving One-Handed Touchscreen Operation by Patting the Back of the Device - K. Seipp, K. Devlin

int52 InGrid: Interactive Grid Table - M. Ziat, J. Fridstrom, K. Kilpela, J. Fancher, J. J. Clark

int53 OJAS - Open Source Bi-Directional Inductive Power Link J. Mikkonen, R. Gowrishankar, M. Oksanen, H. Raittinen, A. Kolinummi

int54 TwitterRadio: Translating Tweets into Music - F. Morreale, A. Miniukovich, A. De Angeli

int55 HamsaTouch: Feel the World through Your Palm - H. Kajimoto, M. Suzuki, Y. Kanno

int56 Imaginary Reality Basketball: A Ball Game Without a Ball P. Baudisch, H. Pohl, S. Reinicke, E. Wittmers, P. Lühne, M. Knaust, S. Köhler, P. Schmidt, C. Holz

int57 Draco: Bringing Life to Illustrations - R. H. Kazi, F. Chevalier, T. Grossman, S. Zhao, G. Fitzmaurice

int58 RunRight - Real-Time Visual and Audio Feedback on Running - S. Nylander, M. Jacobsson, J. Tholander

int59 GaussBricks: Magnetic Building Blocks for Constructive Tangible Interactions on Portable Displays - R-H. Liang, L. Chan, H-Y.Tseng, H-C. Kuo, D-Y. Huang, D-N.Yang, B-Y. Chen

int60 Cushionware: A Practical Sitting Posture-based Interaction System - G. Liang, J. Cao, X. Liu, X. Han

int6I Mechanical Force Redistribution Floor Tiles - A. M. Grau, C. Hendee, A. S. Karkar, H. Su, M. Cole, K. Perlin

int62 Wrigglo:Shape-Changing Peripheral for Interpersonal Mobile Communication - J. Park, Y-W. Park, T-J. Nam

int63 Interacting with The Vocal Chorder - Re-empowering the Opera Diva - C. E. T. Unander-Scharin, A. Unander-Scharin, K. Höök, L. Elblaus 


\section{Akendi}

Akendi creates meaningful experiences through intentionally directed efforts in user-centred strategy, research, design and testing. Working with digital and physical products, website and software for any device, we optimize the experience you deliver. Akendi also offers courses and certifications in UX that provide in-depth theory mixed with practical application exercises.

\section{Bloomberg LP Champion Sponsor}

Booths $6 \& 7$ Bloomberg connects influential decision makers to a dynamic network of information, people and ideas. Our strength - quickly and accurately delivering data, news and analytics through innovative technology - is at the core of everything we do. With over 15,000 employees in 192 locations, we deliver business and financial information, news and insight around the world.

\section{CHI 2014 Information}

Booth 28a

Student Volunteers staff the Information Desk when the Commons (exhibit hall) is open. They are happy to help answer your questions or find someone who can. At other times, stop by the Registration Desk for information. The Information Desk will also help deliver resumes submitted in response to job postings from registered recruiters.

\section{$\mathrm{CHI} 20 \mathrm{I} 5$}

Booth 28

2015 will be the first year that $\mathrm{CH}$ is hosted in Asia - a tremendous opportunity to showcase Asian thought leaders and cutting edge technologies. Visit our booth to meet conference organizers and hear about innovations we'll see in 20 I5. The conference theme is "Crossings": crossing borders, crossing disciplines, crossing people and technology, crossing art and science, ... crossing me and you.

\section{Elsevier / Morgan Kaufmann}

Booth 26

Elsevier and Morgan Kaufmann will be presenting key titles across Human-Computer Interaction. Please stop by and visit the booth, meet the publishers and editors in person, and take the opportunity to ask any questions and learn more about our author services and content innovation. www.elsevier.com/computerscience and www.store.elsevier.com/Morgan-Kaufmann

\section{EyeGaze - LC Technologies}

Booth 25

LC Technologies is passionate about changing lives with cuttingedge eye tracking solutions. Since 1986 our goal has been to create an unobtrusive human-computer interface, revolutionizing the way we interact with computers/devices. Now used in 44 countries, our eye-tracking systems are seamless extensions of the human experience, providing highly accurate eye movement and gaze point measurements.

EyeTracking, Inc.

Booth 18

EyeTracking, Inc. is the leading provider of eye tracking services, software and expertise. For over a decade we have been at the forefront of innovation in virtually every area of visual behavior and cognitive workload research. Visit our booth to learn about our software: EyeWorks for eye tracking, Quad Server for physiological sensor integration, Workload RT for cognitive workload measurement.

Facebook Contributing Sponsor

Booth 36

Founded in 2004, Facebook's mission is to give people the power to share and make the world more open and connected. People use Facebook to stay connected with friends and family, to discover what's going on in the world, and to share and express what matters to them.
Google Champion Sponsor

Booths 14 \& 15

Google's mission is to organize the world's information, making it universally accessible and useful. Every day, we bring our spirit of innovation and entrepreneurship to work. Come by our booth, meet our engineers and researchers, demo some new products and learn about some of the great opportunities we have at Google.

\section{GRAND NCE Champion Sponsor}

Booths 16 \& 17

GRAND is a research network and commercialization engine whose goal is to address complex issues in digital media and transform multidisciplinary research into user-centred solutions. GRAND explores the use and application of digital media in a variety of settings including entertainment, healthcare, education, environmental sustainability, and public policy.

Microsoft Champion Sponsor

Booths 3, 4 \& 5

At Microsoft, we have a passion for $\mathrm{HCl}$. Our Design and Research professions impact the interactions of millions of users around the globe. At Microsoft, you would collaborate with brilliant people on projects with the potential to change the world. Come by our booth to play, pick up free swag, enter to win Microsoft prizes, and chat about the great opportunities for shaping $\mathrm{HCl}$ at Microsoft.

\section{MillionShort}

Booth 37

MillionShort is an exciting new web search engine that allows the user to remove a section of the top websites from their search results to provide a deeper, more exploratory search. Whether you're removing the top million, 100k, 10k, Ik, or 100 sites, MillionShort allows you to see what you can find when you delve underneath an entire slice of the web.

Morgan \& Claypool Publishers

Booth 13

Morgan \& Claypool is publisher of the Synthesis Digital Library, including the $\mathrm{HCl}$ series edited by Jack Carroll; the assistive technologies series, edited by Ron Baecker; and the series on information science, edited by Gary Marchionini. Please visit our booth for free eBooks and discounted print copies.

MultiTouch

Booth 24

The MultiTaction interactive displays feature the World's first and only 55" Ultra-Thin Bezel LCD with built-in touch and unlimited touch points. MultiTaction displays can be stacked together to create massive multi-user interactive surfaces supporting simultaneous touch, IR pen, Enriched Reality, and user identification. For more information, please visit www.multitaction.com.

now publishers

Booth 2

now publishers publishes high quality reference, research and review journals in business and technology. The Foundations and Trends journals publish state-of-the-art review articles written by leading researchers in the field with the references linked to the original articles and allows for updating by the author and community.

\section{Oxford University Press}

Booth 19

Oxford University Press is pleased to publish Interacting with Computers on behalf of BCS, The Chartered Institute for IT and Interaction, a specialist group from BCS.Visit the Oxford University Press stand for free journal copies and discounted books! For more information visit www.iwc.oxfordjournals.org and look at our related books at www.oup.com. 
EXHIBITORS ALPHABETICALLY (CONTINUED)

Samsung Research America

Booth 23

Samsung's philosophy is based on perpetual innovation and good corporate citizenship. Our practices have proven successful we are one of the fastest growing companies in America, and an acknowledged leader in the digital convergence revolution. Samsung Research America and Samsung User Experience Center America welcomes you to $\mathrm{CHI} 2014$ !

\section{SAP}

Booth 38

As market leader in enterprise application software, SAP helps companies of all sizes and industries run better. We have more than 25 I,000 customers in over I 88 countries and employ 66,000 people at locations in more than 130 countries. Our UX professionals are working on some of today's hottest applications, stop by our booth and see how SAP is changing the way our customers do business.

SensoMotoric Instruments, Inc.

Booth 39

$\mathrm{SMI}$ is a leading provider of eye and gaze tracking systems to a global market. Our advanced analysis software provides visualizations that simplify the interpretation of eye tracking data. Let us show you how to add an eye tracker to your existing set of tools: smivision.com/egts.

\section{Springer}

Booths II \& 12

Explore the full range of print and electronic publications in $\mathrm{HCl}$ (including the $\mathrm{HCl}$ series) at our booth. Get 20\% discount on our (e)books, discover our Open Access portfolio (including Journal on Interaction Science, Journal of Trust Management), and don't miss the chance to discuss your book proposal in person with Beverley Ford \& Helen Desmond.

\section{Sulon Technologies}

Booth 27

Sulon Technologies engineers, designs and distributes The Cortex, the first-ever fully immersive spatial gaming platform that delivers a contextually aware augmented virtual reality experience.The Cortex is a wireless wear-and-play device that leverages existing mobile devices. It transforms any physical space into a dynamic holodeck-like experience that can be walked through and interacted with.

The MIT Press

Booth 40

The MIT Press publishes extensively in Human-Computer Interaction.

Tobii Technology

Booth 8

TobiiTechnologyisthegloballeaderineyetrackingandgazeinteraction. Tobiiofferscutting-edgeandaward-winningproductsandservicesthat are revolutionizing research, institutions and industries worldwide. Founded in 200I and based in Sweden, Tobii has a global presence with international offices and a worldwide network of customers and partners.

Toronto University Consortium for

Accessibility Research and Education

(TUCARE) Champion Sponsor

Booth 20

Toronto is THE foremost city in the world for research and teaching on inclusive design and on accessible, assistive, and seniors'technology, leveraging strengths of the University of Toronto (Computer Science, Occupational Science), OCAD Univ., Ryerson Univ., and Toronto Rehabilitation Institute. Stop by the booth to learn about opportunities for postdoctoral fellowships and graduate study.

Yahoo! Labs Contributing Sponsor

Booth 10

Yahoo Labs serves as Yahoo's incubator for bold experimentation, applying its scientific findings to create personalized, delightful experiences for Yahoo's users and enhance value for its advertisers. From idea to product innovation, Yahoo Labs is responsible for the algorithms behind the Web experience for Yahoo's hundreds of millions of users. Stop by our booth to find out how you can join us..
EXHIBITORS BY BOOTH \#

now publishers

Microsoft Champion Sponsor

$3,4 \& 5$

Bloomberg LP Champion Sponsor

$6 \& 7$

Tobii Technology

Akendi

Yahoo! Labs Contributing Sponsor

Springer Booth

II \& 12

Morgan \& Claypool Publishers

Google Champion Sponsor

$14 \& 15$

GRAND NCE Champion Sponsor

$16 \& 17$

EyeTracking, Inc.

Oxford University Press

TUCARE (Toronto University) Champion Sponsor

SmartEye AB

Samsung Research America

MultiTouch

EyeGaze - LC Technologies

Elsevier / Morgan Kaufmann

Sulon Technologies

CHI 2014 Information

CHI 2015

Facebook Contributing Sponsor

MillionShort

SAP

SensoMotoric Instruments, Inc

The MIT Press 


\section{Exhibit Hall E (Commons)}

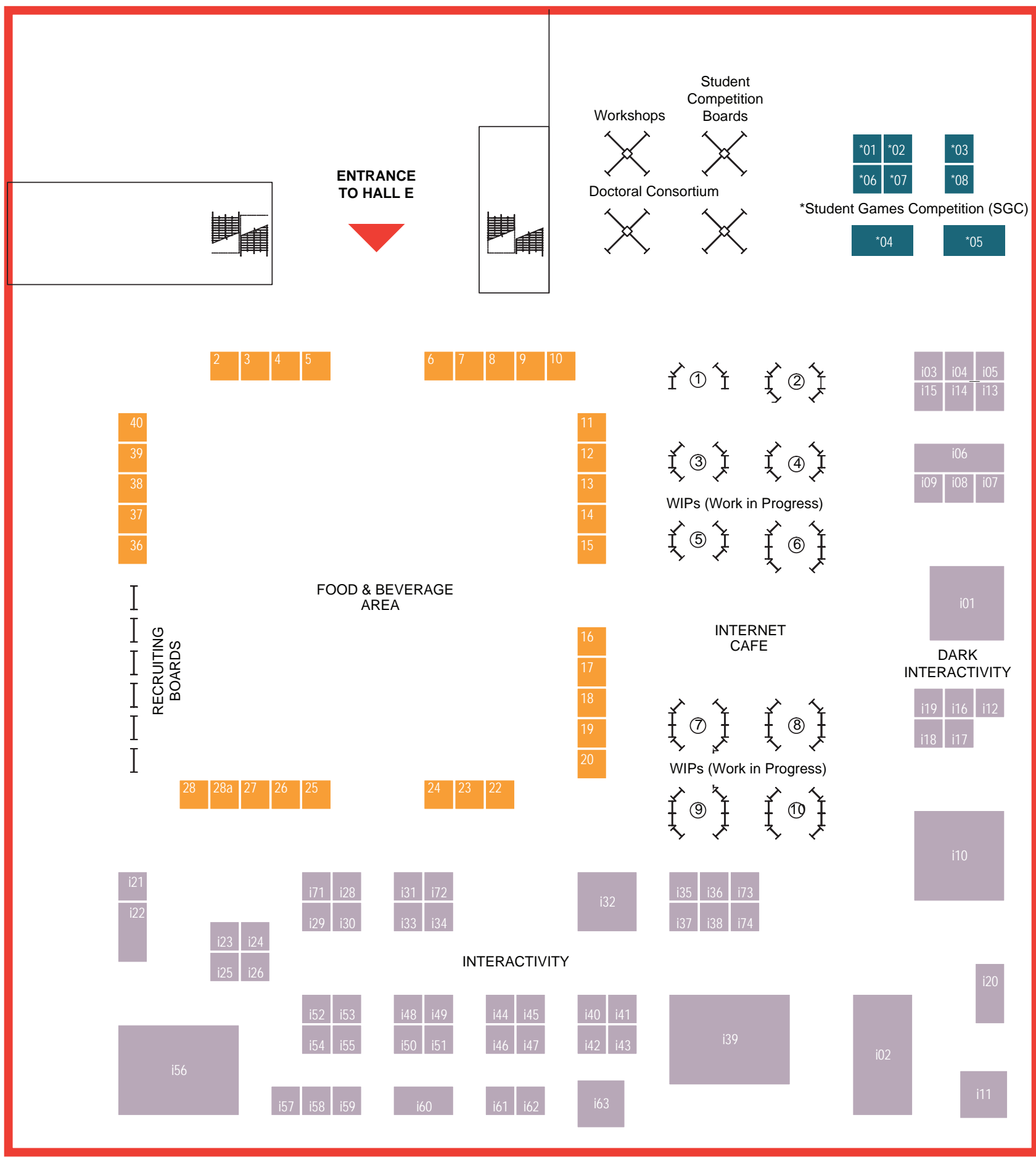

Exhibits

Interactivity Students Games
Booths I - 40

Booths i0I - i74

Booths *0I - *08 
South Building: Level 700

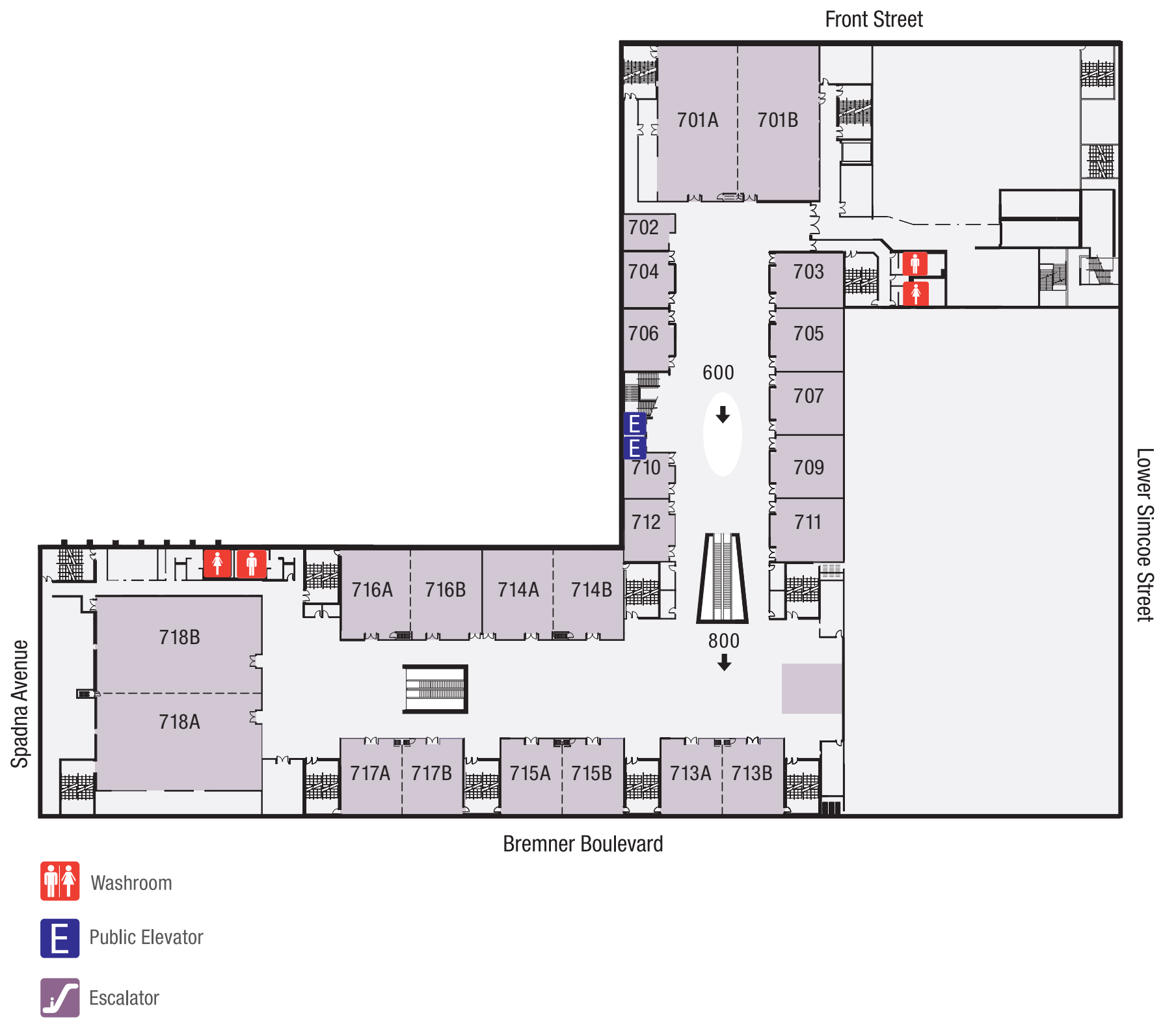




\section{South Building: Level 800}

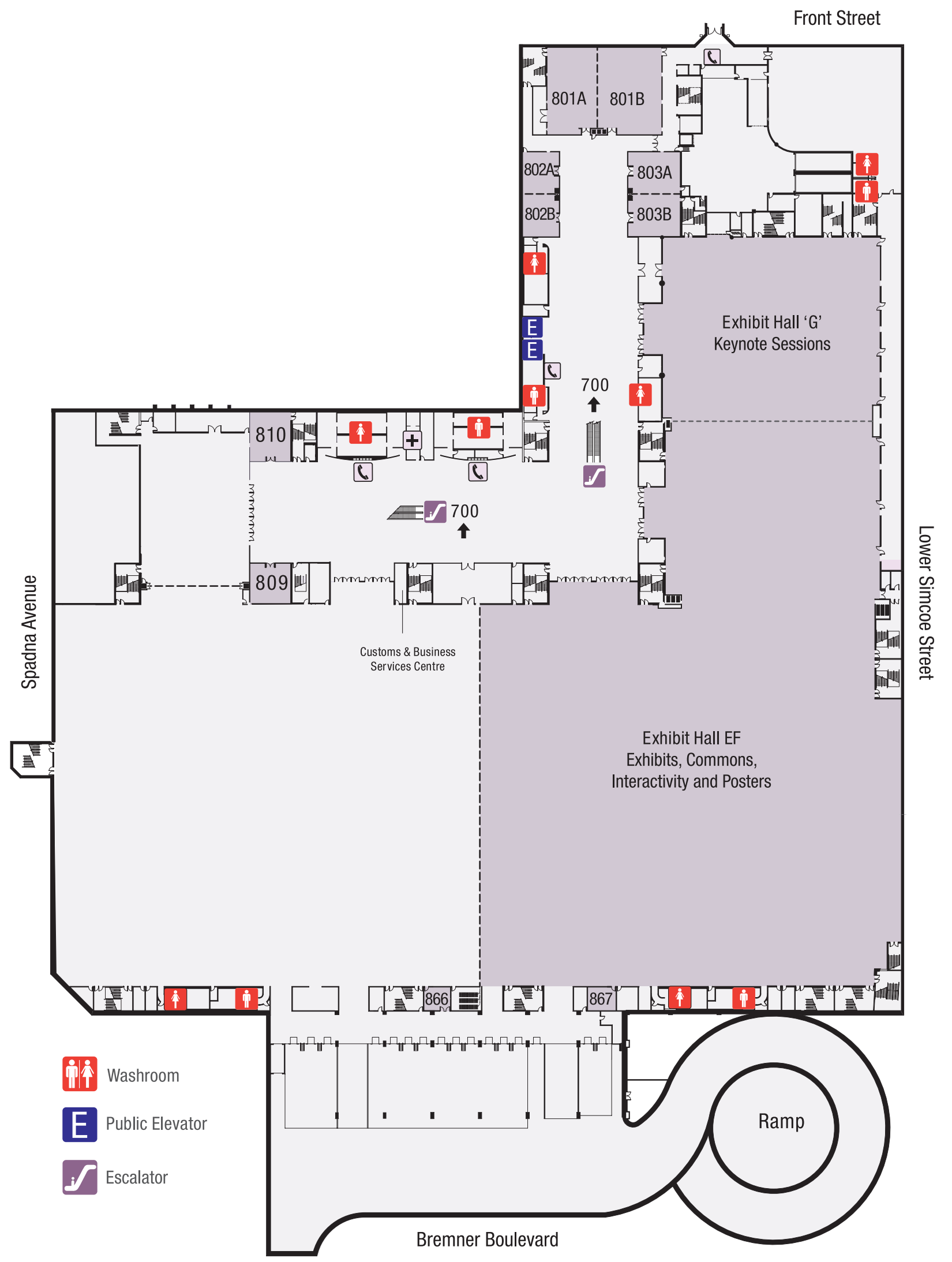




\section{South Building: Level 600}

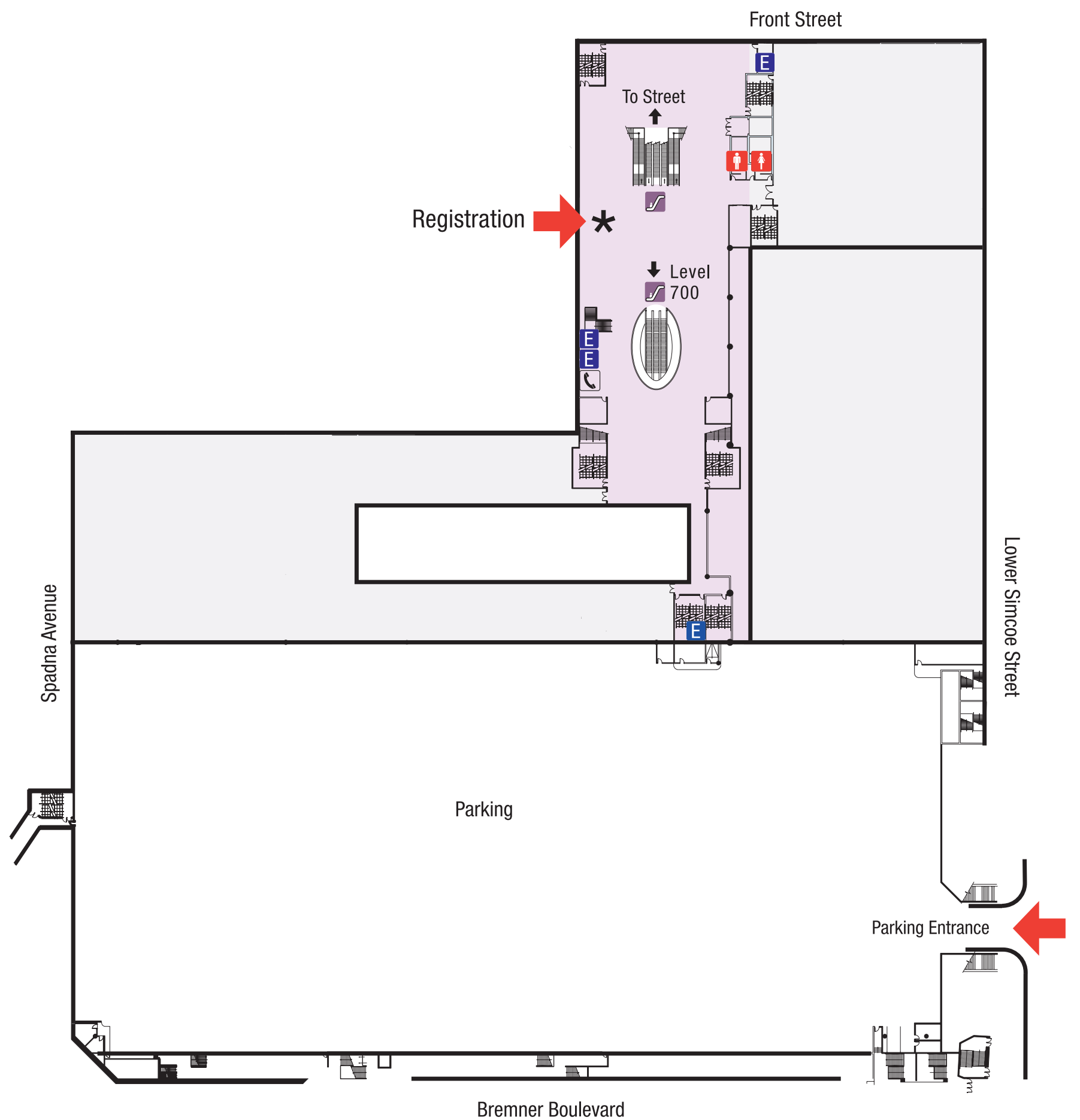

Washroom

Public Elevator

Escalator 


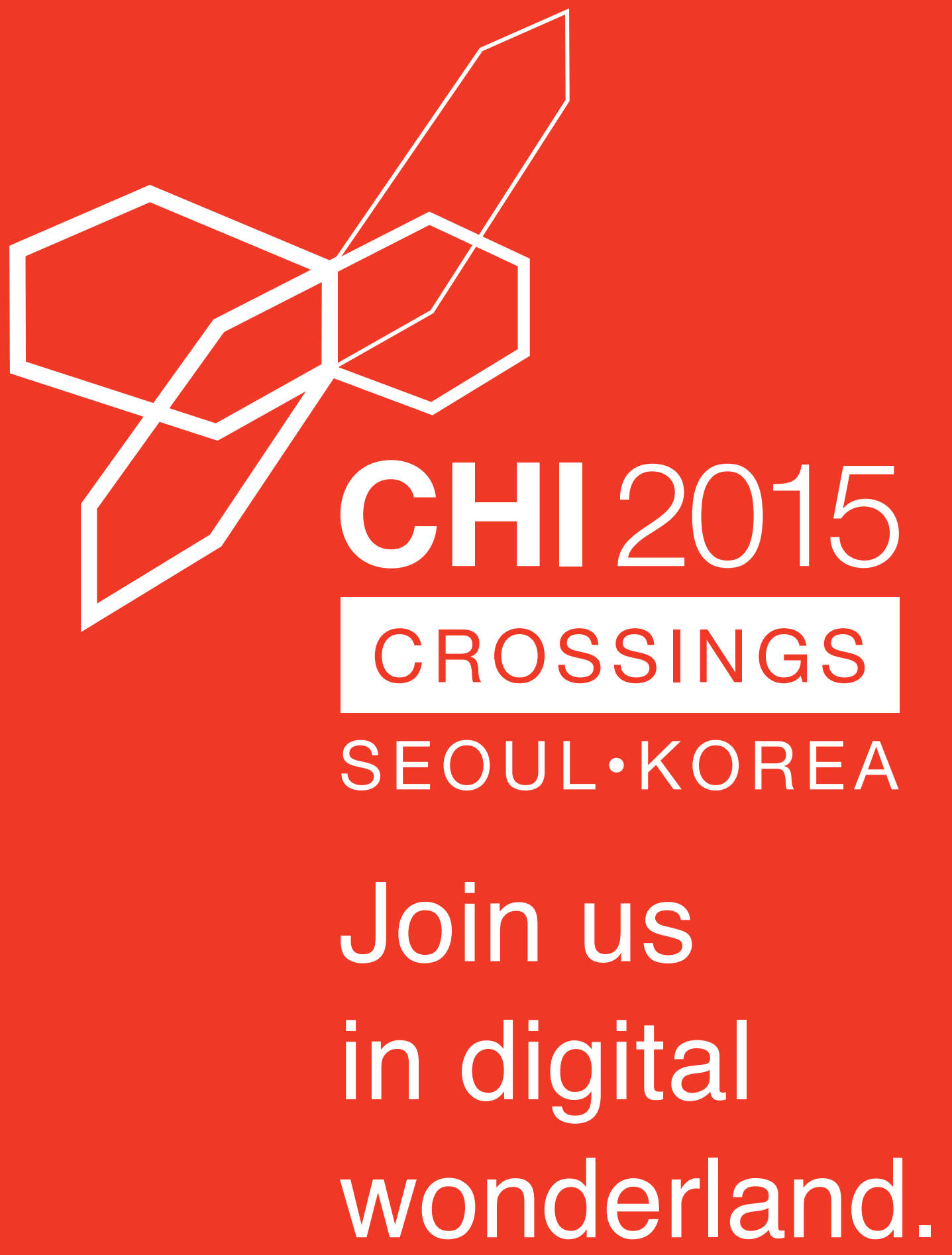

18-24 APRIL 2015

chi2015.acm.org 
$\mathrm{CHI}$ Champion Sponsors

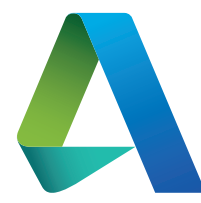

AUTODESK
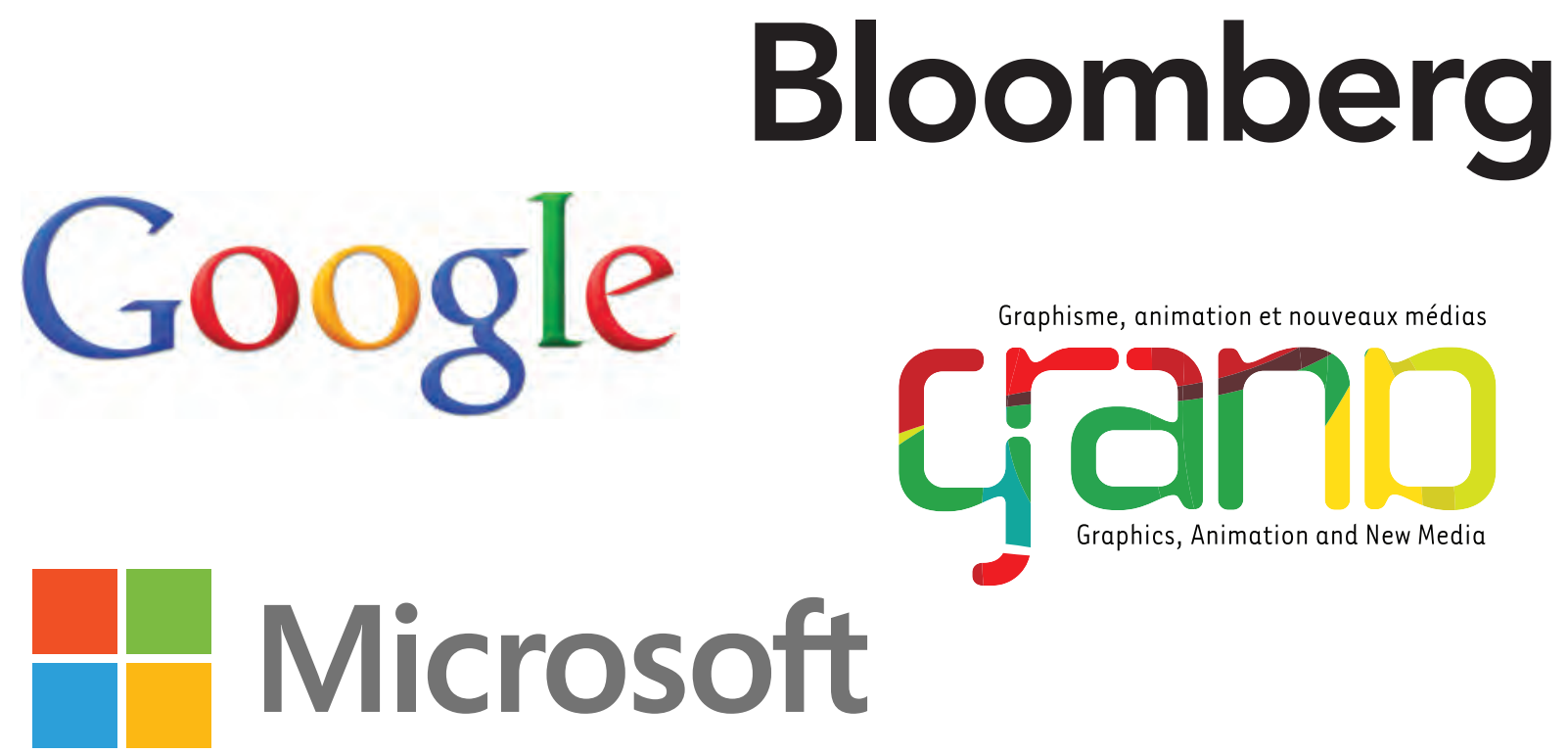

Microsoft

Graphisme, animation et nouveaux médias
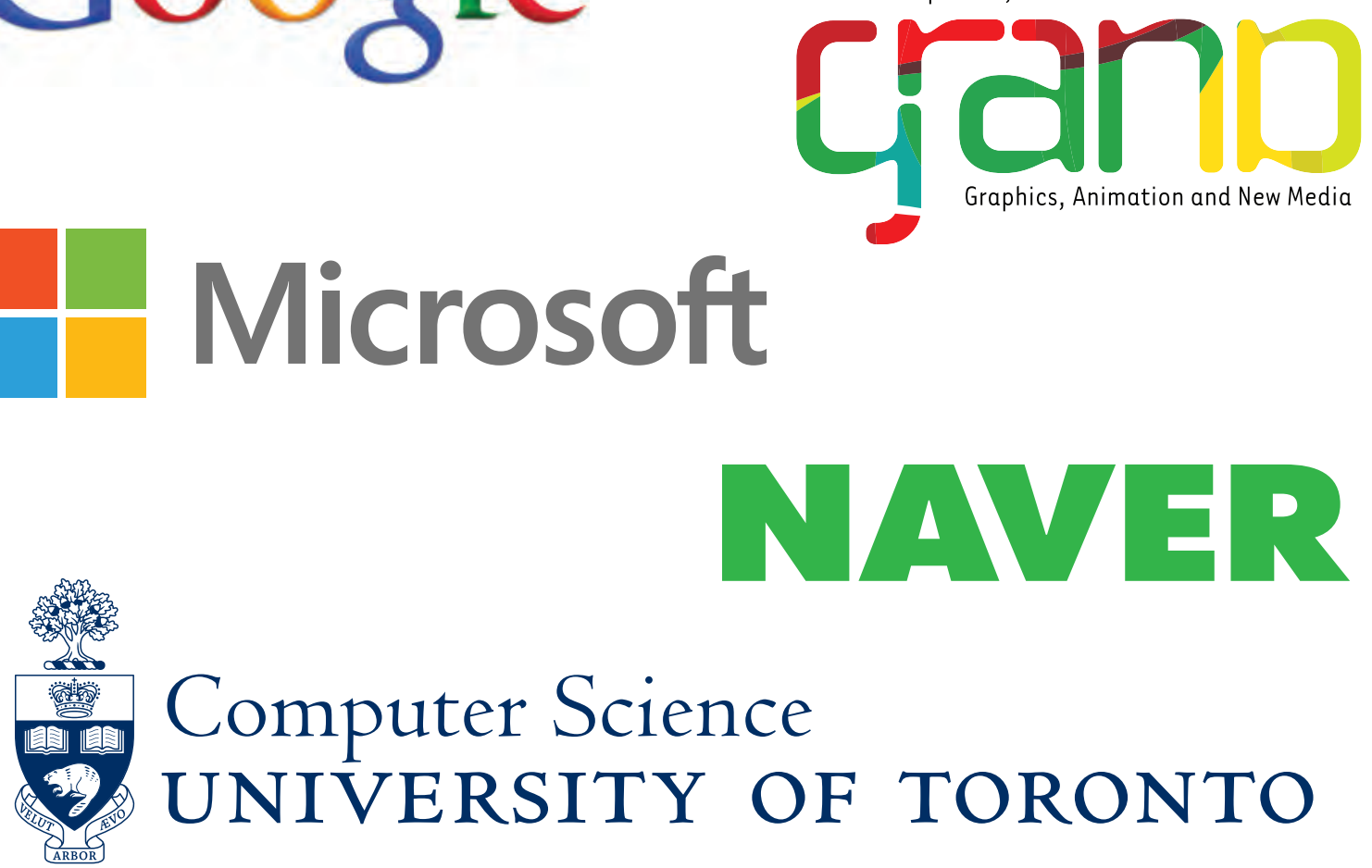

Computer Science

UNIVERSITY OF TORONTO

$\mathrm{CHI}$ Contributing Sponsors

\section{facebook.}

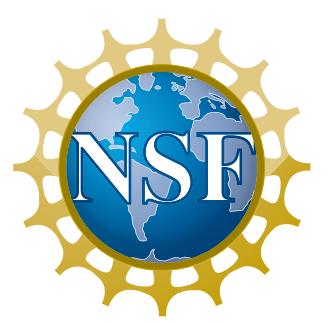

YAHOO! LABS

\section{Friends of $\mathrm{CHI}$}

Disney Research Newcastle University University of California Irvine University of Maryland UMBC Virginia Tech 